\title{
Reporting on risk and control
}

Citation for published version (APA):

Deumes, R. W. J. (2005). Reporting on risk and control. [Doctoral Thesis, Maastricht University].

Datawyse / Universitaire Pers Maastricht. https://doi.org/10.26481/dis.20050916rd

Document status and date:

Published: 01/01/2005

DOI:

10.26481/dis.20050916rd

Document Version:

Publisher's PDF, also known as Version of record

\section{Please check the document version of this publication:}

- A submitted manuscript is the version of the article upon submission and before peer-review. There can be important differences between the submitted version and the official published version of record.

People interested in the research are advised to contact the author for the final version of the publication, or visit the DOI to the publisher's website.

- The final author version and the galley proof are versions of the publication after peer review.

- The final published version features the final layout of the paper including the volume, issue and page numbers.

Link to publication

\footnotetext{
General rights rights.

- You may freely distribute the URL identifying the publication in the public portal. please follow below link for the End User Agreement:

www.umlib.nl/taverne-license

Take down policy

If you believe that this document breaches copyright please contact us at:

repository@maastrichtuniversity.nl

providing details and we will investigate your claim.
}

Copyright and moral rights for the publications made accessible in the public portal are retained by the authors and/or other copyright owners and it is a condition of accessing publications that users recognise and abide by the legal requirements associated with these

- Users may download and print one copy of any publication from the public portal for the purpose of private study or research.

- You may not further distribute the material or use it for any profit-making activity or commercial gain

If the publication is distributed under the terms of Article $25 \mathrm{fa}$ of the Dutch Copyright Act, indicated by the "Taverne" license above, 
Reporting on Risk and Control 
Reporting on Risk and Control

Copyright $\bigcirc$ R.W.I. Deumes, Maastricht 2005

Proefschrift Universiteit Maastricht

ISBN 90-5278-475-2

Druk: Universitaire Pers Maastricht 


\title{
Reporting on Risk and Control
}

\author{
PROEFSCHRIFT
}

ter verkrijging van de graad van doctor aan de Universiteit Maastricht, op gezag van de Rector Magnificus, prof. mr. G.P.M.F. Mols, volgens het besluit van het College van Decanen in het openbaar te verdedigen op vrijdag 16 september 2005 om 12.00 uur

door

Rogier Willem Jozef Deumes

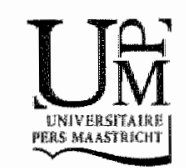




\section{Promotores}

prof. dr. S.J. Maijoor

prof. dr. W.R. Knechel (University of Florida)

\section{Beoordelingscommissie}

prof. dr. F. Moers (voorzitter)

prof. dr. P.C. Schotman

prof. dr. M. Willekens (Katholieke Universiteit Leuven) 


\section{Contents}

Acknowledgements $\quad$ ix

1 Introduction 1

1.1 Introduction 1

1.2 Outline 2

1.3 Sample 4

1.4 Data collection 4

1.5 Structure of the dissertation 5

Endnotes 6

2 Voluntary reporting on internal control by listed Dutch companies 9

Abstract 9

2.1 Introduction 9

2.2 Background 10

2.3 Prior research 11

2.4 Theory 12

2.4.1 Agency theory 12

2.4.2 Voluntary reporting on internal control 13

2.5 Hypotheses 14

2.5.1 Agency problems between management and shareholders 14

2.5.2 Agency problems between shareholders and debt holders 15

2.5.3 Company size 15

$\begin{array}{ll}2.5 .4 \text { Control variables } & 15\end{array}$

$\begin{array}{ll}\text { 2.6. Research design } & 17\end{array}$

$\begin{array}{ll}\text { 2.6.1 Sample and data collection } & 17\end{array}$

2.6.2. Dependent variable 17

2.6.3 Explanatory variables 19

$\begin{array}{lll}2.7 & \text { Results } & 20\end{array}$

2.7.1 Descriptive statistics pertaining to ICRS 20

$\begin{array}{lll}2.7 .2 & \text { Reliability of ICRS } & 22\end{array}$

2.7.3 Descriptive statistics of agency and control variables $\quad 22$

2.7.4 Univariate tests 24

2.7.5 Multivariate tests $\quad 24$

2.7.6 Sensitivity of the results $\quad 26$

$\begin{array}{lll}2.8 & \text { Summary and conclusions } & 29\end{array}$

Endnotes $3 \Perp$ 
3 How informative are qualitative risk disclosures?

Abstract 35

3.1 Introduction 35

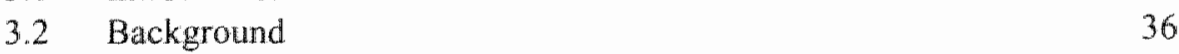

$\begin{array}{lll}3.3 & \text { Research design } & 39\end{array}$

3.3.1 Sample and data 39

3.3.2 Content analysis of risk sections in prospectuses $\quad 40$

3.3.3 Risk disclosures and market determined risk measures 42

3.3.4. Risk disclosures and market-adjusted stock returns $\quad 43$

3.3.5 Risk disclosures and failure of stock price in the aftermarket 45

3.3.6 Control variables 45

3.4. Results 45

3.4.1 Content analysis of risk sections in prospectuses 45

3.4.2. Risk disclosures and market determined risk measures 52

3.4.3 Risk disclosures and market-adjusted stock returns 57

3.4.4 Risk disclosures and failure of stock price in the aftermarket 61

3.4.5 Supplementary analyses 61

3.5 Summary and conclusion $\quad 62$

Endnotes 64

4 The association between firm risk, managerial ownership, board $\begin{array}{ll}\text { composition and ownership concentration } & 67\end{array}$

Abstract $\quad 67$

$\begin{array}{lll}4.1 & \text { Introduction } & 67\end{array}$

4.2 Background and previous research $\quad 69$

4.3 Hypotheses $\quad 73$

$\begin{array}{lll}4.4 & \text { Data } & 74\end{array}$

4.5 Variable definitions and model specification $\quad 74$

4.5.1 Measures of control by outside directors 74

4.5.2 Measures of control by large shareholders 75

4.5.3 Combined measure of control by outside directors and
large shareholders

4.5.4 Measure of managements' equity ownership $\quad 76$

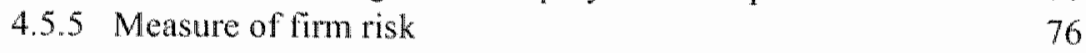

$\begin{array}{ll}4.5 .6 \text { Control variables } & 78\end{array}$

$\begin{array}{ll}4.5 .7 \text { Model specification } & 78\end{array}$

$\begin{array}{lll}4.6 & \text { Results } & 46\end{array}$

4.6.1 Descriptive statistics and univariate tests $\quad 79$

$\begin{array}{lll}4.6 .2 & \text { Multivariate tests } & 84\end{array}$

4.6.3 Separate multivariate tests of IPO and non-IPO firms
in the sample

4.7 Summary and conclusion $\quad 90$

Endnotes $\quad 93$ 
$\begin{array}{ll}\text { Summary and conclusion } & 97\end{array}$

5.1 Introduction 97

5.2 Summary 97

5.2.1 Voluntary reporting on internal control 97

5.2.2 Qualitative risk disclosures 98

5.2.3 Relationship between business risk and control 99

5.3 Limitations 99

5.3.1 Limitations pertaining to the content analysis $\quad 100$

5.3.2 Limitations pertaining to the research strategy 100

5.4 Conclusions, implications and directions for future research 102

5.4.1 Voluntary reporting on internal control 102

5.4.2 Qualitative risk disclosures 104

5.4.3 Relationship between business risk and control 107

$\begin{array}{lr}\text { References } & 109\end{array}$

$\begin{array}{ll}\text { Summary in Dutch (Nederlandse samenvatting) } & 121\end{array}$

$\begin{array}{ll}\text { Curriculum vitae } & 127\end{array}$ 



\section{Acknowledgements}

Although only one person's name appears on the cover of this dissertation, the truth is that many people have contributed to its development. Although none of these people should be held responsible for what I have written - nor do any of them fully agree with everything said - their comments and suggestions made this a much better dissertation than it could otherwise have been.

First and foremost, I owe an immense debt to my promoters, Robert Knechel and Steven Maijoor. Both have been extremely supportive and I thank them for their vision and genuine interest. Their ideas, criticism, patience and encouragement were simply indispensable. Besides my promoters, I thank the members of the evaluation committee, Frank Moers, Peter Schotman and Marleen Willekens, for promptly evaluating and approving the manuscript.

I am also indebted to each of my former and current colleagues at the Department of Accounting and Information Management. Besides providing an enjoyable working environment, they frequently offered help and support. In particular, I thank Erik Peek, Roger Meuwissen, Eddy Vaassen, Mark Vluggen, Caren Schelleman and Leon Timmermans. Several other colleagues have been kind enough to read parts of the manuscript of this dissertation with care and to offer me with helpful criticisms and suggestions. For their thoughtful effort, I would like to thank William Felix, Bill Kinney and Nathan Stuart. I am also very grateful to John van den Berg and Renate Hofman, who have consistently coded many texts of annual reports and prospectuses. Thanks are also due to Euronext Amsterdam, especially Jeroen Huber, for making the archives available.

Finally, I want to express my sincere gratitude to my parents Jos and Jose, my sister Gaby and - of course - Andrea. She endured my hours at the computer, missed meals, postponed vacations and occasional irritability during the writing of this dissertation. I promise [ will make it up to you.

Rogier Deumes

Maastricht, June 2005 


\section{Introduction}

\subsection{Introduction}

Organizations face a wide range of risks from various sources. Managing these risks is an important topic for managers and supervisors. Especially after the most recent wave of financial scandals, policy makers in the United Siates and many European countries called for increased responsibility and accountability of executive directors for addressing risk. Recent best practice provisions for example of the Dutch Committee for Corporate Governance demand the existence of internal risk management and control systems and require transparency regarding the adequacy and effectiveness of such systems towards external stakeholders (Tabaksblat Committee 2003).

In practice, several conceptual risk and control frameworks are available for managers to substantiate their assessment of the adequacy and effectiveness of their internal risk management and control systems. The perhaps best-known frameworks have been developed by the Committee of Sponsoring Organizations of the Treadway Commission (COSO 1992, 2004). The term 'risk' in these frameworks typically refers to the threat that an event or action will adversely affect an organization's ability to achieve its objectives. In their most recent conceptual framework, COSO describes risk management in its entirety as 'a process, effected by an entity's board of directors, management and other personnel, applied in strategy setting and across the enterprise, designed to identify potential events that may affect the entity, and manage risk to be within its risk appetite, to provide reasonable assurance regarding the achievement of entity objectives' (COSO 2004). General responses to risk include avoidance, reduction, sharing and acceptance of risk. A wide range of control activities throughout the organization should help ensure that management's responses to risk are carried out. The framework further stresses that information and communication is needed at all levels of the organization to identify, assess and respond to risk, and to otherwise run the entity and achieve its objectives. In a broader sense, communication about risk and control must take place with investors and other external stakeholders who can substantially affect, or be affected by, the welfare of a firm - so they can readily understand the risks an entity faces and respond accordingly.

In attempt to better understand some aspects of the wide array of practices observed, this dissertation brings together three empirical accounting studies on particular topics related to business risk and control. More specifically, the first study focuses on voluntary reporting on internal control in annual reports of publicly listed companies. The second study deals with qualitative risk disclosures in offering prospectuses that are published when firms issue new securities to investors. The thitd study examines the relationship between business risk and two important sources of control: the supervisory board and large shareholders. 


\section{Chapter I}

The remainder of this introduction is organized as follows. The next section provides a brief outline of the dissertation, giving attention to the purpose and motivation of each study. The third section describes the sample of data used in this dissertation. The fourth section elaborates on a shared aspect of the data collection method: content analysis of recorded communications. The last section summarizes the struchure of this dissertation.

\subsection{Outline}

Accounting, broadly conceived as the measurement and communication of economic information relevant to decision makers (Watts and Zimmerman 1986), includes reporting on risk and internal control to investors and other groups or individuals who can substantially affect, or be affected by, the welfare of the firm. The usefulness of accounting information in the decision making process of investors has been the subject of much academic research over the past decades. Whereas early capital market research in accounting followed a normative approach, attempting to develop an optimal or 'most correct' accounting representation of some true (but unobservable) economic reality, the perspective changed in the late 1960 s to an informational approach (Beaver 1998). From an informational perspective, reporting on risk and internal control can play two distinct, but related, roles. One role is to facilitate investors in making investment and valuation decisions. A second role is to facilitate contracting between parties, such as management and investors. The studies in this dissertation address both these roles.

In the first study, Voluntary Reporting on Internal Control by Listed Dutch Companies, I focus on the contracting role to explain managers' decisions to disclose information about their firms' internal controls. Because the concept of internal control has evolved over time, there has been some confusion about the exact meaning and scope of the term. The Committee of Sponsoring Organizations of the Treadway Commission (COSO 1992) provided a definition that is nowadays common. This definition emphasizes that intemal control is a process within the organization that mitigates the risk that an entity will not achieve its objectives, including reliable financial reporting (Knechel 2001). Knowledge about internal controls is therefore considered an essential element that affects the wellbeing of all stakeholders in a firm, including investors and creditors (Kinney 2000b). Although internal controls are studied in various areas of accounting research, covering very different concepts and studying controls at different organizational levels, most internal control research in accounting has traditionally not been conducted within the context of wider corporate governance issues (Maijoor 2000). In this first study, I draw on the notion that investors and creditors can use information on the quality of internal controls as a means of reducing information risk, i.e. the threat arising from poor-quality information for decision making. By voluntarily reporting on internal control, managers may try to convince investors that they have a sound internal control system in place that provides reasonable assurance about the reliability of reported financial accounting information. Following prior research that suggests that financial 
accounting information plays an important role in defining contract terms and in monitoring these terms (e.g. Lefwich, Watts and Zimmerman 1981, Chow and WongBoren 1987, Craswell and Taylor 1992), I develop and test the hypothesis that voluntary reporting on internal control partly arises as a monitoring mechanism for firms" contracts.'

In the second study, How Informative Are Qualitative Risk Discloswres?, I focus on the decision making role of risk reporting by examining the information content of managers' forward-looking, non-financial risk disclosures in offering prospectuses that are published when firms issue new securities to investors. More specifically, I investigate whether the risk disclosures provide useful information to investors for equity risk assessment. If corporate financial reporting is to be adequately supportive of investment decision making, it must clearly provide information useful to the formation of risk and return assessments (Farrelly, Ferris and Reichenstein 1985). While the earnings figures in traditional financial reports may provide information to assist investors in arriving at estimates of future returns, they may not necessarily provide information to assist investors in estimating the degree of risk. Of the numerous accounting studies that address the empirical relation between accounting numbers and stock market values (see for example Kothari 2001), quite a few have examined the usefulness of financial statement information in equity risk estimation. Most of these studies investigated the cross-sectional association between accounting numbers in financial statements and market based measures of risk, typically beta or total return variance. Ryan (1997), who surveys the literature in this area, finds that earnings variability has historically been the accounting variable most strongly related to equity risk. Ryan notes however that a particular limitation of this stream of research is that most risk research was performed in the $1970 \mathrm{~s}$, and so employs models of the economic environment and data generated by the accounting system at that time (Ryan 1997). Characterizing the accounting system as almost entirely backward-looking, Ryan concludes that this research has little to say about more recent risk disclosure proposals like the American Institute of Certified Public Accountants Special Committee on Financial Reporting's 1994 call for forwardlooking and non-financial disclosures about risk. The study in this dissertation examines managers' forward-looking, non-financial risk disclosures through a detailed content analysis. Empirical tests address the association between quantified measures of these risk disclosures and stock market values. ${ }^{2}$

In the third study, The Association between Firm Risk, Managerial Ownership, Board Composition and Ownership Concentration, the attention shifts to the relationship between business risk and control. The study builds on the notion that business risk plays a vital role in explaining choices by managers and owiners to strengthen control mechanisms. While the first study deals with internal control mechanisms performed by management and other personnel within the firm, the third study examines control exercised by outsiders, more specifically, outside directors and large shareholders. ${ }^{3}$ In line with relatively recent developments in financial ecomomics and management science that have drawn attention to a growing list of logical 
deficiencies that weaken the validity of traditional conceptualizations of risk in empirical research (see Ruefli, Collins and Lacugna 1999), data on business risk are obtained from managers" own risk assessments in prospectuses.

\subsection{Sample}

The samples of data used in this dissertation consist of Dutch companies listed on the Amsterdam Stock Exchange, except investment funds and financial institutions. More precisely, the sample of the first study focuses on all companies that were listed on the Amsterdam Stock Exchange during the period 1997 to 1999. This sample consists of 155,168 and 167 observations for respectively 1997, 1998 and 1999. The sample of the second and third study is confined to all companies that published a prospectus in the period from 1997 to 2000 and has 90 observations (49 initial public offerings of common stock, 31 seasoned offerings of common stock and/or convertible bonds, and 10 stock offerings relating to a merger or demerger). The main reason for relying on relatively small samples is the rather labor-intensive nature of the data-collection method, which is further discussed in the following section. ${ }^{4}$

\subsection{Data collection}

The breadth of managers" communications of economic information to financial claimholders that exist in the accounting area is extensive and involves both quantitative and qualitative information from various sources, including annual reports and prospectuses. Included in the many methods used to study accounting communications is content analysis. Content analysis can be described as an observational research method that is used to systematically evaluate symbolic content of all forms of recorded communications (Kolbe and Burnett 1991). The communications can be analyzed at many levels, including single words and phrases.

All three empirical studies in this dissertation rely on content analysis to quantify qualitative communications to financial claimholders. While the first study quantifies qualitative communication about internal control in annual reports, the second study quantifies qualitative communication about risk in prospectuses. The third study uses the results of the content analysis of the second study to measure business risk and make inferences about the relationship between business risk and control. Using content analysis provides at least two benefits. First, it allows an unobtrusive appraisal of the communications about risk and internal control. This unobtrusiveness is particularly valuable for the measurement of risk in the third study, because direct methods of - necessarily ex-post - inquiry of management or investors might yield biased responses. Second, content analysis allows assessment of the association between firm characteristics and message content (the first study), in addition to the association between message content and investor responses (the second study). This way, content analysis provides an empirical starting point for generating evidence about the nature and effects of communications about risk and internal control. 
While the perceived benefits seem to justify use of content analysiss, careful consideration needs to be given to its potential weaknesses and procedures to avoid these weaknesses. Without doing so, the method is susceptible to the effects of researcher bias, which can affect the decisions made in the collection, analysis and interpretation of data. Researchers and others agree that distinguishing characteristics of content analysis are that it must be objective, systematic, and quantitative (Kassarjian 1977). The requirement of objectivity demands that the categories of analysis are defined precisely enough to enable other analysts, following identical procedures with the same set of data, to arrive at similar conclusions. Systematization means that the inclusion and exclusion of communications content or analysis categories is done according to consistently applied rules. A second meaning of systematic is that the findings must have theoretical relevance and be generalizable. The quantification requirement refers to measurement of the extent of emphasis or omission of any given analytic category and implies that the data be amenable to statistical methods, not only for precise and parsimonious summary of findings but also for interpretation and inference (Kassarjian 1977).

To minimize researcher's subjectivity and obtain an objective and systematic quantification of the communications content, 1 used precise operational definitions of categories and followed detailed rules and procedures for coding. This reduces researcher bias and allows replication by others (a check on researcher bias). In addition, I employed a second, trained, independent coder. This enables assessment of interjudge reliability, i.e. the degree of consistency between coders applying the same set of categories to the same content. Interjudge reliability is largely influenced by the procedural issues mentioned and is often perceived as the standard measure of content analysis quality (Kolbe and Burnett 1991). ${ }^{5}$

Data obtained through content analysis of annual reports and prospectuses were combined with data from various other archival data sources, such as a public database on stock ownership of the Dutch exchange supervisor 'Autoriteit Financiële Markten' and the commercial databases 'DATASTREAM', 'REACH' and 'Het Financieel Economisch Lexicon'.

\subsection{Structure of the dissertation}

The remainder of this dissertation is organized as follows. The first empirical study, which deals with voluntary reporting on internal control in annual reports, is presented in chapter 2. The second empirical study, which focuses on the information content of qualitative risk disclosures in prospectuses, forms chapter 3 . The third empirical study, which investigates the association between firm risk, managerial ownership, board composition and ownership concentration, makes up chapter 4. Finally, chapter 5 summarizes and concludes this dissertation. 


\section{Chapter I}

\section{Endnotes}

'Related accounting research that focuses on managers' financial reporting choices from a contracting perspective is often called "positive accounting research". See Wats and Zimmerman (1990) for a review of positive accounting research from the $1980 \mathrm{~s}$ and Fields, Lys and Wincent (2001) for a review of this literature from the 1990s. Healy and Palepu (2001) review the "woluntary disclosure literature' that supplements the positive accoumting literature by focusing on stock market motives for accounting and disclosure decisions. As Healy and Palepu point out, both the positive accounting literature and the voluntary disclosure literture have examined the capital market consequences of changes in corporate reporting. Posilive accounting theory research has focused on effects of changes. in accounting methods and regulatory decisions to change standards. Voluntary disclosure research has examined the capital market effects of corporate disclosure, eng. more accurate analyst forecasts, increased market liquidity for securities, and a reduced cost of capital (Healy and Pallepu 2001).

2 To some extent similar accounting research that examines the association between financial accounting numbers and stock market values is ofter referred to as 'value-relevance research'. See Holthausen and Watts (2001) and Barth, Beaver and Landsman (2001) for a contrasting assessment of the value-relevance literature.

${ }^{3}$ Although researchers have been long interested in investigating the interdependence between various monitoring and control instruments, the findings teported in this dissertation provide only supportive evidence of complementary and substitution relationships between the mechanisms investigated in the first and third study. In this context, complementarity (substitutability) means that implementation of one device increases (decreases) the marginal returns of other devices. Although complementarity is a matter of order (i.e. doing move of one thing increases the returns to doing wore of another'), it is symmetric in the sense that if doing more of mechanism a raises the value of increases in mechanisms $b$, then increasing $b$ also raises the value of increasing $a$ (Milgrom and Roberts 1995). According to Lokshin, Carree and Belderbos (2004), the only conclusive econometric test for complementarity and substitutability is based on the "production function" approach, in which corporate performance is relatted to exclusive combinations of control and monitoring devices. However, due to endogeneity problems in studying the relationship between organizational performance and monitoring and control mechanisms (see for example Hemalin and Wcisbach 2003), this approach could not be used to examine possible interdependency between the monitoring and control devices examined in the first study (voluntary reporting on internal control) and the third study (outside directors and large shaveholders). To provide (merely) supportive evidence of complementarity and substitution relationships, wariables that measure the level of control by outside directors and large shareholders in the third study, are included in the first study as explanatory variables in the model that explains the axtent of voluntary reporting on intemal control. A (further) potential limitation of this approach is that it assumes that the relationship between these explanatory variables and the explained variable is not reciprocal. If changes in the extent of voluntary reporting on intemal control actually affect changes in board composition and ownership concentration, this assumption would be violated.

"As a result, a threat exists to the external validity of the three studies. While the samples of data used are representative of their target populations (i.e. all listed Dutch non-financial companies in the period 1997 to 1999 in the first study and all non-financial Dutch companies that issued securities in 
Introduction

the period 1997 to 2000 in the second and third study), generalizing the findings to other populations, settings or time periods is hazardous.

${ }^{5}$ A common way to calculate interjudge reliability is the percentage of agreement, the the totat number of agreements divided by the total number of coding decisions. A weakness of the coefficient of agreement is that when the number of categories decreases, the probability of interjudge agreement by chance increases. For this reason, 1 also calculate Pereault and Leigh's index of reliability for nominal data (see Perreault and Leigh 1989 and Grayson and Rust 2001 ). 



\section{CHAPTER 2}

\section{Voluntary Reporting on Internal Control by Listed Dutch Companies}

\section{Abstract}

This chapter examines the monitoring role of voluntary reporting on internal control. Agency theory predicts that company management voluntarily adopts monitoring mechanisms in the presence of agency problems. By testing the hypothesis that company management voluntarily reports more (less) on internal control in the anmual report if agency problems are higher (lower), the study investigates whether voluntary reporting on internal control is a monitoring mechanism. Company characteristics proxy for agency problems and a disclosure index measures the extent of voluntary reporting on internal control. The sample consists of Dutch companies listed on the Amsterdam Stock Exchange during the period 1997 to 1999.

The main results indicate that voluntary reporting on internal control can be viewed as a monitoring mechanism. Controlling for other factors, the extent of reporting on internal control is systematically related to company characteristics that proxy for agency problems. Sensitivity analyses reveal that two items in the disclosure index account for this result. Disclosures of activities to manage risk and reporting the fact that the supervisory board discussed the internal control system in their meetings seem to be consciously disclosed by company management for monitoring purposes.

\section{I Introduction}

The issue of reporting on internal control has been of considerable interest to policy makers involved in corporate governance issues. Although various private and public sector groups have recommended company management to report on internal control, others have questioned its usefulness. Motivated by the controversy about the usefulness of reporting on internal control, several authors investigated the subject (e.g. Raghunandan and Rama 1994, McMullen, Raghunandan and Rama 1996, Hermanson 2000, Willis and Lightle 2000). The purpose of this study is to investigate whether reporting on internal control is useful as a monitoring mechanism.

Theoretical and empirical agency literature has demonstrated that company management voluntarily adopts monitoring mechanisms in the presence of agency problems. By testing the hypothesis that company management voluntarily reports more (less) on internal control in the annual report if agency problems are higher (lower), this study examines whether voluntary reporting on internal control is employed as a monitoring mechanism. Company characteristics proxy for agency problems and a disclosure index measures the extent of voluntary reporting on internal control. The sample consists of Dutch companies listed on the Amsterdam Stock 
Exchange during the period 1997 to 1999. The Dutch environment provides a suitable setting for this study because reporting on internal control was not legally required during this period. The following section presents a brief background on public policy recommendations on internal control reporting in the Netherlands. Section 3 discusses previous empirical research. Section 4 describes the theoretical framework and section 5 develops the hypotheses. Section 6 details the research design. The results are presented in section 7 . The final section summarizes and concludes the chapter.

\subsection{Background}

In the Netherlands, the Peters Committee (1997) and more recently the Tabaksblat Committee (2003) have provided a number of recommendations and best practice provisions regarding reporting on internal control. Dutch companies have a two-tier board structure with a managing board consisting of inside directors and a supervisory board consisting of outside directors. In accordance with Dutch law, the supervisory board is responsible for the supervision of management policy and the general course of affairs in the company. Both the Peters Committee and the Tabaksblat Committee have put forward that at least once a year the supervisory board should discuss the results of the assessment of internal controls by the managing board. The fact that such a discussion has been held (and not necessarily the content of the discussion) should be mentioned in the supervisory board's report in the company's annual report. The Peters Committee further recommended that the managing board should report in writing to the supervisory board on the mechanisms used to control financial risk. The main items in this report should be a permanent part of the annual report. Extending the Peters Committee's recommendations, the corporate governance code of the Tabaksblat Committee demands that the managing board declares and substantiates in the annual report that the risk and internal control systems are 'adequate and effective'. The management board must also report on the operation of the internal risk management and control system during the year under review and in doing so describe any significant changes that have been made and any major improvements that are planned.

Compared to recommendations and regulations on internal control reporting in the United Kingdom (e.g. Cadbury Committee 1992a, 1992b, Rutteman Committee 1994, Hampel Committee 1998a, 1998b, Turnbull Committee 1999) and the United States (e.g. Cohen Commission 1978, Treadway Commission 1987, Committee of Sponsoring Organizations of the Treadway Commission (COSO) 1992, Public Oversight Board 1993 and especially the Sarbanes-Oxley Act of 2002), the recommendations of the Peters Committee and the best practice provisions of the Tabaksblat Committee are less extensive and detailed. Moreover, before the corporate governance code of the Tabaksblat Committee came into force and companies must comply to the code (or explain in their annual report whether, and if so why and to what extent, they do not apply the best practice provisions), reporting on internal control was completely voluntary in the Netherlands. In contrast, in the United Kingdom stock exchange listing rules resulted much earlier in a requirement to report 
on internal control by requiring compliance to the Combined Code of the Hampel Committee (1998b). As a result of Sarbanes-Oxley Act of 2002, the most rigorous requirements for reporting on internal control currently apply to companies whose securities are publicly traded in the United States. Managers of these companies must personally certify to internal control over financial reporting and all annual reports must contain an internal control report wherein management affirms its responsibility for maintaining an adequate system of internal control and assesses the effectiveness of the system. Moreover, the company's independent auditor must issue a report on internal control over financial reporting, which includes both an opinion on management's assessment and an opinion on the effectiveness of the company's internal controls over financial reporting.'

\subsection{Prior research}

Considering the attention for internal control reporting, relatively little empirical research has been conducted in this area. Content analyses of amnual reports of 1993 and 1998 of Fortune 100 companies in the United States revealed that respectively $80 \%$ and $76 \%$ of the companies voluntarily included a management report on internal control (Raghunandan and Rama 1994, Willis and Lightle 2000). All reports stated that the company maintained an internal control system, but the level of detail in which the internal control system was described varied considerably. A question that arises is what explains the cross-sectional variation in the extent of voluntary reporting on internal control. Willis and Lightle suggested that the differences in content may reflect variations in how companies structure their internal control system or may reflect differences in companies' reporting philosophies. McMullen er al. (1996) further explored voluntary reporting on internal control. Their study investigated the association between voluntary reporting on internal control and the absence of financial reporting problems, defined as enforcement actions of the Securities and Exchange Commission and other corrections to previously reported earnings. The results indicated that only smaller companies are less likely to have financial reporting problems if management reports on internal control. Based on a survey of financial statement users, Hermanson (2000) observed that respondents perceived that internal controls are important. Respondents also agreed that voluntary reporting on internal control provides additional information for decision making. Furthermore, respondents agreed that voluntary reporting on internal control motivates management to improve internal controls and enhances oversight of controls. In addition, the findings of Hermanson suggested that both executives and financial statement users view voluntary reporting on internal control as costly. Cost of reporting on internal control may arise from collecting the necessary information and evaluating the internal control system before reporting on it. Executives have repeatedly emphasized the costs of preparing internal control reports (Solomon and Cooper 1990). McMullen et al. (1996) argue that relative costs may be greater for smaller companies than for larger companies. 


\section{Chapter 2}

Although prior research provides useful insight in the potential usefulness and perceived costs and benefits of voluntary reporting on internal control, the observed cross-sectional variation in voluntary reporting on internal control has not been systematically explained. Hence, it is not clear why company management voluntarily reports on internal control. This study contributes to prior research by developing the argument that company management employs voluntary reporting on internal control as a monitoring mechanism. The analyses focus on whether relative costs and benefits of monitoring explain the cross-sectional variation in the extent of voluntary reporting on internal control. In this way the study also contributes to the empirical literature on voluntary monitoring that is discussed in the following section.

\subsection{Theory}

Many empirical studies have employed agency theory to explain voluntary adoption of monitoring mechanisms by company management. This section discusses the theoretical background and voluntary monitoring mechanisms that have previously been studied. Subsequently, it is argued that voluntary reporting on internal control is a possible monitoring mechanism.

\subsubsection{Agency theory}

The theoretical framework that prior studies have used to explain voluntary adoption of monitoring mechanisms is primarily based on the work of Jensen and Meckling (1976). The agency relationship between managers and investors gives rise to agency problems because managers are expected to act in their own interest, which need not be consistent with the interests of investors. Investors are aware of the potential agency problems and anticipate the behavior of managers when they price their claims. Investors' price protection encourages managers to demand contracts that restrict their value-reducing actions. Contracts however will not reduce the efficiency loss of agency problems unless investors can monitor whether management meets contractual agreements. Investors' price protection gives management an incentive to make expenditures on monitoring mechanisms to reduce the efficiency loss of agency problems. Consequently, the higher the potential efficiency loss of agency problems, the greater managements' incentives to voluntarily employ monitoring.

Many empirical studies have used this framework to investigate voluntary adoption of monitoring mechanisuns by company management. Various monitoring mechanisms have been studied. Several authors (e.g. Leftwich, Watts and Zimmerman 1981, Chow and Wong-Boren 1987, Craswell and Taylor 1992) investigated whether voluntary financial reporting is associated with variables that proxy for agency problems. Financiall reporting is wiewed as a monitoring mechanism because contracts between management and investors are often defined in accounting numbers. Chow (1982) examined the association between voluntary external auditing and agency variables. External auditing is viewed as a monitoring mechanism because it improves the quality of financial accounting information. Others investigated the relationship between agency problems and quality differentiated external audits (e.g. Francis and 
Wilson 1988, DeFond 1992) and companies purchasing timelly reviews (Ettredge, Simon, Smith and Stone 1994). Similarly, Pincus, Rusbarsky and Wong (1989), Bradbury (1990), Collier (1993), Menon and Williams (1994), and Collier and Gregory (1999) investigated whether voluntary formation of audit committees and audit committee activities are correlated with agency problems.

\subsubsection{Voluntary reporting on internal control}

Beside external control, internal control - including internal auditing - may serve as a monitoring device that reduces efficiency loss of agency problems (Anderson, Francis and Stokes 1993, DeFond 1992). Internal control is viewed as a monitoring mechanism because the system provides management with more reliable information for financial reporting purposes (Keasy and Wright 1993). Although in general external control may have an advantage over internal control in detecting management fraud, internal control may be better in detecting unintentional errors and employee wrongdoing (Hay and Knechel 2001). Besides traditional accounting controls, the current concept of internal control also refers to operational controls and includes risk assessment and risk management (Mills 1997, Short, Keasy, Wright and Hull 1999, Hay and Knechel 2001). ${ }^{2}$

For investors however, internal control is not directly observable because the system is in essence a process within the organization. In addition, dispersed investors have little or no incentive to actively monitor internal control. ${ }^{3}$ As a result, investors may not be fully informed on the company"s internal controls. In the presence of agency problems, management may want to convince investors that they do not pursue their own goals at the expense of investors and take optimal actions with respect to internal control to provide investors with reliable financial reporting information. A possible way for management to inform investors is to disclose private information on internal control in the annual report. If investors perceive that the information is credible and relevant (e.g. not already available from other sources), voluntary reporting on internal control can be viewed as a monitoring mechanism that mitigates the efficiency loss of agency problems. ${ }^{4}$

Although investors have a variety of information sources available, the results of McMullen (2000) indicate that financial statement users perceive that voluntary reporting on internal control provides additional information. A potential altemative source of information that McMullen specifically addresses in her survey is the audit report. Respondents disagree that reporting on internal control is irrelevant if the financial statements are audited. This suggests that financial statement users expect that they do not obtain the same information about internal control from an unqualified audit report alone.

As credibility is an issue with relatively clear-cut accounting numbers, it may also apply to the issue of internal control reporting where the measurement and reporting standards are much less defined. Credibility of voluntary disclosures can be maintained however by a number of mechanisms. A possible reason why investors may perceive that management is truthfully revealing private information on internal 
control is the presence of outside directors and the review of unaudited parts of the annual reports by auditors to ensure that these parts do not contain information that is inconsistent with the audited disclosures. A further discipline is the reputational cost likely to be imposed on managers if they are caught out lying by whistle-blowing or by subsequent adverse events and internal control failures.

Investors" perception of both credibility and relevance may differ between reporting on internal controll by the managing directors and reporting on internal control by the supervisory directors. Investors may view the latter as more reliable because the members of the supervisory board are generally outsiders, and the former as more relevant because managing directors have more inside information.

\subsection{Hypotheses}

Agency theory predicts that if voluntary reporting on internal control is a monitoring mechanism, company management will voluntarily report more (less) on internal control if agency problems are higher (lower). Below, the variables are discussed that proxy for agency problems. A distinction is made between agency problems between management and shareholders, and agency problems between shareholders and debt holders.

\subsubsection{Agency problems between management and shareholders}

The first proxy for agency problems between management and shareholders is management's ownership share of the company. Higher managerial ownership will lower agency problems because managers' and shareholders' incentives are more aligned (Jensen and Meckling 1976). This leads to the firrst hypothesis:

$\mathrm{H}_{1}$ : Ceteris paribus, there is a negative association between the degree of managerial ownership and the extent to which company management reports on internal control.

The second proxy for agency problems between management and shareholders is the extent to which small (individual), rather than large (institutional) investors hold the company's shares. The net benefit of monitoring mechanisms implemented by company management may be higher for individual investors with small shareholdings as it is relatively more expensive and difficult for these investors to actively monitor management's activities. Milgrom and Roberts (1992) argue that larger shareholders are possibly more willing and able to play an active monitoring role. Following this argument, agency problems are lower if a company is owned by large investors. This leads to the second hypothesis:

$\mathrm{H}_{2}$ : Ceteris paribus, there is a negative association between the degree of ownership by large investors and the extent to which company management reports on internal control. 
Voluntary Reporting on Internal Control

2.5.2 Agency problems between shareholders and debt holders

Leverage is used in this study as a proxy for agency problems between shareholders and debt holders. One problem between shareholders and debt holders is that shareholders have an incentive for excessive risk taking on behalf of debt holders. Jensen and Meckling (1976) and others have suggested that higher leverage will increase agency costs because the potential for wealth transfers from debt holders to shareholders increases. This leads to the third hypothesis:

$\mathrm{H}_{3}$ : Ceteris paribus, there is a positive association between the degree of leverage and the extent to which company management reports on internal control.

\subsubsection{Company size}

Chow (1982) argues that external agency problems increase with company size because the amount of potential wealth transfers increases with company size. This implies that the benefits of monitoring are positively related to company size. In addition, Chow and others (e.g. Pincus et al. 1989) suggested that monitoring devices involve costs that are subject to economies of scale. If reporting on internal control is costly, larger companies can possibly better afford these expenses. An alternative explanation for a positive relationship between company size and reporting on internal control is that company size is also a proxy for the problem of moral hazard 'internal' to the operation of the company. The larger an organization becomes, the weaker the control exercised by top management over subordinates" actions (Williamson 1967). A possible remedy for the costly consequences of organizational loss of control is to enhance internal control mechanisms (Abdel-khalik 1993). If larger organizations have better internal controls, managers of larger organizations may be more likely to report on internal control. ${ }^{6}$ This leads to the fourth hypothesis:

$\mathrm{H}_{4}: \quad$ Ceteris paribus, there is a positive association between company size and the extent to which company management reports on internal control.

\subsubsection{Control variables}

This section discusses five categories of variables that are also possibly systematically associated with voluntary reporting on internal control. ${ }^{7}$

Degree of foreign operations - The establishment of foreign operations creates political, economic and cultural risks not found in domestic companies. In addition, the complexity of transactions often increases due to joint ventures, international tax issues, and foreign exchange transactions. Foreign operations therefore require additional internal control systems to manage these international risks (Hermanson and Hermanson 1994). Because disclosures about internal control can inform investors about how management is dealing with control problems resulting from foreign 
operations, the degree of companies" foreign operations may affect the extent of voluntary reporting on intemal control by company management.

Industry classification - Industry classification and voluntary reporting on internal control may be related for two reasons. First, different industries display different patterns of disclosure (Botosan 1997). Watts and Zimmerman (1986) argue that companies in the same industry face similar incentive problems and use similar contracting structures and accounting procedures. Others suggest that industry membership is a surrogate proxy for variables that are associated with voluntary disclosure, like political costs (e.g. Bazley, Brown and Izan 1985) and proprietary costs (e.g. Craswell and Taylor 1992, Harris 1998). Second, the type of industry is likely related to the risks that a company deals with. If internal control systems are conditional upon the risks facing an organization (Hay and Knechel 2001), management of companies active in the same industry may have similar internal controls to report on.

Quality of independent auditor - Voluntary reporing on internal contral may be systematically associated with the quality of the independent auditor, because higher audit quality is considered a monitoring mechanism that may complement (reinforce) or substitute other monitoring mechanisms (Francis and Wilson 1988, DeFond 1992). The nature of the interdependency between the quality of the independent audit and voluntary reporting on internal control is unclear. On the one hand, the review of unaudited parts of the annual report by a higher quality auditor may increase investors' perception of the credibility of voluntary reporting on intenal control. If this increases the effectiveness of voluntary reporting on internal control as a monitoring mechanism, the presence of a high quality independent auditor would increase the marginal benefits of voluntary reporting on internal control. On the other hand, investors may perceive that voluntary reporting on internal control is less relevant if the financial statements are audited by a higher quality independent auditor. From this point of view, the presence of a higher quality independent auditor would decrease the marginal benefits of voluntary reporting on internal control. ${ }^{8}$

Monitoring by outside directors - Similarly, monitoring by outside directors may increase or decrease the marginal benefits of voluntary reporting on internal control. Again, the nature of the interdependency between these monitoring mechanisms is unclear. A possible reason for a complementary relationship is that the level of monitoring by outside directors increases investors" perception of the credibility of voluntary reporting on internal control, and hence its effectiveness as a monitoring mechanism. Alternatively, substitution may occur if investors perceive that woluntary reporting on internal control becomes less relevant if top management is more adequately monitored by outside directors. 
Foreign stock exchange listing - Foreign stock exchanges have different requirenents regarding reporting on internal control. Listing rules in the United Kingdom for example result in less freedom in the reporting choice on internal control. Because the Dutch stock exchange requires that companies with a listing at a foreign stock exchange provide the Dutch market with the same information as the foreign market, a foreign stock exchange listing may influence the extent to which company management reports on internal control.

\subsection{Research design}

\subsection{Sample and data collection}

The sample consists of all Dutch companies listed on the Amsterdam Stock Exchange during the period 1997 to 1999 for one or more years, except investment funds and financial institutions (e.g. banks and insurance companies). The final sample counts 155,168 and 167 observations for respectively 1997, 1998 and 1999 (i.e. 490 company-year observations). The total number of different companies in the final sample is $192 .^{9}$ Data on the dependent variable was retrieved from companies' annual reports. Most data on the explanatory variables was available in the public Dutch databases 'REACH' and 'Het Financieel Economisch Lexicon'. In addition, data was obtained from public databases of the Dutch exchange supervisor 'Autoriteit Financiële Markten'.

\subsubsection{Dependent variable}

The extent of voluntary reporting on internal control is measured with an internal control reporting score (ICRS). ICRS was obtained in three steps, which are described below. Measuring internal control reporting this way is similar to disclosure indices used in prior studies that investigated the association between company characteristics and the level of disclosure (e.g. Chow and Wong-Boren 1987, Botosan 1997). Although these studies have shown that disclosure indices are a useful research tool, deriving an aggregate scale is difficult, as it requires subjective assessments by the researcher applying the technique. Therefore it is critical to assess the intenal consistency of ICRS and to examine the sensitivity of the results for alternative measures of ICRS.

The first step in determining ICRS was to identify the items regarding reporting on internal control. By referring to the previously mentioned public policy reports on corporate governance and internal control, a list of 6 separate reportable items is generated. The separate items are presented in Table 1 panel A, and are discussed below. The first item is derived from recommendations on internal control reporting by the Peters Committee (1997). The remaining items are derived from public policy reports in the United States (COSO 1992) and the United Kingdom (Cadbury Committee 1992a, Hampel Committee 1998a, Turnbull Committee 1999). ${ }^{10}$

Item 1 - As discussed before, the Peters Committee (1997) recommended that at least once a year the supervisory board should discuss the results of the internal control 
system's assessment by the managing board. The fact that such a discussion has been held (and not necessarily the content of the discussion) should be mentioned in the supervisory board's report in the company's annual report. Typically, the supervisory board reported on this item by stating that "in our meetings attention was paid to the internal control system'. A number of reports emphasized the presence of the external auditor in these meetings by stating that in the presence of the external auditor, the internal control system was discussed".

Item 2 - Besides identifying the objectives of internal control, COSO (1992) recommended that management should report whether an internal control system has been established to achieve these objectives. This leads to including item 2 , which is valued one if the managing board states the objectives of the company's internal control system in the annual report. Frequently reported objectives of the internal control system are managing risk assaciated with business activities, controlling the effectiveness and efficiency of business activities, safeguarding of assets, complying with laws and regulation, and reliable management and financial reporting.

Jiem 3-COSO (1992), the Cadbury Committee (1992a), the Hampel Committee (1998a) and the Turnbull Committee (1999) have emphasized management's responsibilities for internal control and recommended that management reports on their responsibilities in the annual report. Most companies reporting on this item stated that "within the framework established by the managing board, operational management is responsible for the functioning of the internal control system'.

Item 4 - Another approach for management to discuss its responsibilities is to state its belief as to whether it has fulfilled specific responsibilities (COSO 1992). Management may address for example the effectiveness or the adequacy of the entity's internal control system. The Cadbury Commitlee (1992a) has also recommended that directors report on the effectiveness of the company's system of internal control. The Hampel Committee (1998a) encouraged directors to report on the effectiveness but did not require stating an opinion. Generally, companies reporting on item 4 stated that 'the managing board considers the internal control system to be adequate' without addressing the basis for this assessment. Companies reporting on item 4 also point out the inherent limitations of internal control by stating that the system provides only 'reasonable assurance'.

ltem 5 - The Turnbull Committee (1999) considered information on how management makes use of the work of the internal auditor to be important as it provides information on how the managing board has reviewed the effectiveness of the system. COSO (1992) also recommended discussing the program of internal auditing. Companies reporting on this item often stated that 'the internal auditors monitor the internal control system and report their findings to the managing board'.

Item 6 - COSO (1992) identifies risk assessment as an important component of internal control. The Turnbull Conmittee (1999) mentions that internal control is one of the principal elements in the management of risks and the fact that there is an ongoing process for identifying, evaluating and managing company's risk should be reported in the annual report. Companies reporting on item 6 discuss their activities to 
manage risk. Often mentioned are activities to transfer risk (e.g. through derivatives or insurance), activities to share risk (e.g. via alliances or pricing), policies and procedures to mitigate risk (e.g. credit checks or centralized approvals), and activities to avoid risk at source (e.g. avoiding interest rate risk by borrowing in local currencies).

The second step in obtaining ICRS was fully examining the annual reports of companies in the sample to identify the presence of each item. Dutch annual reports consist of financial statements and so called 'other information', like the report of the supervisory board and the report of the managing board. Item I was found in the report of the supervisory board. Item 2 to item 5 were found in the report of the managing board. Item 6 was found in both the report of the managing board and the footnotes to the financial statements. To control for subjectivity in interpreting the annual reports, a second trained independent rater examined the annual reports. Both examinations are in substantial agreement. Percentage agreement for each item ranged from $94 \%$ to $100 \%$. Perreault and Leigh's interjudge reliability index ranged from .93 to 1.00 where .80 (and .70 in exploratory research) is considered a lower limit (Perreault and Leigh 1989). After jointly re-examining the annual reports for which the initial examinations differed, the researchers agreed about the classification of each item.

The third step taken was to calculate an unweighted score for each company in the sample by summing the individual items company management reported on. This implies that all items are considered to be equally important. The resulting variable ICRS ranks the extent to which company management voluntarily reports on internal control and is therefore treated as an ordered variable. Section 7.6 discusses the sensitivity of the results for each item included in ICRS.

\subsubsection{Explanatory variables}

The explanatory variables follow from the hypotheses developed in section 5 . The measurement of each variable is described below.

$H_{1}-$ Managerial ownership (MO). In the Netherlands it is not required to report the percentage of shares held by company management in the annual report. Owners of more than $5 \%$ of the shares of a listed company however are required to report their ownership share to the Dutch stock exchange supervisor 'Autoriteit Financiele Markten". "Because this data is publicly available, the names of the shareholders were compared with the names of the members of the managing board. Managerial ownership was calculated by adding up the percentage of shares theld by members of the managing board. As a result of this, management shareholdings smaller than $5 \%$ are not accounted for. $\mathrm{H}_{2}$-Ownership by large investors (LI). Using the data reported to the Dutch stock exchange supervisor, the percentage of shares owned by large investors was calculated by adding up the percentages of shareholdings of nonmanagers greater than $5 \%$ (i.e. shareholdings of less than $5 \%$ are considered to be small investors). $\mathrm{H}_{3}$ - Leverage (LEV). Leverage is measured in this stucly as the ratio of the book value of debt to the sum of the market value of equity and the book value of debt. $H_{4}-$ Company size (SIZE). Company size is measured in this study as the 
natural logarithm of the sum of the market value of equity and the book value of debt. Control variable - Foreign operations ( $F O$ ). The relative degree of a company's foreign operations is measured in this study as the ratio of the number of foreign subsidiaries to total subsidiaries. Control variables - Industry (MAN and TRADE). Industry membership is measured with two dummy variables that identify companies that are active in the manufacturing and trade sector. ${ }^{12}$ Control variable - Quality of independent auditor (AQ). A dummy variable indicating the presence of a (then) Big Six or Big Five auditor is used as a surrogate of audit quality. ${ }^{13}$ Control variable Monitoring by outside directors (OD). The level of monitoring by outside directors is measured in this study as the ratio of the number of outside directors (i.e. the number of supervisory directors excluding so-called 'affiliated' directors) to total directors. Control variables - Foreign stock exchange listing (LSE and NYSE). Foreign stock exchange listing is measured with two dummy variables that identify companies traded on the London Stock Exchange and the New York Stock Exchange.

\subsection{Results}

\subsubsection{Descriprive statistics pertaining to ICRS}

Panel A of Table I shows the frequencies of reporting on separate items of ICRS during 1997 to 1999 for companies in the sample. Company management most frequently reports item 1 and 6 . McNemar tests are used to investigate the significance of the year-to-year differences in reporting on elements of ICRS ${ }^{14}$ When comparing the reporting of 146 companies that are included in both sample year 1997 and 1998, the test indicates that these companies report significantly less on item 2 in 1998 $(p<.05)$. When comparing the reporting of 152 companies that are included in both sample year 1998 and 1999 , the test indicates that these companies report significantly less on item I in $1999(p<.05)$.

Panel B of Table 1 presents the descriptive statistics of the aggregate ICRS, i.e. an un-weighted score for each company in the sample calculated by summing the individual items company management reported on. Although ICRS is ranked from 0 to 6 , few companies reported 3 or more items. As a result, the average value of $I C R S$ is quite low. Kolmogorov-Smirnov tests show that the assumption about the normality of the distribution for $/ C R S$ in all sample years can be rejected $(p<.01)$. In addition, the significance of the year-to-year difference in the distribution of ICRS during 1997 to 1999 is investigated. In spite of the two significant year-to-year differences in the reporting on elements of ICRS, Wilcoxon signed-rank tests indicate that the distribution of the aggregate ICRS does not differ significantly between the years: ICRS of 1997 was paired with $1998(p>47 ; N=146)$ and $1999(p>84 ; N=130)$, and ICRS of 1998 was paired with $1999(p>.94 ; \mathrm{N}=152))^{15}$ This indicates that company management consistently reports on internal control during the period 1997 to 1999.

Nevertheless, panel $B$ of Table 1 shows that for the full sample the mean value of ICRS decreases from 1997 to 1998. Considering the equal distribution of ICRS in the paired sample, this is due to companies that are only included in one of the sample- 


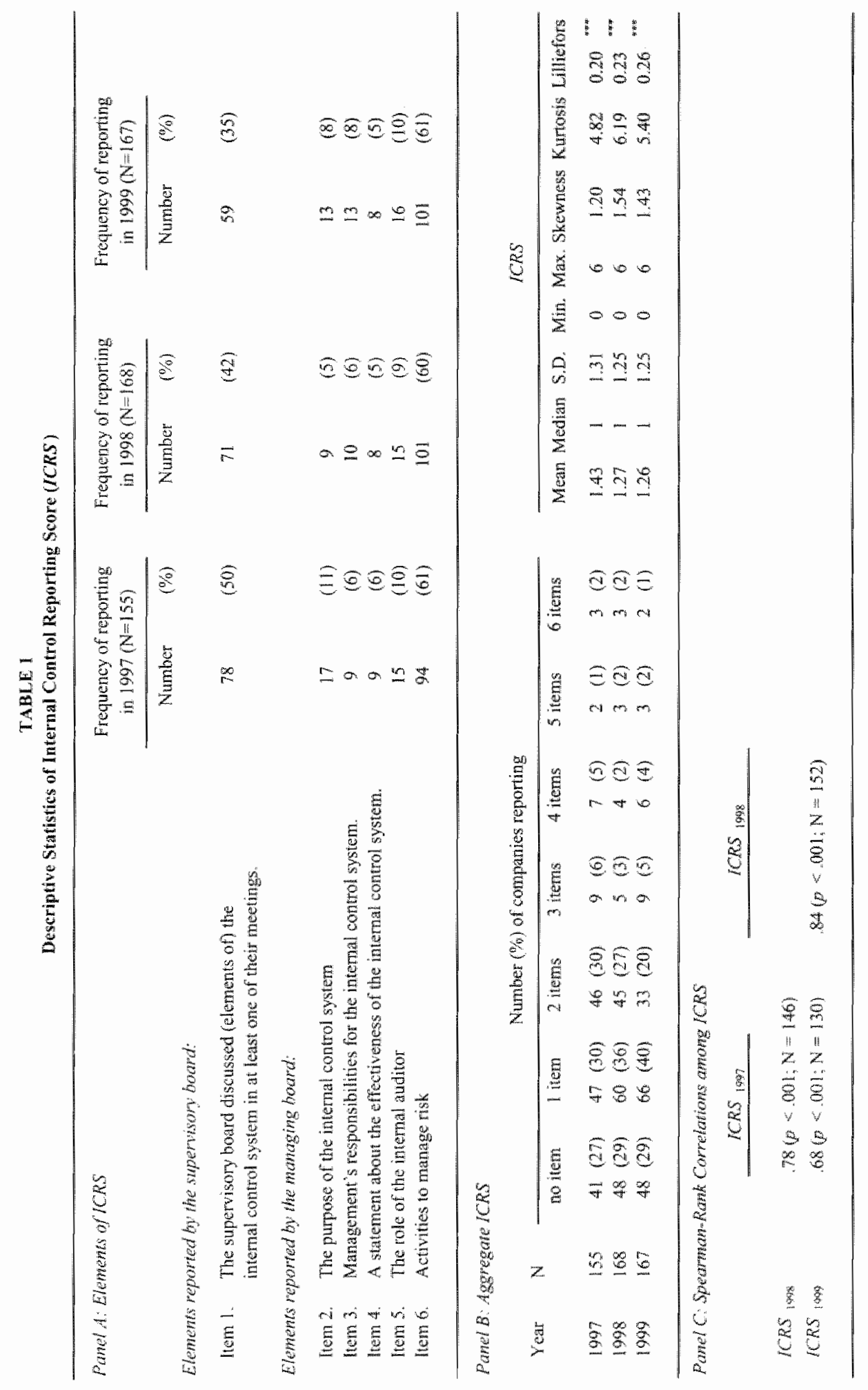


years. Mann-Whitney $U$ tests showed that for 9 companies that are only included in sample year 1997, the mean value of ICRS is not significantly different from the other 146 companies in sample year $1997(p>88 ; \mathrm{N}=155)$. In contrast, for 22 companies that are new in sample-year 1998 , the mean value of ICRS is significantly lower compared to the other 146 companies included in sample year $1998(p<.001 ; \mathrm{N}=168)$. A likely explanation for this Iinding is that the new companies in the sample of 1998 have significantly different company characteristics that are hypothesized to influence ICRS. ${ }^{16}$

Panel $\mathrm{C}$ of Table 1 presents the Spearman-rank correlations among ICRS in paired samples. The high and significant correlation coefficients further indicate that company management consistently reports on internal control during the period 1997 to 1999 .

\subsubsection{Reliability of ICRS}

Several tests were carried out to assess the statistical reliability of ICRS. A first indication for the reliability of ICRS is the consistency in reporting of companies in the paired samples during 1997 to 1999. A second measure of reliability is internal consistency, which applies to the consistency among the items in a summated score. Individual items of the score should all be measuring the same construct and thus be highly inter-correlated. Rules of thumb suggest that item-to-total correlations exceed .50 and that inter-item correlations exceed .30 (Robinson, Shaver and Wrightsman 1991). For the total sample of 1997, 1998 and 1999, the average item-to-total correlation is .57. All coefficients of the item-to-total correlations are statistically significant at the $1 \%$ level. In addition, the average inter-item correlation is .39 and most coefficients of the inter-item correlations are statistically significant at the $1 \%$ level. The high inter-item correlations show that all items comprising ICRS tend not to be reported, unless another item is also reported. Further verification revealed that item 2 was not reported by the sample companies, unless item 6 was also disclosed. Another type of diagnostic measure is the reliability coefficient that assesses the consistency of the entire scale, with Cronbach's alpha being the most widely used measure. Cronbach's alpha for the sample of 1997, 1998 and 1999 is $.72, .74$ and .70, respectively. The generally agreed lower limit for Cronbach's alpha is .70 , although it may decrease to .60 in exploratory research (Robinson et al. 1991). Botosan (1997), who used a similar disclosure index to investigate the determinants of corporate disclosure, reported a Cronbach's alpha of .64 .

\subsubsection{Descriptive statistics of agency and control variables}

Table 2 presents the descriptive statistics of the agency and the control variables. Several variables are skewed and have high kurtosis. Lilliefors tests showed that the assumption about the normality of the distribution can be rejected at conventional probability levels $(p<10)$ for $L E V$ in sample year 1999 and for $M O, L l, F O$ and $O D$ in all sample years. 
Voluntary Reporting on Internal Control

TABLE: 2

Descriptive Statistics of All Variables

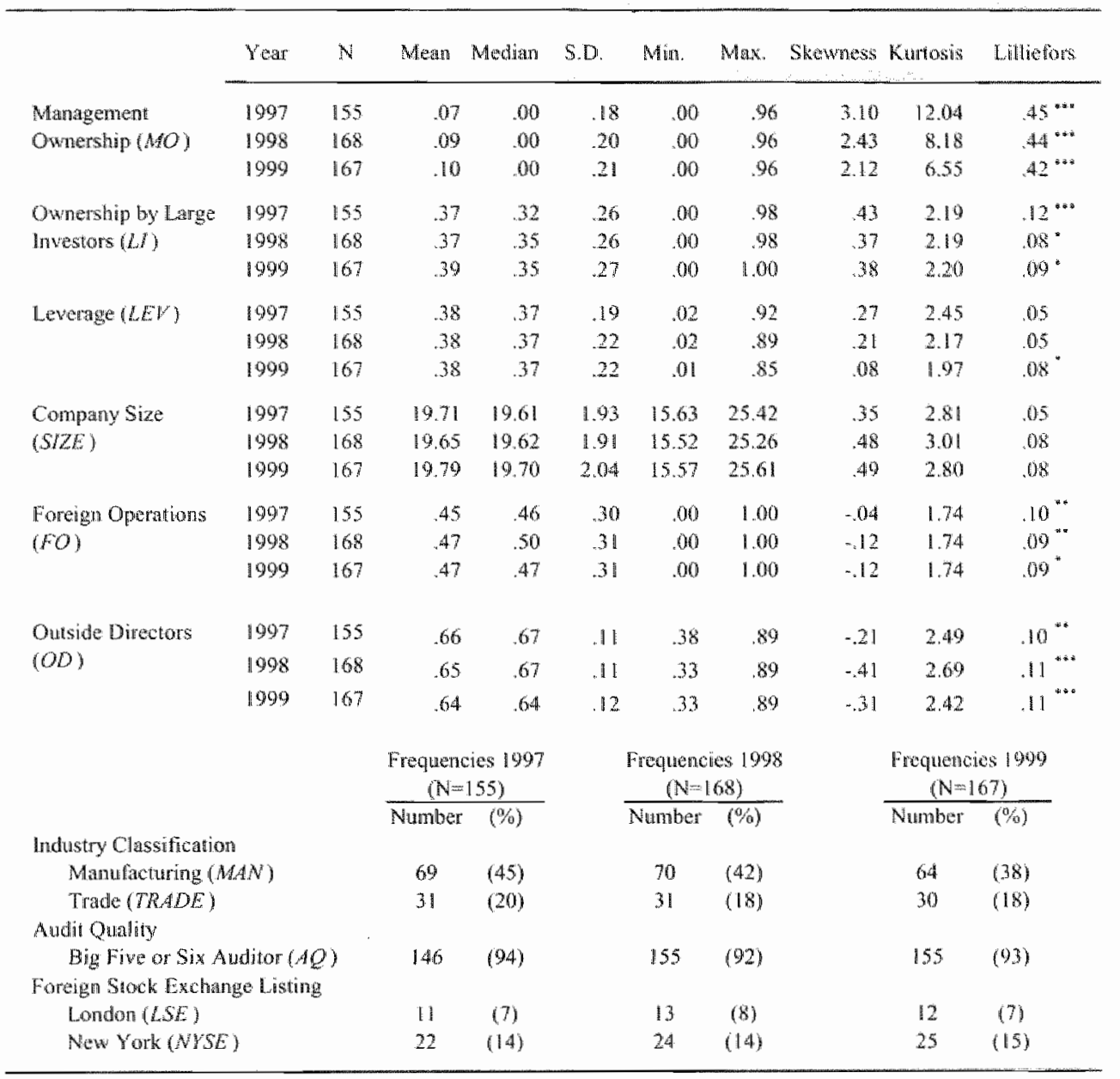

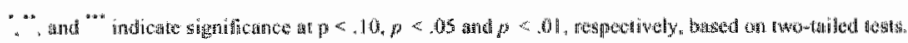

$\therefore$ Vorratule defliminion:

\begin{tabular}{|c|c|c|}
\hline AO & $=x$ & 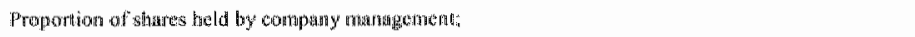 \\
\hline$L A$ & $=\pi$ & Proportion af shatres held by larges inwesiors: \\
\hline LEF & $:=$ & 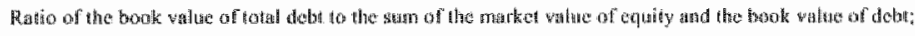 \\
\hline $\operatorname{SRE}$ & $=$ & 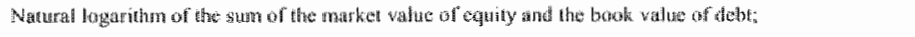 \\
\hline$F O$ & $=$ & 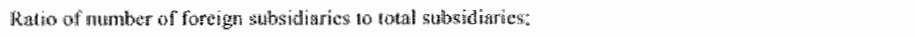 \\
\hline$M A H^{\prime}$ & $\because$ & 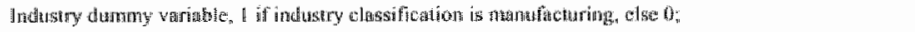 \\
\hline TRADEE & $=$ & 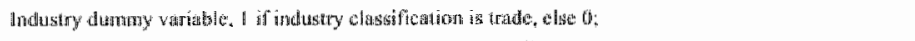 \\
\hline$A Q$ & $=$ & 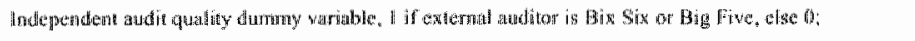 \\
\hline o & $=$ & 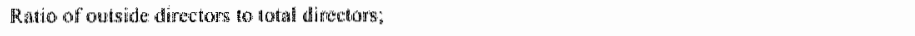 \\
\hline $\mathscr{S S E}$ & $=$ & 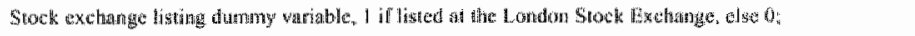 \\
\hline MYSE & $=$ & 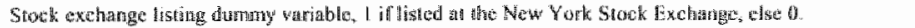 \\
\hline
\end{tabular}




\section{Chapter 2}

\subsubsection{Univariate tests}

Panel A of Table 3 presents pairwise Spearman-rank correlations among ICRS and agency variables. ${ }^{17}$ The correlations provide a univariate test for each agency variable. The results show that $M O$ and SIZE are significantly correlated with ICRS in the direction hypothesized in all sample years $(p<.01)$. LI is significantly correlated with JCRS in the direction hypothesized in 1997 and $1999(p<.01$ and $p<.05)$, but only weakly in $1998(p<10)$. LEV is significantly correlated with ICRS in the direction hypothesized in 1998 and $1999(p<.01)$, but is not significantly correlated with ICRS in 1997.

TABLE 3

Correlations annong Variables

Pand A: Cornetarions among ICRS and Agency Vornablens

\begin{tabular}{|c|c|c|c|c|}
\hline & $M O$ & LI & $1 E V$ & $S I Z 4$ \\
\hline RCRS & $-.24^{* 4}$ & $-.19^{* * *}$ & .04 & $.49^{\mathrm{cos}}$ \\
\hline ICRS WGH & $-30^{\circ}$ & $-14^{*}$ & $.24^{6 * x}$ & $.53^{\circ \circ}$ \\
\hline JCRS & $-26^{* * 2}$ & $-.15^{* * *}$ & $.21^{\cdots *}$ & $47^{\circ \cdot 4}$ \\
\hline
\end{tabular}

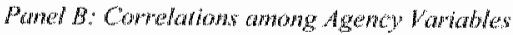

\begin{tabular}{|c|c|c|c|c|c|c|c|}
\hline 1997 & $M O$ & $L I$ & $\triangle E$ & & & & \\
\hline$L I$ & $-.23^{-4.4}$ & & & & & & \\
\hline LEV & $-18^{*}$ & $.17^{0 * 4}$ & & & & & \\
\hline $5 R 2 E$ & $-16^{.4}$ & $-36^{k * 4}$ & $-.16^{\mathrm{kt}}$ & & & & \\
\hline logs & $M O$ & $\Delta$. & $L E Y$ & 1999 & MO & $L$ & $\angle E Y$ \\
\hline$L /$ & $-.29^{* *: 8}$ & & & $L I$ & $-34^{*}$ & & \\
\hline$L E V$ & $-23^{a+18 x}$ & $.16^{\circ d}$ & & LEY & $-19^{\text {k.t }}$ & 10 & \\
\hline$S H Z E$ & $.117^{9 *}$ & $-29^{* * a}$ &. .07 & $S I Z E$ & $-.22^{\text {ikstite }}$ & $-19^{* *}$ & -.07 \\
\hline
\end{tabular}

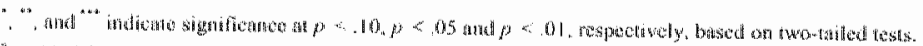

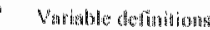

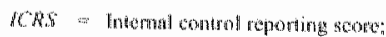

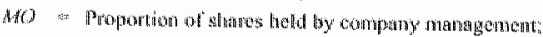

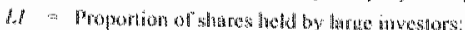

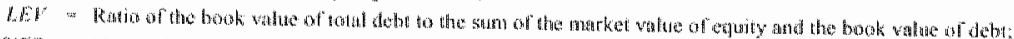

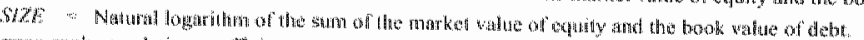

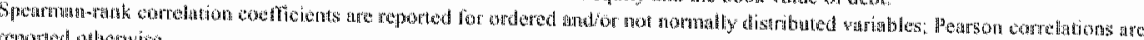
remartell atherwis.

\subsubsection{Multwariate tests}

Panel B of Table 3 presents the correlations among the agency variables. Many correlation coefficients are significant and the degree of correlation suggests that the results of the univariate tests may be overstated. A multivariate test is an appropriate means to consider simultaneous effects of the explanatory variables on ICRS. For this reason, all agency and control variables are included simultaneously in a multivariate model. Additional tests for multicollinearity gave no indication of any potential 
harmful effects. Ordered probit analysis is used to estimate the multivariate model. ${ }^{18}$ The ordered probit model takes into account the ordinal nature of ICRS and makes no assumptions regarding the distribution of the explanatory variables. ${ }^{19}$ The estimated coefficients of an ordered probit analysis however must be interpreted with care (Greene 2000). ${ }^{20}$ Table 4 shows the results of the ordered probit analysis.

TABLE 4

Ordered Probit Analyses of the Association between the ICRS, Agency and Control Variables "

\begin{tabular}{|c|c|c|c|c|}
\hline Variables & $\begin{array}{l}\text { Predicted } \\
\text { sign }\end{array}$ & $\begin{array}{c}1997 \\
(N=155)\end{array}$ & $\begin{array}{c}1998 \\
(N=168)\end{array}$ & $\begin{array}{c}1959 \\
(N=167)\end{array}$ \\
\hline \multicolumn{5}{|l|}{ Agency larabler } \\
\hline Management Ownership (MO) & - & $-2.03^{n+*}$ & $-1.45^{* \times 2}$ & $-1.03^{\text {**t }}$ \\
\hline Large finvestors $(L /)$ & - & $-1.03^{n *}$ & $-69^{*}$ & $-83^{* * *}$ \\
\hline Leverage $(L E V)$ & + & .09 & $1.26^{* * 2}$ & $1.09^{* \ldots *}$ \\
\hline Company Size (SIZE) & + & $.26^{* * *}$ & $34^{\circ \cdots *}$ & $.25^{\alpha \rightarrow * *}$ \\
\hline \multicolumn{5}{|l|}{ Control Voriables } \\
\hline Foreign Operations $(\mathrm{FO})$ & & $.64^{\circ}$ & $.46^{\circ}$ & .29 \\
\hline Manufacturing $(M A N)$ & & .15 & .07 & .17 \\
\hline Trade (TRADE) & &.$\$ 9$ & .19 & .28 \\
\hline Andit Quality $(A Q)$ & & .31 & .17 & -.06 \\
\hline Outside Directors $(O D)$ & & $1.46^{\circ}$ & $1.11^{\circ}$ & .92 \\
\hline London Stock Exchange (LSE) & & $62^{*}$ & $.70^{\circ}$ & $1.10^{\text {*a* }}$ \\
\hline New York Stock Exchange (NYSE) & & -.52 & -.37 & -.28 \\
\hline Log Likelihood & & -196 & -192 & .204 \\
\hline 1. S Statistic & & 77 & 91 & 75 \\
\hline Probability & & .00 & .00 & .00 \\
\hline "Pserudo' $\mathrm{R}^{2}$ & & $16 \%$ & $19 \%$ & $16 \%$ \\
\hline
\end{tabular}

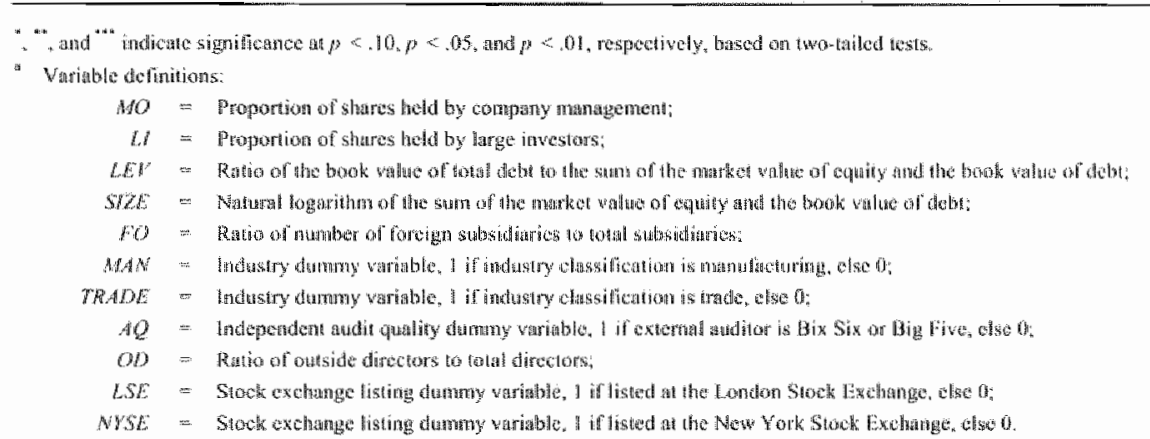

Considering the maximized values of the log-likelihood function and the values of the models' likelihood ratio (LR) statistic, the null hypothesis of no statistical association can be rejected at the .00 level of confidence in each sample year. The 'pseudo' $\mathbb{R}^{2}$ measures the ordered probit model's goodness of fit. The values of the likelihood ratio index are $16 \%, 19 \%$ and $16 \%$ for respectively 1997,1998 and 1999.

The results of the ordered probit analysis show that all agency variables are significantly correlated with ICRS at the $5 \%$ level in the direction hypothesized in at least two sample years. $M O$, the first proxy for agency problems between management 


\section{Chapter 2}

and shareholders, is significantly correlated with ICRS in the direction hypothesized in all sample years $(p<.01$ in 1997 and 1998 , and $p<.05$ in 1999). $L l$, the second proxy for agency problems between management and shareholders, is significantly correlated with /CRS in the direction hypothesized in 1997 and $1999(p<.05)$, but is only weakly significant in $1998(p<10)$. LEV, which proxies for agency problems between shareholders and debt holders, is significantly correlated with ICRS in the direction hypothesized in 1998 and $1999(p<.01)$, but is not significantly correlated with ICRS in 1997. Finally, SIZE is significantly correlated with ICRS in the direction hypothesized in all sample years $(p<01)$. Overall, the results of the ordered probit analysis show that ICRS is systematically associated with agency variables in the direction hypothesized. Hence, the results are consistent with the explanation that voluntary reporting on internal control is a monitoring mechanism.

The results further show that $L S E$, a control variable for a listing at the London Stock Exchange, is significantly positively correlated with ICRS in all sample years $(p<10$ in 1997 and 1998 and $p<.01$ in 1999). FO, a control variable for the degree of a company's foreign operations and $O D$, a control variable for the degree of monitoring by outside directors, are both weakly significantly positively correlated with ICRS in 1997 and $1998(p<10)$. Measures for the control variables for industry membership and the quality of the independent auditor are not significantly correlated with ICRS. In summary, the findings for the control variables correspond with the explanations for a positive association between ICRS and a listing at the London Stock Exchange, the degree of foreign operations and the level of monitoring by outside directors. The findings however do not support the explanations for differences in ICRS due to industry classification and audit quality.

\subsubsection{Sensitivity: of the results}

Obtaining a disclosure score is difficult because deciding which items should be included in calculating the score requires subjective judgment. ICRS in the previous analyses is the sum of all items company management reported on. Although ICRS is ranked from 0 to 6 , few companies reported 3 or more items. Moreover, all items are equally weighted. Because item 1 and item 6 are most frequently reported, these items probably dominate ICRS. Consequently, the main results are likely mainly influenced by item 1 and 6 . For this reason, I tested the sensitivity of the main results for separate elements included in ICRS, as well as for the composition of ICRS. Using binary probit regression, I first separatelly examined the items that likely dominate ICRS. An indicator variable $I C R /$ measures reporting on item 1 ( $\|$ if reporting item $I$, else 0 ) and an indicator variable $I C R 6$ measures reporting on item 6 ( 1 if reporting item 6 , else 0 ). Next, II investigated the less frequently reported items 2 to 5 together using binary probit regression. ${ }^{21}$ An indicator variable ICR2-5 measures reporting on any of these items ( 1 if reporting item 2 to 5 , else 0 ). Finally, I examined two 'truncated' internal control reporting scores (TRICRSI and TRICRS2). TRICRSI is calculated by summing $I C R I, I C R 2-5$ and ICR6 and is as a result ranked from 0 to 3. TRICRSZ is calculated by summing $I C R I$ and $I C R 6$ and is as a result ranked from 0 to 2 . Ordered probit 
regression is used to analyze TRICRSI and TRICRS2. Table 5 presents the results of the binary and ordered probit regressions of ICRI, ICR2-5, ICR6, TRICRSI and TRICRS 2 on all agency and control variables.

For TRICRSI the significance of the coefficients of the agency variables is identical to those reported in Table 4. Comparing the results of TRICRSI and TRICRS2, it appears that including (excluding) items 2 to 5 in the score strengthens (weakens) the significance of the coefficients of the agency variables only slightly. More specifically, including items 2 tot 5 in the score improves the significance of the coefficient of $L I$ in 1998 from not significant $(p>10)$ to weakly significant $(p<.10)$, improves the coefficient of $M O$ in 1999 from moderately significant $(p<.05)$ to strongly significant $(p<.01)$ and improves the coefficient of $M O$ in 1999 from weakly significant $(p<10)$ to moderately significant $(p<.05)$. This confirms the expectation that the significance of the coefficients of the agency variables in the main analyses are primarily influenced by the most frequently reported items (i.e. item I and item 6 ) and to a lesser extent by the less frequently reported items (i.e. items 2 to 5 ). The results for ICRI, ICR2-5 and ICR6 further indicate that in the main analyses:

- Item 1 accounts for the significance of the coefficients of MO in 1997 and 1998 and for the significance of the coefficient of $L I$ in 1997 ;

- Item 6 accounts for the significance of the coefficient of $L /$ in 1999 and for the significance of the coefficients of $L E V$ in 1998 and 1999;

- Both item 1 and item 6 account for the significance of the coefficients of SIZE in 1997, 1998 and 1999.

So, while the main results are primarily influenced by item 1 and item 6 (the two most frequently reported items), the influence of item 1 on the results decreased and the influence of item 6 increased during the period 1997 to 1999 . The decreased influence of item 1 in 1999 goes together with a significant decrease in reporting on this item in 1999 (see section 7.1). Seemingly, the supervisory board gradually lost interest in this item that was recommended by the Peters Committee in 1997.

Overall the findings for item 1 and 6 support the explanation that management reports on these items for monitoring purposes. However, the findings for items 2 to 5 provide only weak support this explanation, in spite of the fact that reporting on these items was strongly recommended in intermational public policy reports on corporate governance and contrary to the finding in section 7.2 that these items tend to be reported together with other items. One possible explanation for finding rather weak associations between company characteristics that proxy for agency problems and reporting on item 2 to 5 is that reporting on these items was not recommended by the Peters Committee (1997). As a result, a number of managers in the sample may have been uninformed about these recommendations. In addition, managers who were familiar with the recommendations may have thought that this information was not useful for investors. For example, managers may have considered the purpose of an internal control system (item 2) and their responsibilities for internal controls (item 3) evident to anyone who read the COSO report (1992). With respect to reporting on the effectiveness of internal controls (item 4 ), a further explanation may be that this issue 


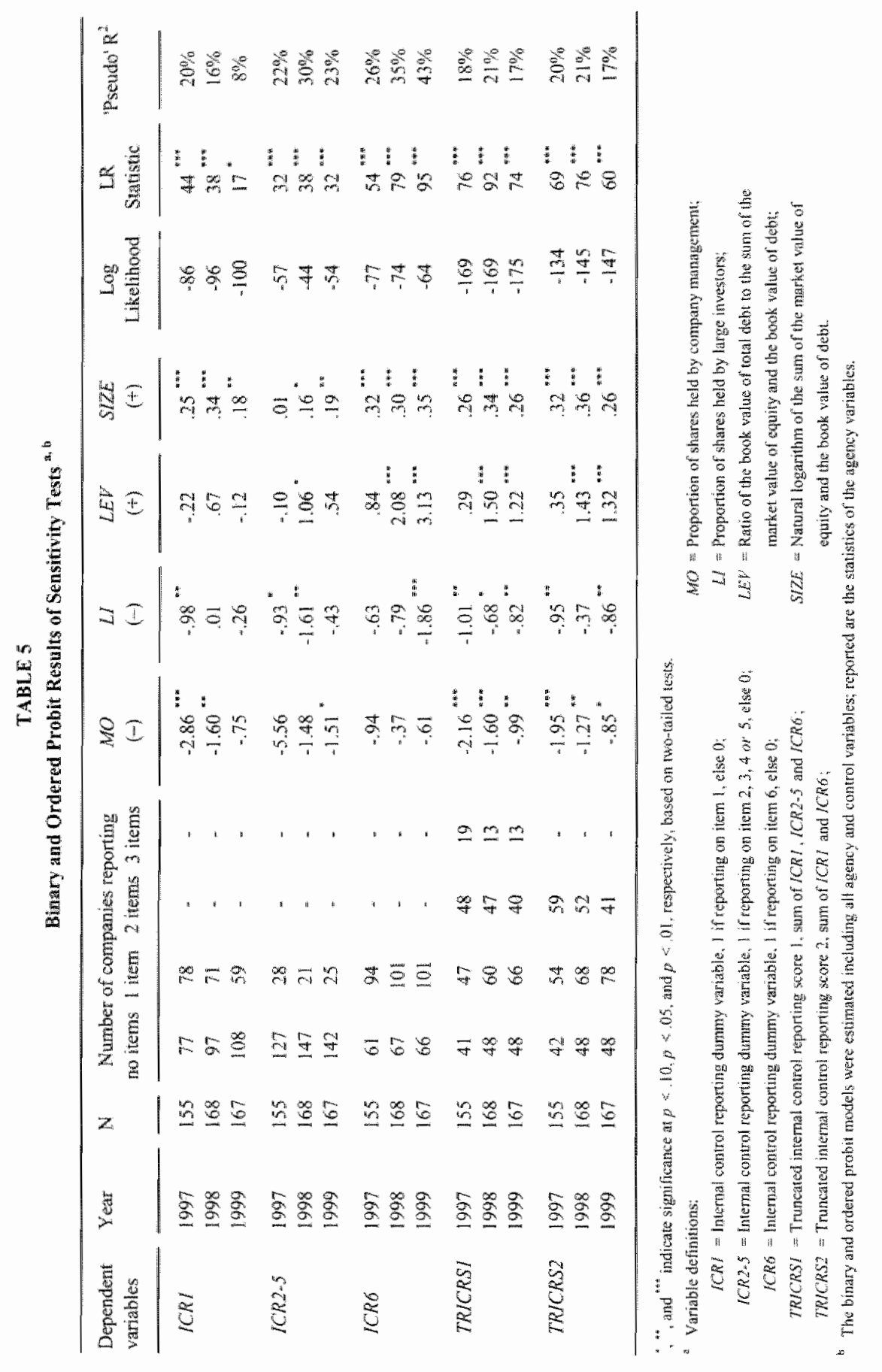


was rife with controversy, in particular about the costs of such disclosures, but also about the criteria that should be used to evaluate internal controls, about whether managers should report about past effectiveness or future effectiveness, about whether such statement is credible without independent assurance, about the inherent limitations of internal controls, and about the scope of internal controls reported on (e.g. internal controls over financial reporting, internal controls over operations or both). As a result, the average manager in the sample may have perceived that reporting on the effectiveness of internal controls is too costly and/or too problematic.

\subsection{Summary and conchusion}

The aim of this study was to examine the monitoring role of voluntary reporting on internal control by company management. For this purpose, I developed the argument that voluntary reporting on internal control is a monitoring mechanism that mitigates the efficiency loss of agency problems. Agency theory predicts that if voluntary reporting on internal control is a monitoring mechanism, company management will voluntarily report more (less) on internal control if agency problems are higher (lower). The sample consists of Dutch companies listed on the Amsterdam Stock Exchange during the period 1997 to 1999. A disclosure score (ICRS) measured the extent of voluntary reporting on internal control.

Overall, the results correspond with the explanation that voluntary reporting on internal control is a monitoring mechanism. The main results in section 7.5 show that ICRS is systematically associated with company characteristics that proxy for agency problems in the direction hypothesized, while controlling for the degree of foreign operations, industry classification, the quality of the independent auditor, the level of monitoring by outside directors and foreign stock exchange listing. First, the results support that ICRS decreases if managerial ownership is higher $\left(\mathrm{H}_{1}\right)$. Second, ICRS decreases if ownership by large investors increases $\left(\mathrm{H}_{2}\right)$. Third, except for 1997, ICRS is found to be positively associated with leverage $\left(\mathrm{H}_{3}\right)$. Fourth, the evidence supports that ICRS increases with company size $\left(\mathrm{H}_{4}\right)$. The results further suggest that ICRS is higher for companies that are listed at the London Stock Exchange, and, except for $\$ 999$, higher for companies with a higher degree of foreign operations and a higher level of monitoring by outside directors.

Sensitivity tests indicate that two items in the disclosure index account for the main results. The results suggest that disclosures of activities to manage risk (item 6) and reporting the fact that the supervisory board discussed the internal control system in their meetings (item 1) are consciously reported for monitoring purposes. Moreover, the influence of item 1 on the results seems to have decreased and the influence of item 6 seems to thave increased during the period 1997 to 1999 . On the other hand, the sensitivity tests reveal that relatively infrequent disclosures about the purpose of internal controls (item 2), managements' responsibilities for the system (item 3), the effectiveness of internal controls (item 4 ) and the role of the internal auditor (item 5) are only weakly associated with company characteristics that proxy for agency problems, suggesting that these items are to lesser extent reported for monitoring 
purposes (on average). One possible explanation for the latter finding is that several managers in the sample were not familiar with the international public policy recommendations that lie behind reporting on these items. Another possible explatnation is that the average manager in the sample thad too many doubts about reporting on these items for monitoring purposes.

The results of the study should be considered in the light of the following limitations. Potential measurement error and bias may exist in measuring the extent of voluntary reporting on internal control. Measurement error also exists for the variable management ownership, because shareholdings smaller than $5 \%$ of total shares are not accounted for.

Notwithstanding these limitations, the findings of this study may be relevant to the public policy debate on internal control reporting and motivate further research. Part of the public policy debate has focused on the issue whether reporting on internal control should be voluntary or mandatory. Empirical evidence on relative costs and benefits of private production of information and governmentally regulated production of information can inform this discussion (Watts and Zimmerman 1986). This study has started with examining relative costs and benefits of private production of information on internal control. The results suggest that private contracting incentives exist for reporting on internal control. As a result, without further empirical evidence of the relative cost and benefits of regulation it is unclear whether regulation will improve economic efficiency. Investigating the relative cost and benefits of governmentally regulated production of information on internal control was not the purpose of this study, but is an interesting and important topic for future empirical research. 


\section{Endnores}

'See McMullen ef al. (1996) and Hermanson (2000) for an extensive overvew of the public policy debate and recommendations on internall control reporting in the United States Gieiger and Taylor (2003) discuss the background and details of the Sarbanes-Oxley Act's internal control certifications. Mills (1997) provides an overview of public policy recommendations on internal control reporting in the United Kingdom up to the Hampel Committee (1998a, 1998b). The final report of the Hampel Committee (1998a) and its Combined Code (Hampel Committee 1998b) recommended that directors review the effectiveness of the internal control system and report to the shareholders that they have done so. The auditor should report on internal control privitely to the directors. A compliance statement in the listing rules supports the Combined Code. A working party of the Commitiee (Turnbull Committee 1999) issued new guidance to implement the requirements on internal controf and reporting on internal control.

${ }^{2}$ Based on a survey of finance directors of large listed companies in the United Kingdom, Mills (1997) observed that most respondents perceive that their internal control system includes both financial and operational controls, and that risk assessment and risk management are essential aspects of internal control.

3 Jensen and Meckling (1976) demonstrated that investors do not care if monitoring is conducted because competition in the capital market leads to price protection and ensures that investors earn a normal retum. Others have argued that monitoring is a public good and that inwestors will free ride.

"Besides informing investors about the companies" internal control system, woluntary reporting on internal control may also improve internal control. The Public Oversight Board (1993) noted that company management would evaluate the internal control system before reporting on it and that evaluating the system will lead to improvements of the system. McMullen at al. (1996) argucd that reporting on internal control helps to communicate the "tone at the top' by sending a clear message within the organization about the expected control environment. Management may also make additional investments in internal control to be able to report on 'good' internal controls. Hermanson (2000) observed that respondents perceived that voluntary reporting on intemal control motivates management to improve internal control.

"A possible explanation for this is twofold. First, auditing standards require that the external auditon" obtains an winderstanding of the internal control system that is at least sufficient to plan the audit and to develop an effective audit approach. However, the external auditor may or may not ewaluate the strength of internal control when certifying funancial statements. In particular, the anditor may decide that it is more economical to audit details of financial statements (e.g. transactions and balances) than the process that produced them. Second, in case the auditor evaluates the strength of internal controls, the evaluation mainly concerns internal controls that are relevant for certifying the financial statements, which are not necessarily the same internal controls that are relevant for the efficiency and effectiveness of business processes. Both explanations are in line with the results of Hermanson (2000). Providing respondents with a "nartow" definition of reporting on internal control, including financial-reporting controls only, financial statement users disagreed that reporting on internal control is irrelevant if the financial statements are audited. Prowiding respondents with a 'broad' dlefinition of reporting on intemal control. including controls that go beyond funancial reporting and include ceriain 


\section{Chapter 2}

operational and compliance controls, frnancial statement users strongly disagreed that reporting on intemal control is irrelevant if the financial statements are audited.

"Ball and Foster (1982) pointed out that results conforming a "size hypothesis" can have many other alternative explanations. In a comment on Watts and Zimmerman (1979), who used company size as a proxy for political cost. Ball and Foster noted that competing hypotheses have been advanced to explain differences across companies in their corporate disclosure decisions. Company size has been used as a proxy for many of these altemative hypotheses, e.g. competitive advantage and information production costs.

"Besides these five categories of control variables, several other variables that are possibly related to volwintary reporting on internal control were considered, including companies" asset composition (measured as the ratio of receivables and inventory to total sales), labour intensity (measured as the ratio of personnel expenses to total experses or as the ratio of employees to total sales), book-tomarket value (measured as the ratio of the book value of assets to the market walue of equity), profit margin (measured as net result divided by net sales), net loss in the last wo years, and presence of an audit committee (measured with a dummy variable). Additional tests show that while reducing the number of observations per independent variable, including these additional control variables in the multivariate tests does not substantially influence the results reported in section 7 and leacls to identical conclusions.

From the perspective of the auditor, more complete disclosures about internal controls may benefit the reputation of the audit firm. Independent auditors that seek to maintain a reputation of higher quality may as a result positively influence the extent of internal control reporting in their clients" annual reports. Interestingly, many bodies involved in the standard setting process regarding reporting on internall control have their roots in the auditing profession. Haring (1979), Watts and Zimmerman (1986) and Meier, Alam and Pearson (1993) argue that auditors" position on a proposed standard is positively related to their clients" positions. However, the auditors " position may not be determined by their clients' positions alone and anditors' interests can differ from those of their clients. Watts and Zimmerman (1986) suggest that the auditor has an incentive to support standards that make more work For the auditor. Meier ef al. expect that auclitors will favour standards that increase the demand for their monitoring role. The strong lobby of auditors for standards on reporting on internal control suggests that reporting on internal control is beneficial for their clients, but is also consistent with the notion that reporting on internal control makes more work for the extemall auditor (e.g. in providing external assurance that the internal control system is well designed and operates effectively).

"The intial sample counted 159,175 and 176 companies for respectively 1997,1998 and 1999 (i.e. 510 company-year observations) and the totat number of different companies in the initial sample is 199. For 20 company-year observations not all necessary data was available.

There is no indication that the timing of the publication of the public policy reports led to increases in the reporting on internal control during the period 1997 to 1999 . Between the exposure draft of the report of the Peters Committee in October 1996 and publication of the final repont in June 1997, all listed companies had the opportunity to take notice of the recommendations of the Peters Committee. No ammual report in the sample of 1997 were finalised before publieation of the final report of the Peters Committee. Finding no significant difference in reporting on item 1 between 1997 and 1998 
(see section 7.1), suggests that companies did not wait until 1998 with implementing the recommendations of the Peters committee on reporting on internal control. Although the Hampel report and the Tumbull guidance were published after 1997 , their recommendations and gudance were based on public opinions developed earlier and on actual reporting practices in previons years. This makes it possible that companies reported the reconmended information atrexdy in 1997 . No significant year-to-year increases were found during 1997 to 1999 for reporting on item 2 to item 6 (see section 7.1)

iT The requirement results from the Disclosure of Major Holdings in Listed Companies Act. Shareholders must disclose if their percentage of ownership moves into a different band than immediately before. The bands are $0-5 \%, 5-10 \%, 10-25 \%, 25-50 \%$ and $662 / 3 \%$ or more. As a result, a transaction performed by a shareholder does not result in a new obligation to notify if it does not move the holding into a new band. In addition, new share issues reduce a shareholder's percentage holding without creating a new obligation to notify.

13 The multivariate analyses were also performed with a more elaborate set of industry dummy variables based on wo- and three-digit codes of the North American Industry Classification System (NAICS). The manufacturing sector, where almost half of the companies in the sample are active, was subdivided into: mamufacturing of food and beverage; textile, apparel and paper; chemicals, plastics and rubber; primary metal and metal products; and machinery, computer, electronic products and electrical equipment. The trade sector was subdivided into: wholesale trade and retail trade. Companies active in other sectors were subdivided into: construction, transportation and warehousing: information services; professional scientific and technical services; and other. Including dummy variables for each of these sub sectors does not influence the results reported in section 7 and leads to identical conclusions.

13 The multivariate analyses were also performed while controlling for each Big Six or Big Five auditor separately. This does not influence the results reported in section 7 and leads to identical conclusions.

14 McNemar tests are used because the separate items of JCRS are dichotomous variables.

is Wilcoxon signed-rank test are used bewase aggregate /CRS is a not nomally distributed ordered variable.

it Consistent with the hypotheses in section $5, M O$ is $15 \%$ higher $(p<001$; $N=168), L E V$ is $22 \%$ lower $(p<.001 ; N=168)$, and the sum of the market value of equity and the book value of debt is (21.88 billion lower $(p<05 ; \mathrm{N}=68)$ for new companies in sample year 1998. An alternative explanation is that new companies in the sample of 1998 have other characteristics that were not hypothesised to influence ICRS. For example, because most of these companies recently went public, they nay be unfamiliar with external reporting practices or have recently issued a prospectus containing similar information. Although Mann-Whitney $U$ tesis show no significant difference in ICRS for companies that went public in 1997 and 1999, the multivariate analyses in section 7 were also performed while controlling for the possibility that going public is systernatically related to management's decision to report on internal control (dummy variable, 1 if company went public in sample year, else 0). The results of these analyses revealed no significant effect for this dummy wariable and led to identical conclusions 


\section{Chapter 2}

otherwise. This finding suggests that the difference in ICRS for companies that went public in 1998 is likely the result of different company characteristics that are hypothesised to influence /CRS.

17 Kendall's tau, another nomparametric measure of association, yielded identical results for both direction and significance of all reported correlation coefficients.

1: Following the work of Aitchison and Silvey (1957) the ordered probit model is set up as follows: $y^{*}$ $=\beta *+2$; where $y *$ is the unobserved dependent wariable, $x$ is a vector of explanatory variables, $\beta$ is an unknown parameter vector, and a represents the error term which is caused by unobserwed factors. Instead of $y^{*}$ the following is observed: $y=0$ if $y^{*} \leq \mu_{1} ; y=1$ if $\mu_{1} \leq y^{*} \leq \mu_{2} ; y=2$ if $\mu_{2} \leq y^{*} \leq \mu_{3} ; \ldots$; $y=6$ if $\mu_{6} \leq y^{*}$; where $\mu$ is a vector of unknown theshold values that is estimated with the $\beta$ vector. The error term $\varepsilon$ is assumed to have a standard nomal distribution. The probability of observing each value of $y$ is calculated as follows: $\operatorname{Prob}(y=k)=\Phi\left(\mu_{k+1}-\beta^{\prime} x\right)-\Phi\left(\mu_{k}-\beta^{\prime} x\right)$; where $\Phi$ is the cumulative distribution function of 2 . The probabilitics of observing each walue of $y$ are used to derive a log likelihood function. Estimates of $\beta$ and $\mu$ are obtained by maximising the log likelihood function. The model can also be estimated with a logistically distributed disturbance. This trivial modification of the formulation makes wirtually no difference in practice (Greene 2000).

19. Alhough the outcome of ICRS is discrete, multinomial logit analysis would fail to account for the orlinal nature of this variable. Ordinary regression on the other hand would treat the difference between a score of 0 and 1 , the same as the difference between a score of 1 and 2 , whereas in fact they are only a ranking (Greene 2000 ).

20 The derivative of $\operatorname{Prob}(y=0)$ has the opposite direction sign from the coefficient estimate and the derivative of Prob $(y=6)$ has the same sign as coefficient estimate. The signs of the changes in the other probabilities are ambiguous as for each probability the marginal effect of changes in $\mathrm{x}$ is equal to $\partial$ $\left.\Phi\left(\mu \mu_{k}+1-\beta x\right) / \partial x\right]-\left[\partial \Phi\left(\mu_{k}-\beta^{x} x\right) / \partial x\right]$

${ }^{21}$ I examined these items together because it is unlikely that item 2 to 5 dominate $/ C R S$ individually. Moreover, the limited number of observations of reporting on these items hinder testing these items separately. 


\title{
How Informative Are Qualitative Risk Disclosures?
}

\begin{abstract}
The aim of this chapter is to examine the information content of top management's forward-looking qualitative risk disclosures when they issue new securities to investors. Through a detailed content analysis of the risk sections in offering prospectuses, I investigate what sorts of risk are disclosed and whether the disclosures are associated with stock market values. The sample consists of 90 prospectuses of Dutch companies that issued securities on the Amsterdam Stock Exchange in the period from 1997 to 2000 . Public equity markets in this period seemed willing to invest in extremely risky businesses and listing and issuing rules allowed management considerable latitude in the nature, degree and form of their risk disclosures.

The content analysis reveals that management mostly assigns the label 'risk' to factors - either inside or outside the firm - that could adversely impact future firm performance. In addition, management describes risk as loss or probability of loss, variance, lack of information, and lack of control by small investors. The findings of subsequent empiricall tests are uniformly supportive of the view that forward-looking qualitative risk disclosures are a useful source of information about equity risk. First, the risk disclosures are positively associated with the variability of returns (total return risk) and the covariance of returns with the market (systematic risk) in the period after disclosure. Second, the risk disclosures are positively associated with average marketadjusted stock returns in the period after disclosure, which is consistent with the view that the market judges firms with more extensive risk disclosures to be riskier, and penalizes them with a higher cost of capital. Third, the risk disclosures are positively associated with extreme declines in stock price in the period after disclosure, suggesting that the risk disclosures warn investors for possible seriously negative outcomes.
\end{abstract}

\subsection{Introduction}

A widely perceived shortcoming of current financial statements is that they provide a snapshot of the company based on previous history, but give little or no indication of a firm's exposure to different sorts of risk in the future. While standard setters increasingly require management to give investors a better sense of the risks to which a firm is exposed, relatively little is known about how markets react to risk disclosures. Extant research on risk disclosures has exclusively focused on quantitative disclosures in financial statements and on specific categories of risk, especially market risk, 
overlooking possible interrelationships among the many types of risk that are present in an organization "s environment.

The aim of this study is to extend prior risk disclosure research by examining managements" forward-looking qualitative risk disclosures when firms issue new securities to inwestors. More specifically, I perform a detailed content analysis of the risks disclosed in prospectuses for new public offerings of securities. The content analysis is designed to determine what sorts of risk are described, how these risks are correlated, and - most importantly - whether the risk disclosures provide useful information for equity risk assessment. The sample consists of 90 prospectuses of Dutch companies that issued securities on the Amsterdam Stock Exchange in the period from 1997 to 2000 . This setting is especially interesting because public equity markets in the late 1990 s seemed willing to invest in extremely risky businesses that had never made profits and might never do so. Moreover, listing and issuing rules in that period allowed management considerable latitude in the nature, degree and form of risk disclosures.

Overall, the evidence is consistently supportive of the view that forwardlooking qualitative risk disclosures in prospectuses are a useful source of information about equity risk. The findings are threefold. First, the results indicate that risk disclosures are positively associated with the variability of returns (total return risk) and the covariance of returns with the market (systematic risk) in the months after publication of the prospectus. Second, the results show that the risk disclosures are positively associated with average market-adjusted stock returns in the months after publication of the prospectus. This is consistent with the view that the market judges firms with more extensive risk disclosures to be riskier, and penalizes them with a higher cost of capital. Third, the results indicate that the risk disclosures are positively associated with declines in stock price below regular levels (so-called "penny stocks') in the months after publication of the prospectus, which suggests that risk disclosures can provide a warning to investors about the possibility of outcomes that may threaten the viability of the firm.

The remainder of the chapter is organized as follows: The next section provides relevant background information and presents the research questions. The third section details the research design. The results are included in the fourth section. The final section summarizes and concludes the chapter.

\subsection{Background}

One common criticism of financial statements is that they lack adequate disclosures about risk and uncertainty to be supportive of investment decision making (Schrand and Elliot 1998).' From the mid 1980s there have been many calls within the accounting profession to re-evaluate the type of information provided to investors. Major questions asked by developers of standards on risk reporting are: (1) Which types of risk should be disclosed? and (2) How should these risks be measured? Related to the first question, an underlying issue is the definition of risk, as either a two-sided concept that represents a firms" exposure to both upside and downside 
How Informative Are Qualitative Risk Disclosures?

outcomes, or a one-sided concept that measures only the potential for losses (Schrand and Elliot 1998).

Some risk disclosure proposals advocate revolutionary change of the existing accounting system into a more dynamic sort, such as the American Institute of Certified Public Accountants (AICPA) Special Committee on Financial Reporting's call for forward-looking non-financial risk disclosures (AICPA 1994). More recently, the AICPA Special Committee on Enhanced Business Reporting envisioned a crucial role for forward-looking non-financial information to provide investors, among others, with a comprehensive picture of company risk (AICPA 2004). In 1997, the Securities and Exchange Commission's Financial Reporting Release (FRR) No. 48 required quantitative and qualitative disclosures about exposure to market risk inherent in derivates (SEC 1997). Following highly publicized derivative losses in the 1990s, FRR No. 48 responded to appeals from investors and other constituents for enhanced public disclosure of firms' exposures to market risk (Linsmeier and Pearson 1997). FRR No. 48 defines market risk as loss due to adverse changes in market rates or prices, such as interest rates, foreign currency exchange rates, and commodity prices. ${ }^{2}$ In response to this regulation, several empirical studies examined the usefulness of quantitative market risk disclosures (e.g. Rajgopal 1999, Linsmeier et al. 2002, Jorion 2002, Thornton and Welker 2004). In short, this research stream suggests that quantitative market risk disclosures provide useful information to investors. Although FRR No. 48 recognizes the limitations of quantitative disclosures and requires that companies qualitatively describe their primary market risks and derivative accounting policies, none of these studies specifically addressed the usefulness of qualitative market risk disclosures.

Moreover, and despite the importance of market risk disclosures and studies that have examined this issue, market risk is only one type of risk among the host of risks and uncertainties concerning a business enterprise's future. As Barth noted in Schrand and Ellioft (1998), there is little extant research relating to operating risk, probably because these risks are inherently firm-specific. Without additional disclosures, she argues, it is difficult for researchers and investors outside the firm to identify which risks are important to the firm, the magnitude of the firm's exposure to the risks, and how the firm manages the risk. Barth concludes that much remains to be learned about risk disclosures, including: (1) Which risks are important to investors operating risks, financial risks or other risks? (2) Are explicit quantitative estimates of risk exposure or qualitative data most useful in assessing risk? and (3) How should correlations among risks be addressed?

This study takes the opportunity to address Barth's questions by performing a detailed investigation of managements' forward-looking qualitative disclosures about a wide range of risks in prospectuses that accompany security offerings. More specifically, ] examine which kinds of risk are disclosed in prospectuses, how these risks are interrelated, and how the qualitative risk disclosures can be measured empirically. Studying the first issue provides insight in what sorts of risk management considers important for investors to assess the risk of investing in the firm's securities, 
as well as further evidence on how top managers and investors conceptualize risk. Furthermore, 1 investigate whether the qualitative risk disclosures in prospectuses contain useful information for investors about future equity risk.

Despite arguments that managements" forward-looking risk disclosures are more relevant than risk disclosures based on historical (realized) outcomes, many seem to question the reliability and consequently the usefulness of risk disclosures of possible future outcomes (Schrand and Elliot 1998, 280). Similarly, quantification of risk disclosures is viewed as beneficial 'because it improves the credibility of the disclosures and makes them ex-post verifiable' (Schrand and Elliot 1998, 280). Hodder et al. $(2001,63)$ maintain that qualitative market risk disclosures do not compensate for the lack of quantitative market risk information because 'even if companies do disclose this information, it is very difficult, if not impossible, for individuals to use this qualitative information to generate their own quantitative risk assessments".

Although the SEC requires a concise and logically organized discussion of the most significant risk factors, many have argued that current rules are inadequate because they are 'subjective, open-ended and ambiguous, which allows firms to report almost anything (or nothing) without violating the requirements' (Schrand and Elliot 1998, 274). Assuming that this is indeed the case, Jorgensen and Kirschenheiter's (2003) model of managers" equilibrium strategy for voluntary disclosing information about risk, yields clear predictions. In the partial equilibrium that Jorgensen and Kirschenheiter derive, managers voluntarily disclose if their firm has a low variance of future cash flows, but withhold the information if their firm has highly variable cash flows. ${ }^{3}$ However, Hribar (2004) argues when discussing Guo et al.'s (2004) study on the competitive costs of product-level disclosures in prospectuses, that the SEC requires that prospectuses contain full, true and plain disclosures of all material facts. Combined with the heightened litigation risk for both the firm and the underwriter, this leads to intense scrutiny by other parties involved in the transaction, even more than for annual reports (Hribar 2004). According to Beatty and Welch (1996), this especially applies to risk diselosures because issuers and experts (and primarily the auditor and underwriter) can mitigate their exposure to legall liability by disclosing more risk factors in the prospectus. However, by shifting risk to investors, the marketability of the issue is reduced and the issue price could be lowered (Beatty and Welch 1996).

In the Netherlands, listing and issuing rules of the Amsterdam Stock Exchange require top management to sign a responsibility statement that the information in the prospectus is accurate and that no information necessary for a reasonable investor to make an investment decision is omitted. The lead manager (an investment bank or stockbroker admitted to the exchange) provides assistance in drafting the prospectus and must conduct a 'due diligence' investigation into the accuracy and completeness of the information provided in the prospectus. This investigation is usually performed in cooperation with other experts like auditors and legal advisors. Although litigation risk is not as severe as in the United States, the lead manager's and other experts' reputations are at stake. For this reason, the risk disclosures in a prospectus are likely 
reliable, capturing fundamental aspects of investment risk. Nonetheless, the listing and issuing rules do not specifically preseribe which risks should be discussed in the prospectus and allow management a large degree of flexibility to express their judgment about those risks that they consider relevant for investors. However, this may be a virtue of the current standards rather than an inadequacy. As Hribar (2004) explains, more detailed prescriptions and too severe legal liability can lead to boilerplate rather than meaningful disclosures. Managers' superior knowledge about firm-specific risk factors and comparative advantage in judging how economy wide and industry wide events may impact the firm in the future likely enables them to make relevant risk disclosures without detailed prescriptions.

Before examining managements' risk disclosures in prospectuses, it is important to consider how both managers and (individual) investors conceptualize risk. Whereas empirical studies in accounting and finance commonly use earnings variability, variance of returns, or covariance of retums with the market as measures of equity risk, experimental research with individuals indicates that individuals (1) are poor at assessing variance, (2) may not view variance as relevant to risk assessment. and (3) have questionable ability to judge covariance (Lipe 1998). March and Shapira (1987) discuss the results of two studies on high-level executives' perceptions of risk and point out three clear differences from risk conceived as the variance of the probability distribution of possible outcomes: (1) Risk is primarily associated with negative outcomes; (2) Risk is not primarily a probability concept and the magnitude of possible bad outcomes seems most important; and (3) Most executives show little desire to reduce risk to a single quantifiable construct. A vice-president for finance reported that 'No one is interested in getting quantified measures' and a senior vice president observed 'You don't quantify the risk, but you have to be able to feel it' (March and Shapira 1987, 1408). Recognizing the numerous aspects of risk in an organization, a majority of the executives felt that risk could not be captured by a single number or a distribution and that quantification of risk was not an easy task. Baird and Thomas (1990) surveyed 146 financial analysts concerning their definitions of risk. The top four definitions of risk based on frequency of mention were: (1) size of loss, (2) probability of loss, (3) variance of returns, and (4) lack of information. Olsen (1997) surveyed 630 portfolio managers and 740 individual investors about their perception of investment risk. Principal risk attributes appeared to be (1) the potential for a large loss, (2) the potential for a below-target returns, (3) investor's feeling of control, and (4) the level of knowledge about an investment. Likely, managements. risk disclosures are to some degree geared to these conceptualizations of risk.

\subsection{Research design}

\subsubsection{Sample and data}

The sample consists of 90 Dutch firms that issued securities on the Amsterdam Stock Exchange in the period from 1997 to $2000{ }^{4}$ More specifically, the sample includes 49 $(54 \%)$ initial public offerings (IPOs) of common stock, 31 (34\%) seasoned offerings of 
common stock and/or convertible bonds, and $10(11 \%)$ stock offerings relating to a merger or demerger. The primary data source is the prospectus that firms must publish when they issue securities. Stock returns are retrieved from the financial database 'DATASTREAM'.

The information required in a prospectus is set out in the listing and issuing rules of the Amsterdarn Stock Exchange and includes a firm's assessment of risks. The risk assessment is provided in a separate section of the prospectus and the cover of the prospectus typically refers to this section as "certain factors that should be carefully considered by prospective investors'. Although other parties may be involved in drafting the risk section, it is treated in the rest of this study as a manifestation of perceptions, beliefs, and judgments of top management as a group.

\subsubsection{Content analysis of risk sections in prospectuses}

In previous research on IPOs, the number of risk factors described in the risk section of the prospectus is a common proxy for ex-ante risk (see for example Simunic and Stein 1987, Feltham, Hughes and Simunic 1991. Beatty and Zajac 1994 and Beatty and Welch 1996). A simple count of these risk factors combines them into one single measure that is comparable to a summated scale. ${ }^{5}$ An advantage of this approach is that it does not focus on one particular risk, i.e. isolating specific risks to the exclusion of other possibly interrelated risk factors. However, a disadvantage of adding up (different) risk factors is that unidimensionality and internal consistency of the risk factors is assumed but cannot be tested for. Unidimensionality and internal consistency are essential requirements for a composite measure and imply that the composite measure should consist of risk factors that load highly on one single dimension (Hattie 1985, McDonald 1981) and are strongly associated with each other, representing a single concept (Nunnally 1978). For a multifaceted concept like risk, unidimensionality and internal consistency are not realistic assumptions when simply counting the number of risk factors disclosed in the risk sections of the prospectuses.

Instead of a mere count of the number of risk factors listed in the risk section of the prospectus, the alternative approach taken in this study is to investigate the attributes of risk described by top management. A discovery-oriented procedure known as content assessment was applied first. The purpose of this procedure was to take an open-ended look at the risk sections across prospectuses to make a preliminary identification of the kinds of risk that are described. Next, a content analysis was undertaken to systematically evaluate the content of the risk sections.

The content analysis involved four broad stages: (1) Development of an appropriate coding scheme that lists the expected risk factors that are disclosed in the risk sections; (2) Coding of the texts of the risk sections; (3) Reduction of data into composite measures of risk disclosure; and (4) Empirical tests of the information. content of the risk disclosures. Each stage is discussed below in more detail.

Coding scheme - In the first stage, a wide range of literature on risk and risk management was used to develop an appropriate coding scheme that lists broad content categories and different risks lactors related to these categories (see Miller 
1992 for an overview of this literature and a similar categorization of risk). Column 1 of Table 1 summarizes the final coding scheme by listing the names of the broad categories and accompanying risk factors. Each risk factor of the coding scheme is described by a number of words or phrases that detail the meaning of the risk factor. Typical examples of risk factors per category are provided in section 4.1, which also further explains Table 1.

Coding procedure - In the second stage, I matched the words and phrases in the texts of the risk sections with the coding scheme and identified for each text whether the risk factor was mentioned or not. ${ }^{6}$ A pretest was performed on a subset of the sample, providing further understanding of the textual disclosures. As a result, several risk factors of the coding scheme were refined and others were added. Using the improved coding scheme, the coding process was applied to the full sample.

An advantage of this manual approach over a computer-aided content analysis is that humans can better judge the meaning of words and phrases within a context. A disadvantage is that a manual approach is less cost effective and flexible. In addition, human raters can make mistakes and are prone to researcher bias. To assure the reliability of the coding process, a second trained, independent rater coded a randomly chosen subset of 24 texts (26.7\% of the entire sample). This method follows Schnatterly (2003). Percentage agreement for the risk factors ranged from $83 \%$ to $100 \%$. Perreault and Leigh's interjudge reliability index ranged from .82 to 1.00 , where .80 (and .70 in exploratory research) is considered a lower limit (Perreault and Leigh 1989). All coding discrepancies were resolved by jointly reexamining the texts and determining an appropriate identification where we disagreed.

Data reduction - The third stage of the content analysis concerned a statistical reduction of the collected data ( 48 dichotomous variables for each firm in the sample, each variable representing a different risk factor) into a smaller set of new, composite dimensions or component scores with a minimum loss of information. While the nature and character of the original data is retained, a smaller set of composite measures enables subsequent multivariate empirical analyses.

The technique that was used for this purpose is principal components analysis by alternating least squares optimal scaling (PRINCIPALS). ${ }^{7}$ Compared to standard principal components analysis, which assumes linear velationships between numeric variables, PRINCIPALS allows variables to be scaled at the nominal or ordinal level. In addition, the method substantially increases the number of variables that can be included in the analysis, given a certain sample size. PRINCIPALS is used as an exploratory technique that does not set any a priori constraints on the estimation of components or the number of dimensions to be extracted. Theoretical support or prior research that justifies a confirmatory approach is currently lacking. Hence, an exploratory approach is considered most useful as a data reduction method.

The data reduction procedure resulted in three component scores that were named Risk Disclosure Score 1, 2 and 3 (RDS1, RDS2 and RDS3) (see section 4.1 for detailed results). Because RDSl explains about twice as much variance of the risk factors than RDS2 and RDS3 and represents far more risk factors than RDS2 and 
RDS3, the main analyses focus on RDSI. Supplementary analyses consider RDS2 and RDS3.

Empirical tests of information content of risk disclosures - The fourth stage empirically assesses whether the information in the risk sections, as measured by RDS1, is useful for evaluating and predicting equity risk. Three different analyses are employed to examine the relationship between the risk disclosures and subsequent outcomes using: (1) market determined measures of equity risk after publication of the prospectus; (2) market-adjusted stock returns after publication of the prospectus; and (3) deelines in stock price to dramatically low levels after publication of the prospectus. Figure I summarizes the longitudinal nature of the data used in these tests.

FIGURE 1

Temporal Relationship of Data"

\begin{tabular}{|c|c|c|}
\hline "PCOST" & "Present" & "Furure" \\
\hline 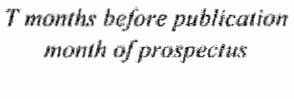 & $\begin{array}{c}\text { publication } \\
\text { month of } \\
\text { proxpectus }\end{array}$ & $\begin{array}{c}\text { Twomblas aftere publication } \\
\text { whonth of prospecters }\end{array}$ \\
\hline
\end{tabular}

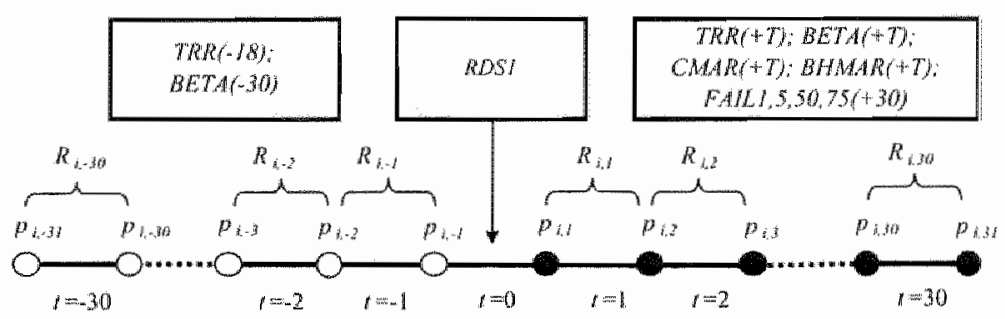

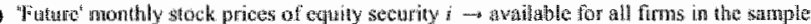

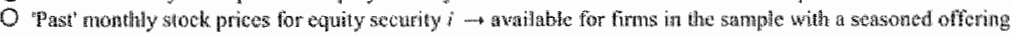

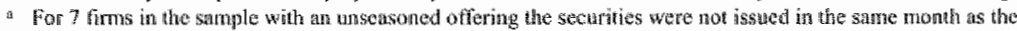

prospactus was published, but in the nat month. For these firms $r=0$ is necessarily dhe month in with the securites are

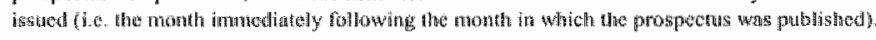

\subsubsection{Risk disclosures and market determined risk measures}

If managements" ex-ante qualitative risk disclosures are useful for equity risk evaluation and prediction, and RDSI adequately captures the content of the disclosures, $R D S 1$ should be positively correlated with ex-post measures of equity risk. To test this conjecture, I examine the association between RDSI and two market determined equity risk measures that are often used in empirical research: (a) Total return risk $\left(T R R_{i}\right)$, defined as the standard deviation of returns on equity security $i$; and (b) Beta $\left(B E T A_{i}\right)$, which measures the systematic risk of equity security $i$ and is defined as the covariance of returns on equity security $i$ and the return on the market portfolio divided by the variance of the return on the market portfolio. ${ }^{8}$

For the full sample, I calculate correlations between $R D S I$ and $T R R(+T)$, which is TRR calculated using $T$ observations of monthly stock returns after publication of the prospectus ("future total return risk"). I also calculate the correlation between RDSI 
and $B E T A(+30)$. which is BETA calculated using 30 observations of monthly stock returns after publication of the prospectus ('future systematic risk'). Aceordingly, I estimate the following models:

$$
\begin{aligned}
& \operatorname{TRR}(+T)=a+b_{1} R D S I+e \\
& B E T A(+30)=a+b_{1} R D S I+e
\end{aligned}
$$

Finding significant positive correlations between $R D S I$ and $T R R(+T)$ and between $R D S I$ and $B E T A(+30)$ provides some evidence that $R D S 1$ can be viewed as a forecast of future equity risk.

Alternatively, based on the ranking of RDSI from low to high, I divide the sample into three equal portfolios that are named low RDSI, average RDSI and high $R D S 1$. For each portfolio, I calculate $T R R(+T)$ for up to 30 months after publication of the prospectus. Finding that the high $R D S I$ portfolio has higher TRR than the low $R D S I$ portfolio, provides further evidence that $R D S I$ can be viewed as a proxy of future equity risk.

For firms in the sample with a seasoned offering (and thus a history of stock returns). I predict $T R R(+T)$ for up to 30 months after publication of the prospectus using a simple model with $R D S I$ and $T R R(-18)$ as explanatory variables. $T R R(-18)$ is calculated using 18 observations of monthly stock returns before the publication of the prospectus ("past total return risk"). Similarly, I predict $B E T A(+30)$ using a simple model with $R D S 1$ and $B E T A(-30)$ as explanatory variables. BETA $(-30)$ was calculated using 30 observations of monthly stock returns before publication of the prospectus ('past systematic risk'). Accordingly, I estimate the following modells:

$$
\begin{aligned}
& T R R(+T)=a+b_{1} R D S I+b_{2} T R R(-18)+e \\
& B E T A(+30)=a+b_{1} R D S 1+b_{2} B E T A(-30)+e
\end{aligned}
$$

In these models, both past equity risk and RDSI are viewed as forecasts of future equity risk. Finding that $b_{l}$ is significant provides additional evidence of the adequacy of $R D S l$ as a predictor of future equity risk.

\subsubsection{Risk disclosures and market-adjusted stock retums}

Finance theory predicts that if stocks are priced rationally, systematic differences in stock returns are due to differences in risk (Fama and French 1995). Firns that the market judges to have riskier prospects have higher expected stock returns than firms with strong prospects, i.e. they are penalized with a higher cost of capital (Fama and French 1992). ${ }^{10}$ Consequently, if managements' ex-ante qualitative risk disclosures are useful for equity risk evaluation and prediction, and if RDSI adequately captures the content of this information, RDSI will be positively correlated witl ex-post stock returns. Studies on short-run underpricing of IPOs suggest that this is indeed the case for first-day stock returns. Using data from the $1990 \mathrm{~s}$, Beatty and Welch (1996) show that a simple count of the number of risk factors in the prospectus is positively related to short-term underpricing, indicating that first-day investors must be compensated for accepting more firm risk. Extending the evidence for first-day stock returns, this study examines whether RDSI is positively correlated with long-run stock returns." 
Two measures of stock return are obtained: (a) Equally weighted cumulative market-adjusted return, $T$ months after the issue date of the prospectus, $C M A R(+T)_{i}$; and (b) Equally weighted buy-and-hold market-adjusted return, $T$ months after the issue date of the prospectus, $B H M A R(+T)_{i}{ }^{12} C M A R(+T)_{i}$ is calculated by summing monthly market-adjusted returns from the first month after publication of the prospectus through $T$ subsequent months:

$$
\operatorname{CMAR}(+T)_{i}=\sum_{i=1}^{r}\left(R_{i, i}-R_{m, i}\right)
$$

where $R_{i, t}$ is the raw return on equity security $i$ in month $t$ after publication of the prospectus and $R_{m, t}$ is the return on the value-weighted market index in month $t$ after publication of the prospectus. $B H M A R(+T)_{i}$ is calculated as the difference between the compounded monthly raw returns on equity security $i$ from the first month after publication of the prospectus through $T$ subsequent months and the compounded monthly raw returns on the value-weighted market index from the first month after publication of the prospectus through $T$ subsequent months:

$$
B H M A R(+T)_{i}=\prod_{i=1}^{r}\left(1+R_{i, s}\right)-\prod_{i=1}^{T}\left(1+R_{m, s}\right)
$$

where $R_{i, t}$ is the raw return on equity security $i$ in month $t$ after publication of the prospectus and $R_{m, t}$ is the return on the value-weighted market index in month $t$ after publication of the prospectus. ${ }^{13}$

For the full sample, 1 calculate correlations between $R D S 1$ and $C M A R(+T)$ and between RDSI and BHMAR $(+T)$ for up to 30 months after publication of the prospectus. Accordingly, I estimate the following models:

$$
\begin{aligned}
& C M A R(+T)=a+b_{1} R D S l+e \\
& B H M A R(+T)=a+b_{1} R D S l+e
\end{aligned}
$$

Finding positive correlations between $R D S /$ and future stock returns provides further evidence of that $R D S /$ can be viewed as a proxy of equity risk.

Alternatively, based on the ranking of RDSI from low to high, I divide the sample into three equal portfolios that are named low RDSI, average RDSI and high RDSI. For each portfolio, I calculate $C M A R(+T)$ and $B H M A R(+T)$ for up to 12 months after publication of the prospectus. Finding that the high RDSI portfolio outperforms the low RDSI portfolio provides further evidence that RDSI can be viewed as a proxy of equity risk.

Finally, for the firms in the sample with a seasoned offering (and therefore a history of stock returns), I predict $C M A R(+T)$ and $B H M A R(+T)$ for up to 30 months after publication of the prospectus using a simple model with RDSI and BETA $(-30)$ as explanatory variables. Accordingly, I estimate the following models:

$$
\begin{aligned}
& C M A R(+T)=a+b_{1} R D S I+b_{2} B E T A(-30)+e \\
& B H M A R(+T)=a+b_{1} R D S I+b_{2} B E T A(-30)+e
\end{aligned}
$$

In these models, both past systematic risk and RDSI are viewed as forecasts of future stock returns. Finding that $b_{1}$ is significant provides additional evidence of the adequacy of RDSI as a proxy of equity risk. 


\subsubsection{Risk disclosures and failure of stock price in the afternarket}

Whereas firms that the market judges to have riskier prospects have higher expected stock returns, riskier firms can also be expected to have a higher probability of extreme negative outcomes. For a sample of IPO firms, Hensler et al. (1997) find that a simple count of the number of risk factors listed in the offering prospectus is significantly related to the failure to survive in the aftermarket, which is defined as delisting from the trading exchange for negative reasons, for example a stock price below the acceptable level.

Listing and issuing rules of the Amsterdam Stock Exchange however do not require delisting of firms in case their stock price falls below 5 euro (so-called 'penny stocks") or even 1 euro. For this reason, I define stock price failure as stocks trading at a price below 1 or 5 euro, 30 months after publication of the prospectus $(F / L / 1+30)$ and FAIL $5(+30)$ ). Accordingly, I estimate the following model:

$$
\text { FALL }(+30)=a+b_{1} \text { RDS } 1+e
$$

To check the robustness of the definition of stock price failure, I alternatively use severe stock price declines (i.e. negative stock returns) of more than $50 \%$ or more than $75 \%$ over a 30 month period (FALL5O(+30) and FALL75(+30)). Finding a positive association between $F A I L(+30)$ and $R D S I$ provides some evidence of $R D S I$ as a proxy of downside equity risk.

\subsubsection{Control variables}

To control for influential variables that are likely associated with the measures of equity risk and risk disclosures, I add several contro $\downarrow$ variables to model 1 to 9 . To control for the effect of firm size, I include SIZE, defined as the natural logarithm of the market value of the firm in million $E$ one month after publication of the prospectus. To control for industry effects, I include an industry dummy variable $I N D$ that is $I$ if the firm operates in a high-risk industry (defined as information technology, biotechnology or telecommunication), and 0 otherwise. In the models that are estimated for the full sample, I control for the type of offering by including an offering type dummy variable IPO that is 1 for IPO firms and 0 otherwise. ${ }^{1 / 4}$

\subsection{Results}

\subsubsection{Content analysis of risk sections in prospectuses}

Risk disclosures - The content analysis revealed that management mostly assigns the label 'risk' to factors, either external or internal to the firm, that could adversely impact future firm performance. In this sense, "risk' actually refers to sources of downside risk. In no single risk section, management referred to risk as being associated with the probability of high performance. These findings confirm March and Shapira's (1987) observations of high-level executives" risk perceptions. 
The first column of Table 1 provides a detailed overview of the kinds of risk that were identified in the risk sections of the prospectuses. In accordance with Miller's (1992) integrated risk framework, I broadly classified the sources of risk as related to: (1) the macro environment; (2) the industry environment; (3) the internal environment of the firm; and (4) other. Apart from describing sources of risk, managements' discussion of risk frequently resembled investors' conceptualization of risk as surveyed by Baird and Thomas (1990) and Olsen (1997). For this reason, I discerned four additional categories:

- Loss or probability of loss, e.g. "We have a history of losses and expect to continue to incur losses in the foreseeable future', "The share price may decrease due to future sale of shares", "Shares purchased in this offering will be diluted immediately because the initial offering price is substantially higher than the book value per share';

- Variance, e.g. 'Our share price may be vollatile', 'Our operating results may be subject to significant fluctuations';

- Lack of information, e.g. "Limited relevance of historic activities and financial performance', 'Our forward looking statements may not be accurate', 'Lack of operating history"; and

- Lack of control, e.g. 'Anti-takeover provisions may prevent a beneficial change of control', 'Control by principal shareholder'.

The second column of Table 1 displays for each risk factor the percentage of firms that reported on this factor. The four most frequently reported risk factors, in order of frequency of reporting, were:

- General economic conditions $(78 \%)$, e.g. 'Sensitivity of results to economic developments", "Fluctuations in the general economy";

- Competition (74\%), e.g. "We operate in a highly competitive industry",

- Regulation and legislation (69\%), e.g. 'The company's ability to commercialize its producls depends upon its compliance with government regulations', 'Unexpected changes in regulatory requirements could adversely affect our business'; and

- Acquisitions, alliances and joint-ventures (69\%), e.g. 'Costs and difficulties of acquiring and iniegrating businesses could impede future growth', "No assurance can be given that desired acquisitions and alliances will be available'.

Aggregating the reported risk factors per category, the most frequently disclosed risk factors appear to be related to the industry environment and the internal environment of the firm (both $29 \%$ ), followed by the macro environment (22\%), and the other categories $(20 \%$ in total). 
How Informative Are Qualitative Risk Disclosures?

TABLE 1

Overview of Risk Disclosures and Resuits of

Principal Conponents Analysǐs by Alternating Least Squares Optïnai Scaling (PRINCIPALS)

\begin{tabular}{|c|c|c|c|c|c|}
\hline \multirow[t]{2}{*}{ Risk fetors } & \multirow[t]{2}{*}{$\begin{array}{c}\% \text { of reported tisk } \\
\text { hactors }\end{array}$} & \multirow{2}{*}{$\begin{array}{l}90 \text { of limus } \\
\text { teporthing on } \\
\text { rastol }\end{array}$} & \multicolumn{3}{|c|}{$\begin{array}{c}\text { Component lowings } \\
\text { on dimension }\end{array}$} \\
\hline & & & 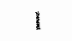 & 2 & 3 \\
\hline Macro emisonmenral somces & $220 \%$ & & & & \\
\hline \multicolumn{6}{|l|}{ Economic } \\
\hline - General economic conditions & & $78 \%$ & . & - & .74 \\
\hline - Cumency, inferest and price fluctuations & & $61 \%$ & - & - & .40 \\
\hline Political & & $30 \%$ & - & - & - \\
\hline Social and environmental & & $11 \%$ & - & - & *. \\
\hline Regulation and legislation & & $69 \%$ & .58 & - & - \\
\hline Technological change & & $44 \%$ & .56 & - & 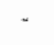 \\
\hline londwary sources & $29 \%$ & & & & \\
\hline Compertition & & $74 \%$ & .57 & - & $\therefore$ \\
\hline Potential entrants & & $373 \%$ & .56 & - & - \\
\hline Substintes & & $310 \%$ & .53 & - & - \\
\hline Suppliars & & $35 \%$ & - & - & .49 \\
\hline Surategic partmets & & $37 \%$ & .60 & - & - \\
\hline \multicolumn{6}{|l|}{ Cumstoners } \\
\hline - Market acceptance & & $12 \%$ & .59 & - & - \\
\hline - Dependence on clients & & $48 \%$ & - & * & - \\
\hline - Changing client requirements & & $19 \%$ & - & - & .45 \\
\hline - Seatomality denand & & $20 \%$ & - & - & $\infty$ \\
\hline Persome: & & $63 \%$ & - & .51 & - \\
\hline Imfergtal sources & $29 \%$ & & & & \\
\hline Dependence on management & & $60 \%$ & - & - & - \\
\hline Dopendence on produci & & $14 \%$ & - & - & - \\
\hline Reseanch and development & & $41 \%$ & .56 & - & - \\
\hline Intellectual property rights & & $31 \%$ & .53 & - & $\cdots$ \\
\hline Product deferots & & $19 \%$ & - & - & - \\
\hline Litabingry & & $46 \%$ & $\therefore$ & .50 & 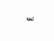 \\
\hline Accounts receivable & & $16 \%$ & - & - & - \\
\hline Information systerns and controls & & $13 \%$ & - & - & * \\
\hline Limited hexibility cost structure & & $16 \%$ & - & - & 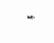 \\
\hline Diebt covernants & & $11 \%$ & .55 & $*$ & $\approx$ \\
\hline Excessive debt & & $12 \%$ & .53 & - & - \\
\hline Minangement of grow th & & $41 \%$ & $\therefore$ & 66 & - \\
\hline Acquisitions alliances and jomtoventures & & $69 \%$ & - & - & - \\
\hline Other wownes & $5 \%$ & & & & \\
\hline Millennizm & & $43 \%$ & - & $\cdots$ & - \\
\hline Enaro & & $20 \%$ & - & - & - \\
\hline
\end{tabular}

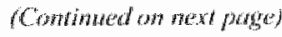


Chapter 3

TABLE I (Continued)

\begin{tabular}{|c|c|c|c|c|c|}
\hline \multirow[t]{2}{*}{ Risk factors } & \multirow[t]{2}{*}{$\begin{array}{l}\text { \% of reported risk } \\
\text { factors }\end{array}$} & \multirow{2}{*}{$\begin{array}{l}\% \text { of firms } \\
\text { reporting on } \\
\text { factor }\end{array}$} & \multicolumn{3}{|c|}{$\begin{array}{c}\text { Component loadings } \\
\text { on dimension }\end{array}$} \\
\hline & & & $\mathbb{1}$ & 2 & 3 \\
\hline Losis and probability of lows & $30 \%$ & & & & \\
\hline $\begin{array}{l}\text { History of losses and expectation to continue } \\
\text { to incur losses }\end{array}$ & & $11 \%$ & .69 & - & - \\
\hline Diliution due to future sale of shares & & $22 \%$ & .72 & - & - \\
\hline Varkinate & $3 \%$ & & & & \\
\hline Volatility of share price & & $20 \%$ & .76 & - & - \\
\hline Variability of operating results & & $16 \%$ & - & ○ & .54 \\
\hline Lack of information & $5 \%$ & & & & \\
\hline Limited opderatung history & & $11 \%$ & .52 & - & - \\
\hline Accuracy of forward looking statements & & $10 \%$ & .55 & - & - \\
\hline Absence of prior public market & & $51 \%$ & - & .63 & - \\
\hline Lack af confrod & $5 \%$ & & & & \\
\hline Takeower defenstses & & $15 \%$ & .40 & - & - \\
\hline Influence of large shareholder & & $45 \%$ & - & - & - \\
\hline Cronbachts coefficient alpha & & & .91 & .85 & 82 \\
\hline Eigenvalue & & & 11.82 & 6.04 & 5.37 \\
\hline$\%$ total variance & & & 24.62 & 12.59 & 11.19 \\
\hline
\end{tabular}

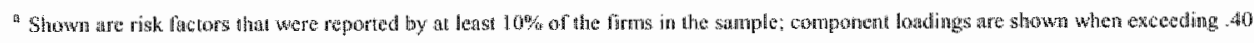

Data reduction - Table I also presents the results of the statistical reduction of the collected data using PRINCIPALS. As expected, the risk disclosures are not unidimensional. I extracted three dimensions that together account for $48 \%$ of the variance of the risk factors. ${ }^{15}$ The eigenvalues were used to decide how many dimensions should be used in the analysis. Using a plot of the eigenvalues (so-called "scree test') all dimensions were retained with eigenvalues in the sharp descent part of the plot before the eigenvalues start to level off. Component loadings exceeding 40 are considered important; if the component loadings are 50 or greater they are considered practically significant. The squared loading reflects the amount of a risk factors' total variance that is accounted for by the component score.

For each dimension, component loadings exceeding .40 are displayed in Table 1. Higher component loadings represent a higher correlation of the risk factor and the component score. As can be seen, the component loadings are scattered across the eight categories. Looking at the risk factors with high component loadings on dimension 1 , this finding seems plausible. Rapid technological change (a macro environmental source of risk) for example likely increases the threat of potential entrants and substitutes (both industry sources of risk), making a company vitally depenclent on the success of its research and development activities and protection of property rights (both internal sources of risk). 
Dimension 1 has the highest eigenvalue (11.82) and accounts for $25 \%$ of the variance of the risk factors. The component score of dimension 1 was simply named Risk Disclosure Score 1 (RDSI). Conceptually, RDSI represents the degree to which each firm in the sample reports on the group of risk factors that have high loadings on dimension 1. Thus, the more disclosure of risk factors with high loadings on dimension 1, the higher RDS1. As can be seen in Table 1, managements" warning for future volatility of the share price has the highest component loading on dimension 1 (.76), followed by the possibility of dilution of the share price (.72), a history of losses and the expectation to continue to incur losses $(.69)$ and dependence on strategic partners (.60). Twelve other frequently reported risk factors have loadings between .50 and .60 . Cronbach"s coefficient alpha assesses the internal consistency of $R D S l$, and is with a value of .91 well above the generally agreed lower limit of .70 (Robinson et al. 1991). Hence, RDSI is a statistically reliable composite measure.

Dimension 2 and dimension 3 account for respectively $13 \%$ and $11 \%$ of the variance of the risk factors and the component scores were named RDS2 and RDS3. Conceptually, RDS2 and RDS3 represent the degree to which each firm in the sample reports on the group of risk factors that have high loadings on dimension 2 and 3 . Managements' warning about their ability to manage growth has the highest component loading on dimension 2 (.66), followed by absence of a prior public market (.63). Only two other risk factors have loadings between .50 and .60 on dimension 2 . The most frequently reported risk factor, general economic conditions, loads highly on dimension $3(.74)$. Only one other risk factor has a loading between .50 and .60 on dimension 3. Cronbach's coefficient alphas of $R D S 2$ and $R D S 3$ are adequate, suggesting that RDS2 and RDS3 are allso statistically reliable composite measures.

Although PRINCIPALS reduced the widely diverse risk disclosures into three unidimensional and statistically reliable composite measures of risk disclosure (which was the main purpose of the data reduction procedure), it is unclear what causes the different dimensions in the risk disclosures. Because RDSI explains about wice as much variance as RDS2 and RDS3 and represents far more risk factors ( 16 component loadings above .50 compared to respectively 4 and 2 for $R D S I$ and $R D S 2$ ), the main empirical analyses focus on RDSI. Supplementary analyses consider RDS2 and RDS3. 
Chapter 3

TABLE 2

Deseriptive Statisties of All Variables

\begin{tabular}{|c|c|c|c|c|c|c|c|}
\hline Wariables & Sample & $M$ & Mean & Median or $\frac{\sqrt{3}}{2}$ & $S D$ & $\operatorname{Min}$ & Max. \\
\hline \multicolumn{8}{|c|}{ Measure of rik disclosumes } \\
\hline$R D S$ & All prospeceluses & 90 & .00 & -44 & 1.00 & -1.03 & 2.99 \\
\hline RDS & Initial public of erings & 49 & .23 & -.30 & 1.04 & -.95 & 2.99 \\
\hline RDS & Seasoned offerings & 31 & -1.18 & -.69 & .98 & -.96 & 2.64 \\
\hline $\operatorname{Ros} 1$ & High rish industry & 35 & 43 & -06 & 1.15 & -.81 & 2.75 \\
\hline RDSI & Low ristle inclustry & 55 & -.29 & -.49 & 78 & -1.03 & 2.99 \\
\hline
\end{tabular}

Market determined wis measwes

\begin{tabular}{|c|c|c|c|c|c|c|c|}
\hline $\operatorname{TRR}(-6)$ & All prospectuses & 90 & .14 & 12 & .08 & .02 & 49 \\
\hline $\operatorname{TRR}(+12)$ & All prospectuses & 89 & .15 & 14 & .09 & .05 & .46 \\
\hline $\operatorname{TRR}(1 / 8)$ & Ali prospectuses: & 86 & .15 & .13 & .08 & .05 & .41 \\
\hline$\pi k R(+24)$ & All prospectuses & 84 & .15 & .14 & .08 & .05 & .39 \\
\hline $\operatorname{RRR}(+30)$ & All prospertuses & 80 & .14 & .13 & .06 & .05 & 37 \\
\hline$B E T A(+30)$ & All prospectuses & 80 & .86 & .74 & .51 & .01 & 1.99 \\
\hline $\operatorname{FinR}(+1+6)$ & Seasoned offerings & 31 & .12 & .11 & .06 & .04 & 31 \\
\hline$T R R(1-12)$ & Sexasoned offerings & 31 & .44 & .10 & .09 & .05 & .46 \\
\hline $\operatorname{TRR}(+18)$ & Seasoned offerings & 31 & .13 & .12 & .07 & .05 & .35 \\
\hline $\operatorname{TRR}(+24)$ & Seasoned offerings & 31 & .13 & .1 & .06 & .06 & .32 \\
\hline $\operatorname{TRR}(+30)$ & Seasoned offerings & 31 & .12 & .11 & .06 & .05 & .30 \\
\hline $\operatorname{TRR}(-18)$ & Seasoned offerings & 31 & .12 & .09 & .08 & .05 & .31 \\
\hline$B E T A(+30)$ & Seasoned offerings & 31 & .86 & .71 & .50 & .20 & 1.95 \\
\hline BETA $(-30)$ & Seasoned offerings & 31 & .75 & .63 & .47 & .01 & 1.81 \\
\hline
\end{tabular}

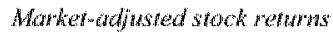

\begin{tabular}{|c|c|}
\hline$C M A R+3)$ & All prospentans \\
\hline$C M A R(+6)$ & All prospectuges \\
\hline$C M A R(+0)$ & All prospectuses \\
\hline$C A A R(+12)$ & All prospestises \\
\hline$C W A R(+18)$ & All prospertuses \\
\hline CWAR $(+24)$ & All prosperstuses \\
\hline$C M A R(+30)$ & All prospectuses \\
\hline$B N M A R(+3)$ & All prospentuses \\
\hline$B M M A R(+6)$ & All prospectuses \\
\hline$B N M A R(+0)$ & All prospectuses \\
\hline$B M M A R(+12)$ & All prospectuses \\
\hline$B H M A R(+18)$ & All prospectuses \\
\hline$B H M A R(+24)$ & All prospectuses \\
\hline$B H M A R(+30)$ & All prospectuse \\
\hline
\end{tabular}

$\begin{array}{llllll}90 & .00 & -.01 & .25 & -.50 & .72 \\ 90 & -.06 & -.12 & .34 & -.80 & .91 \\ 90 & -.04 & -.13 & .50 & -1.18 & 1.47 \\ 89 & -.05 & -.10 & .47 & -1.16 & 1.47 \\ 86 & -.17 & -.21 & .53 & -1.27 & 1.27 \\ 84 & -.19 & -.21 & .59 & -1.49 & 1.16 \\ 80 & -.26 & -.27 & .55 & -1.20 & 1.32 \\ 90 & .00 & -.05 & .27 & -.45 & .86 \\ 90 & . .04 & -.14 & .41 & -.58 & 1.39 \\ 90 & -.03 & -.20 & .54 & -.80 & 1.50 \\ 89 & -.06 & -.20 & .44 & -.93 & 1.49 \\ 86 & -.26 & -.37 & .45 & -.94 & 1.36 \\ 84 & -.32 & -.41 & .49 & -1.15 & 1.17 \\ 80 & -.40 & -.44 & .49 & -1.15 & .56\end{array}$


How Informative Are Qualitative Risk Disclosures?

TABLE 2 (Continued)

\begin{tabular}{|c|c|c|c|c|c|c|c|}
\hline Varilables & Sample & $\mathrm{N}$ & Mean & Median or $\%$ & S.D. & Ming. & $\mathrm{Max}_{\text {. }}$ \\
\hline $\operatorname{CMAR}(+3)$ & Seasoned offerings & 31 & .01 & .00 & .20 & -27 & .49 \\
\hline$C M A R\left(\frac{1}{3}\right)$ & Seasoned offlerings & 31 & -.11 & -.15 & .33 & -.87 & .68 \\
\hline$C M A R(-9)$ & Sersonet ofterings & 31 & -.12 & -16 & .37 & -.93 & .62 \\
\hline CMAR(N+12) & Seasoned offerings & 31 & -.10 & -.22 & .34 & -.56 & .56 \\
\hline$C M A R+18)$ & Seasoned offerings & $3 \pi$ & -.25 &. .35 & .43 & $-9 ?$ & 51 \\
\hline$C M A R(+24)$ & Seasoned offerings & 31 & -.23 & -.27 & .50 & -96 & .90 \\
\hline$C M A R(+30)$ & Seasoned offerings & 31 & -.25 & -.35 & .57 & -1.18 & .72 \\
\hline BHMAR $(+3)$ & Seasoned offerings & 31 & -.01 & -.06 & .23 & -.41 & .62 \\
\hline$B H M A N(-6)$ & Seansoned offerings & 31 & -.10 & -.21 & .38 & -.54 & 99 \\
\hline$D H M A R(+9)$ & Sexsoned offerings & 31 & -13 & -.20 & .39 & -.60 & .86 \\
\hline$B H A A R(+1)$ & Semsoned offerings & 31 & -.15 & -.26 & .35 & -80 & .74 \\
\hline$B H M A R(+18)$ & Sea soned offerings & 3 过 & -.29 & -41 & .36 & 80 & .39 \\
\hline BHMAR $(+24)$ & Seasoned offorings & 31 & $\approx 33$ & .49 & .37 &. .80 & 43 \\
\hline$B H M A R(+30)$ & Seasoned offerings & 31 & -34 & -.32 & 40 & -94 & 30 \\
\hline \multicolumn{8}{|l|}{ Stock price faiture } \\
\hline FALLI +30$)$ & All prospectuses & 80 & & $10 \%$ & & & \\
\hline FALS $(+30)$ & All prospectuses & 80 & & $25 \%$ & & & \\
\hline FAL75(+30) & All prospectuses & 80 & & $20 \%$ & & & \\
\hline FAl $250(+30)$ & All prospectuses & 80 & & $43 \%$ & & & \\
\hline \multicolumn{8}{|l|}{ Conmol variables } \\
\hline $\operatorname{Sin} 2 E$ & All prospectuses & 90 & 5.61 & 5.34 & 1.62 & 2.90 & 9.80 \\
\hline$I N D$ & All prospectuses & 90 & & $39 \%$ & & & \\
\hline $\mathrm{PPO}$ & All prospectuses & 90 & & $54 \%$ & & & \\
\hline SWE & Sessoned offerings & 31 & 6.45 & 6.49 & 1.64 & 3.51 & 9.80 \\
\hline MND & Seassoned offerings & 31 & & $21 \%$ & & & \\
\hline
\end{tabular}

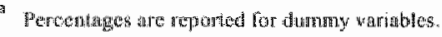

b. Wriable definitions.

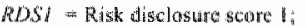

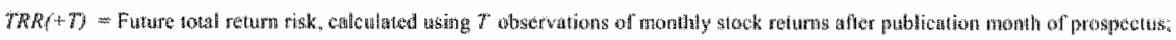

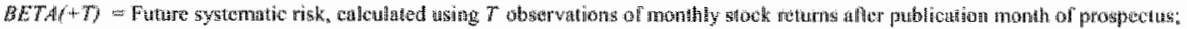

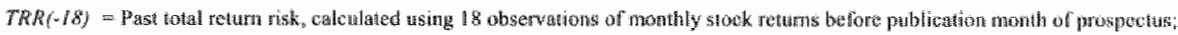

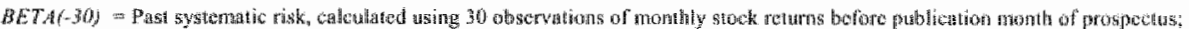

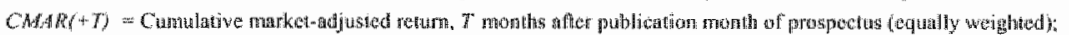

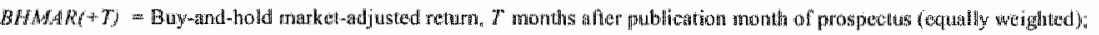

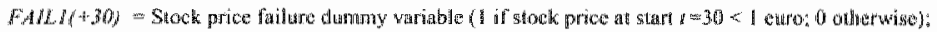

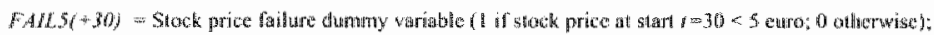

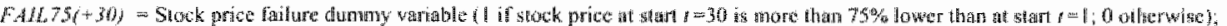

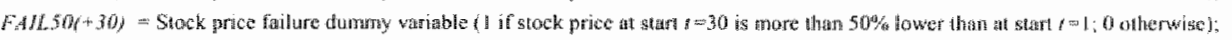

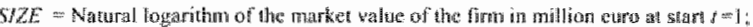

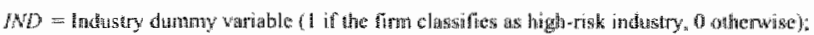

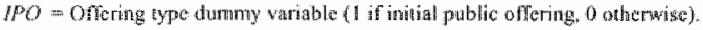


Table 2 displays the descriptive statistics of RDSI for the full sample. Due to the statistical procedure that was used to construct the variable, RDS/ has a mean of 0 and standard deviation of 1 . Table 2 also shows the descriptive statistics of RDSI for separate sub samples of seasoned and unseasoned offerings, and high risk and low risk industries. Additional non-parametric tests show that the difference in RDSI for seasoned-offerings and unseasoned offerings is significant $(p<.05)$, suggesting that management makes more extensive risk disclosures in case of an initial public offering. In addition, firms in a high risk industry have significantly higher RDSI $(p<.01)$.

Table 2 further displays the descriptive statistics of the variables that are used in subsequent analyses: market determined risk measures, market-adjusted stock returns. stock price failure and control variables. ${ }^{16} \mathrm{~N}$ decreases in the aftermarket due to delisting of firms that merged or were taken over. Interestingly, CMAR and BHMAR become increasingly negative over time. From $T=18$ on both $C M A R$ and $B H M A R$ are significantly different from zero $(p<.01)$. This finding is consistent with poor longterm performance of new issues (both seasoned and unseasoned, see for example Ritter 1991, Loughran and Ritter 1995 and 1997, Spiess and Affleck-Graves 1995 and 1999). ${ }^{17}$ FAILI $(+30)$ shows that 30 months after publication of the prospectus, 8 firms in the sample $(10 \%)$ have a stock price that is lower than 1 euro.

Panel A of Table 3 presents the correlations among the independent variables in model 1 to 9. RDSI is significantly positively correlated with $S I Z E(p<.01), I N D$ $(p<.01), I P O(p<.05), T R R(-18)(p<.01)$ and $B E T A(-30)(p<.01)$, suggesting that RDSI reflects to some extent firm size, industry type, offering type, and past equity risk. Panel $\mathrm{A}$ of Table 3 further shows that IPO firms in the sample are significantly smaller and significantly more often active in a high risk industry $(p<.01)$. Finally, firms in a high risk industry have significantly higher past equity risk $(p<.0 \mathrm{I}) .^{18}$

\subsubsection{Risk disclosures and market determined risk measures}

Panel $B$ of Table 3 presents the univariate correlations among RDSI and $T R R(+T)$ and among RDSI and BETA(+30). The results show that RDSI is systematically significantly positively correlated with $T R R$ up to 30 months after publication of the prospectus $(p<.01)$. Moreover, RDS/ is significantly positively correlated with $B E T A(+30) \quad(p<01)$. Compared to the correlation coefficient for TRR $(-18)$, the coefficient for RDSI is higher for month 6,12 and 18, but lower for month 24 and 30 . Compared to the correlation coefficient for $B E T A(-30)$ the correlation coefficient for RDSI is also lower. 
How Informative Are Qualitative Risk Disclosures?

TADP $\mathbf{E}_{3}$

Correlations among Variables

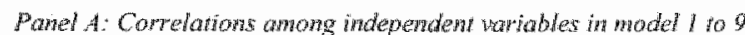

\begin{tabular}{|c|c|c|c|c|c|c|}
\hline & Sarnpla & $N$ & RDSI & $S I Z F^{\prime \prime}$ & $M N D$ & $\operatorname{TRR}(-18)$ \\
\hline \multicolumn{7}{|c|}{ Mode $1,2,5$ and 6} \\
\hline 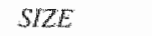 & All prospectuses & 90 & $45^{* 0}$ & & & \\
\hline$M D$ & All prospectuses & 90 & $.35^{* \cdots}$ & .03 & & \\
\hline$A P O$ & All prospectises & 90 & $25^{* *}$ & $-33^{* * 4}$ & $.30^{\cdots *}$ & \\
\hline \multicolumn{7}{|c|}{ Whodel $3,4,7$ and } \\
\hline$S H E$ & Seasoned ofterings & 31 & 54 & & & \\
\hline$M D$ & Seasoned offerings & 31 & $.699^{* 1+n}$ & .14 & & \\
\hline$\pi R R(-18)^{2}$ & Skasoned offerings & 31 & $.74^{* \cdots+2}$ & .17 & $.78^{* *}$ & \\
\hline$B E T A(-30)$ & Seasoned offerings & 31 & $.57^{* * *}$ & 36 & $67^{1 * * *}$ & $65^{* \times *}$ \\
\hline
\end{tabular}

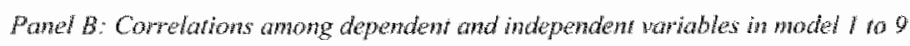

\begin{tabular}{|c|c|c|c|c|c|c|c|c|}
\hline & Sample: & $\mathrm{N}$ & RDSI & $3 Y Z E$ & $1 M D$ & $M O$ & $\operatorname{TRR}(-18)$ & $B E T A(-30)$ \\
\hline \multicolumn{9}{|l|}{ Model 1} \\
\hline $7 x_{n}(-6)$ & All prospecruses & 90 & $57^{\cdots}$ & .17 & $32^{* * \pi}$ & $24^{* *}$ & & \\
\hline $\operatorname{RRR}(+12)$ & All prospectuses & 89 & $52^{* * *}$ & .06 & $53^{* *}$ & $.24^{* *}$ & & \\
\hline$T R R+19$ & All prospectuses & 86 & $57^{\cdots \infty}$ & .05 & $63^{4 \times *}$ & $33^{* x=}$ & & \\
\hline $\operatorname{TRR}(+24)$ & All prospectuses & 84 & $.58^{* * * *}$ & .09 & $64^{40 *}$ & $.33^{0.4}$ & & \\
\hline $\operatorname{TRN}(+30)$ & All prospecinses & 80 & $.52^{* 14}$ & .05 & $.66^{\cdots *}$ & $.30^{\circ}$ & & \\
\hline \multicolumn{9}{|l|}{ Model 2} \\
\hline$B E T A(+30)$ & Ail prospectuses & 80 & $.53^{\circ \ldots}$ & .14 & $.63^{\cdots *}$ & .18 & & \\
\hline \multicolumn{9}{|l|}{ Model 3} \\
\hline$T R R(+6)$ & Seasoned offerings & 31 & $.78^{* * *}$ & $.4 \|^{* *}$ & $.55^{\text {wat }}$ & & $.38^{* *}$ & \\
\hline $\operatorname{RR}(+12)$ & Seasoned offerings & 31 & $.79^{* * *}$ & $.48^{\cdots *}$ & $69^{\text {**i }}$ & & $49^{\circ * *}$ & \\
\hline $\operatorname{TRR}(+8)$ & Soasoned offering & 31 & $.80^{\circ \cdots}$ & $39^{-*}$ & $\left.x\right|^{* 00}$ & & $.75^{* * *}$ & \\
\hline$\pi K R(+24$ & Seasoned of ferings & 31 & $.66^{\circ-x}$ & $32^{\circ}$ & $72^{-006}$ & & $.72^{.64}$ & \\
\hline $\operatorname{TRR}(-50)$ & Seasoned offerings & 31 & $.65^{.00}$ & .28 & $7 y^{* 06}$ & & .74 & \\
\hline \multicolumn{9}{|l|}{ Moder 4} \\
\hline $\operatorname{BET} T(+30)$ & Seasoned offerings & 31 & $.70^{110 * 4}$ & $.40^{\circ}$ & $.48^{\circ \%}$ & & & $.84^{\cdots *}$ \\
\hline \multicolumn{9}{|l|}{ Wodel 5} \\
\hline$C M A R+3$ & All prospectuses & 90 & $36^{* 0 *}$ & .4 & .10 & 44 & & \\
\hline$C M A R(-6)$ & All prospectuses & 90 & $38^{\circ \times 4}$ & $20^{\circ}$ & 05 & .14 & & \\
\hline$C M A R(+9)$ & All mospectuses & 90 & $31^{\cdots}$ & $21^{* *}$ & -.03 & .09 & & \\
\hline$C M A R(+12)$ & All prospectuses & 88 & $.36^{\circ \cdots}$ & .12 & .13 & .07 & & \\
\hline$C W A R t+8)$ & All prospercuses & 83 & $33^{* *}$ & .10 & $23^{*}$ & .10 & & \\
\hline$C M A R(+2 d)$ & All prospectuses & 81 & $.39^{* *}$ & .12 & $31^{n+4}$ & .10 & & \\
\hline$C A R A(+3 A)$ & All prospectuses & 72 & $.25^{* *}$ & $.26^{\circ 4}$ & $.20^{\circ}$ & -.04 & & \\
\hline
\end{tabular}




\section{Chapter 3}

TABLE 3 (Contin ured)

\begin{tabular}{|c|c|c|c|c|c|c|c|c|}
\hline & Sample & $N$ & RDS & $5 H 2 E$ & $M N D$ & $\mathrm{MO}$ & $T R R(-T)$ & $B E T A(-30)$ \\
\hline \multicolumn{9}{|l|}{ Madel o } \\
\hline BHAAR (t) 3$)$ & All prospectuses & 90 & $34^{* *}$ & .14 & .08 & .14 & & \\
\hline$B H M A R(-6)$ & All prospectuges & 90 & $.33^{* * *}$ & $\| 4$ & .17 & .08 & & \\
\hline$B H M A R(+9)$ & All prospectulacs & 90 & $34^{* * *}$ & .14 & .10 & .12 & & \\
\hline BHMAR $(+\sqrt{2})$ & All prospectuses & 89 & $.31 *$ & .06 & .11 & .11 & & \\
\hline$B H M A R(-1 B)$ & All progpectuses & 86 & $.23^{8 * 4}$ & .14 & .17 & 09 & & \\
\hline BINAN $(24)$ & A.lp prospectuses & 84 & $.26^{\text {:** }}$ & .15 & .10 & .00 & & \\
\hline$B A M A R(+30)$ & All protpechuses & 80 & $.25^{*}$ & $.19^{*}$ & $.20^{\circ}$ & .04 & & \\
\hline \multicolumn{9}{|l|}{ Model 7} \\
\hline$C M A R(+3)$ & Sealsoned offerings & 31 & $.45^{\prime \prime \prime}$ & .30 &,- 09 & & & -.07 \\
\hline$C M A R(+6)$ & Seatonend offerings & 31 & $40^{2 x}$ & $.38^{* * *}$ & -.13 & & & -.08 \\
\hline$C M A R(+0)$ & Seasoned ofterings & 31 & .34 & $.36^{\circ}$ & -.20 & & &. .27 \\
\hline$C M A R(+12)$ & Seasoned offering & 31 & $.41^{\circ *}$ & .32 & 0.3 & & & -.11 \\
\hline$C M A R(+18)$ & Seasoned offerings & 31 & $.47^{* *}$ & $.43^{4 *}$ & .00 & & & -06 \\
\hline$C M A R(+24)$ & Seasoned offorings & 31 & $.55^{* \infty}$ & $.50^{* 0}$ & .20 & & & 27 \\
\hline$C M A R(+30)$ & Seasoned offerings & 31 & $.51^{\infty}$ & $56^{* * 4}$ & .11 & & & $36^{*}$ \\
\hline \multicolumn{9}{|l|}{ Modet in } \\
\hline$D M M A R(43)$ & Seasoned offerings & 31 & $41^{\infty}$ & .27 & -.15 & & & -.14 \\
\hline$B H M A R(+6)$ & Seasoned ofterings & 31 & $38^{*}$ & $37^{\circ}$ & -11 & & & -.10 \\
\hline$B H M A R(+9)$ & Sertsoned offerings & $3 \|$ & $.34^{\circ}$ & .29 & -25 & & & -.24 \\
\hline$B H M A R(+12)$ & Seetsoned offerings & 31 & $40^{\circ *}$ & $.36^{*}$ & -.19 & & & -.25 \\
\hline$B M M A R(+\sqrt{ })$ & Suctoned offerings & 31 & $.41^{* 4}$ & $A 1$ & -.21 & & & -.22 \\
\hline$B H A H A(+24)$ & Seasnned offerings & 31 & $50^{10 *}$ & $.48^{-m}$ & .08 & & & .04 \\
\hline$B H M A R(+30 \hat{)}$ & Seasoned offerings & 31 & $.50^{* * 6}$ & $.52^{4 * 4 *}$ & .04 & & & 23 \\
\hline \multicolumn{9}{|l|}{ Mocter 9} \\
\hline PALI $(1+30)$ & All prospectuses & 80 & $.46^{+10}$ & .07 & $.33^{\sin 2}$ & .15 & & \\
\hline$F A / L 5(+30)$ & Alil prospectuses & 80 & $.33^{\ldots+*}$ & .04 & $.45 \%$ & $.22^{m i x}$ & & \\
\hline$F A l L 75(+30)$ & All prospectuses & 80 & $.37^{10 \times 4}$ & -.05 & $58^{* \cdots *}$ & .18 & & \\
\hline FAlL $50(+30)$ & At prospectitses & 80 & $.31^{1000}$ & -.04 & $.36^{* 4 *}$ & .10 & & \\
\hline
\end{tabular}

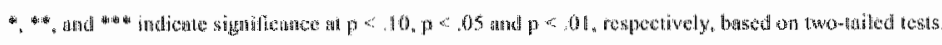

a Viriate dictionitions:

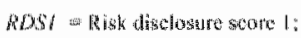

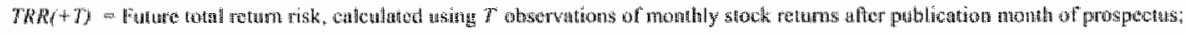

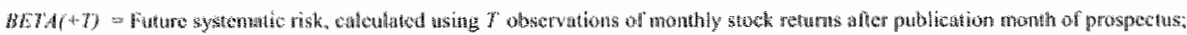

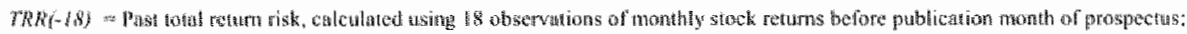

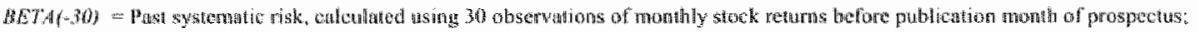

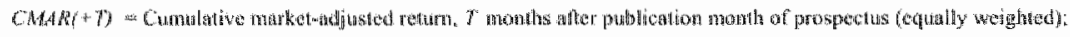

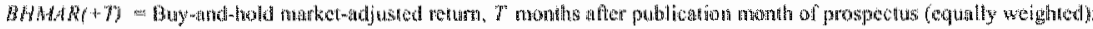

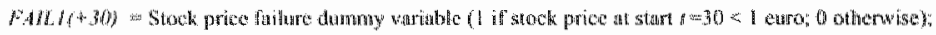

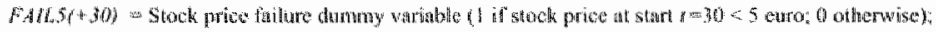

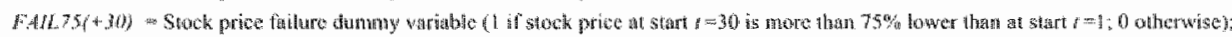

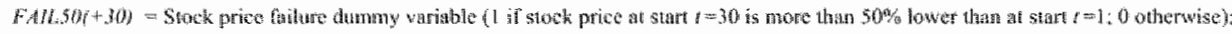

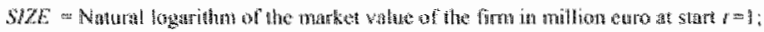

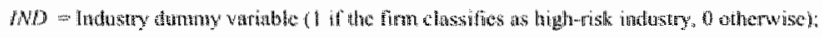

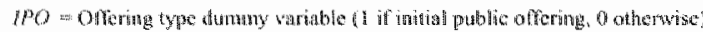


Figure 2 illustrates the significant positive univariate correlations between $R D S I$ and $T R R$ by plotting average TRR up to 30 months after the publication date of the prospectus for three portfolios that were chosen on the basis of the ranking of RDSI. The difference in TRR between the low RDSI portfolio and the high RDSI portfolio is on average $8 \%$ and is statistically significant at $p<.01$ for all months. ${ }^{18}$

FIGURE 2

Average Total Return Risk (TRR) of Three Portfolios

Chosen on the Basis of the Ranking of RDSI

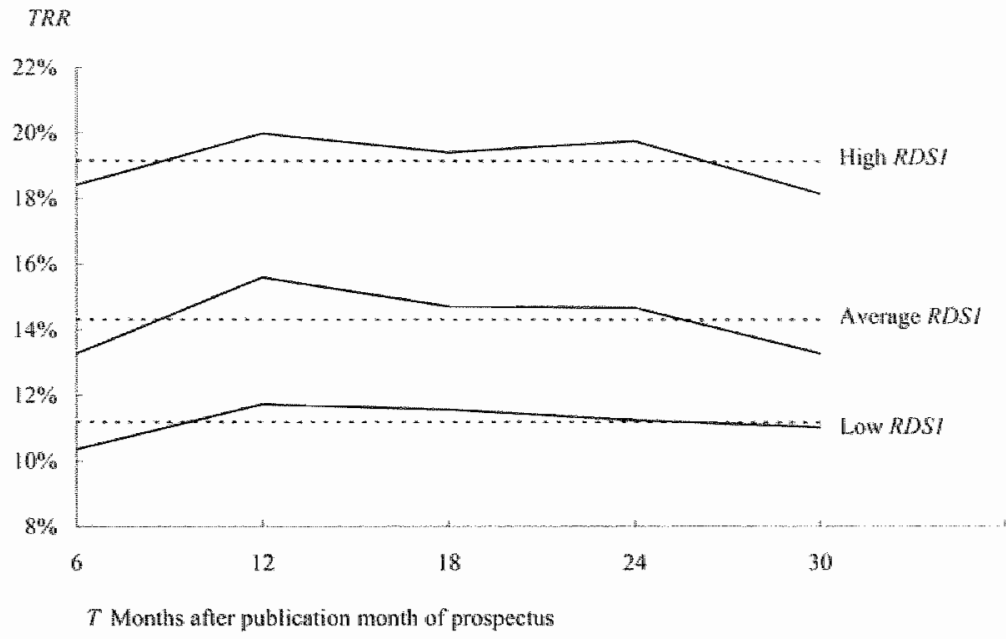

Panel A of Table 4 presents the results of the multivariate regression analyses of model 1 including control variables. All models are significant $(p<.01)$ and adjusted $\mathbb{R}^{2}$ range from $30 \%$ to $54 \%$. RDSI remains significantly positively correlated with $T R R(+T)$ up to 30 months after the issue date of the prospectus $(p<.01)$. IND is also found to be significantly positively correlated with $\operatorname{TRR}(+T)(p<.01)$, except for $\operatorname{TRR}(+6)$.

Panel B of Table 4 presents the results of the multivariate regression analyses of model 3 including control variables. All models are significant $(p<.01)$ and adjusted $\mathrm{R}^{2}$ range from $62 \%$ to $79 \%$. RDSI remains systematically significantly positively correlated with $T R R(+T)$ up to 30 months after the issue date of the prospectus $(p<.05) . I N D$ is also found to be significantly positively correlated with $T R R(+T)$ $(p<.05)$. TRR $(-18)$ however is no longer significantly associated with $T R R(+T)$. 


\section{Chapter 3}

TABLE 4

Ordinary Least Squares Regression Results of Model 1 to 4 Including Control Variables ${ }^{\star}$

\begin{tabular}{|c|c|c|c|c|c|c|c|c|}
\hline \multicolumn{3}{|c|}{ Panel A: Regression Resulls Model I } & \multicolumn{6}{|c|}{$T R R(+T)=a+b_{1} R D S I+b_{2} S I Z E+b_{3} I N D+b_{4} I P O+z$} \\
\hline \multirow{2}{*}{$\begin{array}{l}\text { Dependent } \\
\text { variables }\end{array}$} & \multirow{2}{*}{ Sample } & \multirow{2}{*}{$\mathrm{N}$} & \multicolumn{4}{|c|}{ Estimated Standardized Coefficicnts } & \multirow{2}{*}{ F-value } & \multirow{2}{*}{ Adjusted $\mathrm{R}^{2}$} \\
\hline & & & $b_{i}$ & $b_{2}$ & $b_{3}$ & $b_{*}$ & & \\
\hline$T R R(+6)$ & All prospectuses & 90 & $.47^{\cdots \cdots}$ & .01 & .14 & .01 & $8.93^{* *}$ & $30 \%$ \\
\hline$T R R(+12)$ & All prospectuses & 39 & $.46^{* * * 1}$ & -.14 & .38 & .05 & $12.05^{\circ .68}$ & $38 \%$ \\
\hline$T R R(+48)$ & All prospectuses & 86 & $47^{* *}$ & -.08 & $45^{\circ \cdots *}$ & .05 & $19.77^{* *}$ & $53 \%$ \\
\hline$T R R(+2 A)$ & All prospectuses & 84 & $45^{* * 4}$ & -.04 & $.47^{* *}$ & 08 & $20.62^{* . *}$ & $54 \%$ \\
\hline$T R R(\because 30)$ & All prospectuses & 80 & $.39^{* *}$ & .05 & $.52^{.44}$ & .08 & $17.60^{\circ x}$ & $53 \%$ \\
\hline
\end{tabular}

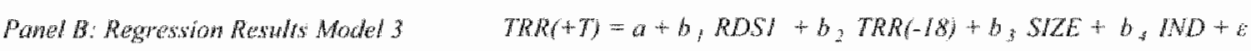

\begin{tabular}{|c|c|c|c|c|c|c|c|c|}
\hline \multirow{2}{*}{$\begin{array}{l}\text { Dependent } \\
\text { variables }\end{array}$} & \multirow{2}{*}{ Sample } & \multirow{2}{*}{ M } & \multicolumn{4}{|c|}{ Estimated Standardized Coefficients } & \multirow{2}{*}{ F-value } & \multirow{2}{*}{ Adjusted $R^{2}$} \\
\hline & & & $b$ & $b_{2}$ & $b_{3}$ & $b_{A}$ & & \\
\hline $\operatorname{TRR}(+6)$ & Seasoned offerings & 31 & $.64^{* * *}$ & .29 & -.15 & $41^{\circ "}$ & $10.26^{4 * 4}$ & $62 \%$ \\
\hline $\operatorname{TRR}(+12)$ & Sexisoned offerings & 31 & $.50^{\prime * *}$ & -.25 & .05 & $58^{* * 6}$ & 13.67 & $69 \%$ \\
\hline $\operatorname{TRR}(+[B)$ & Seasoned offerings & 31 & $43^{\mathrm{oew}}$ & .08 & -06 & $500^{* 4 *}$ & $21.59^{* * *}$ & $79 \%$ \\
\hline$T R R(+24)$ & Seasoned offerings & 31 & $3.44^{\mu *}$ & .05 & .07 & $.62^{\ldots *}$ & $17.5 \|^{* * *}$ & $75 \%$ \\
\hline$T R R(+30)$ & Seasoned offerings & 31 & $.30^{\circ *}$ & .06 & .09 & $.63^{0: 08}$ & $15.60^{10014}$ & $72 \%$ \\
\hline
\end{tabular}

Panel C: Regrestion Results Wodel $2 \quad$ BETA(+30) $=a+b_{1}$ RDST $+b_{2} S / Z E+b_{3} I N D+b_{4} I P O+z$

\begin{tabular}{|c|c|c|c|c|c|c|c|c|}
\hline \multirow{2}{*}{$\begin{array}{l}\text { Dependent } \\
\text { variable }\end{array}$} & \multirow{2}{*}{ Samplle } & \multirow{2}{*}{$\mathbb{N}$} & \multicolumn{4}{|c|}{ Estimated Standardized Coefficients } & \multirow{2}{*}{ Fralue } & \multirow{2}{*}{ Adjusted $R^{2}$} \\
\hline & & & $b$ & $b_{2}$ & $b_{3}$ & $b_{4}$ & & \\
\hline$B E T A(+30)$ & All prospectuses & 80 & $33^{* \cdots *}$ & .08 & $50^{* * *}$ & .00 & $13.27^{m \ldots}$ & $46 \%$ \\
\hline
\end{tabular}

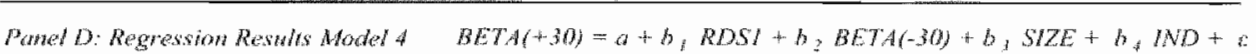

\begin{tabular}{|c|c|c|c|c|c|c|c|c|}
\hline \multirow{2}{*}{$\begin{array}{l}\text { Dependest } \\
\text { vatiable }\end{array}$} & \multirow{2}{*}{ Sample } & \multirow{2}{*}{$N$} & \multicolumn{4}{|c|}{ Eatimated Standardized Coefticients } & \multirow{2}{*}{ F-value } & \multirow{2}{*}{ Adjusted $\mathrm{R}^{2}$} \\
\hline & & & $b_{i}$ & $b_{3}$ & $b_{3}$ & $b_{j}$ & & \\
\hline$B L I A(+30)$ & Suthond offerings & $\$$ & $.76^{i \cdots 4}$ & $.54^{+\infty .00}$ & .14 & -.05 & $7.76^{* 4 \%}$ & $60 \%$ \\
\hline
\end{tabular}

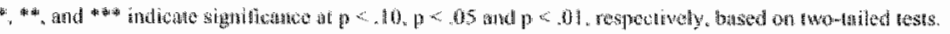

sariable gentinitions:

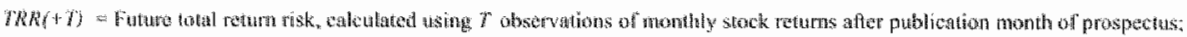

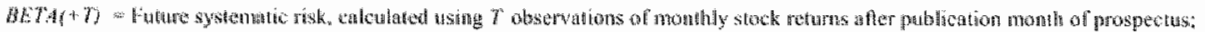

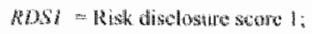

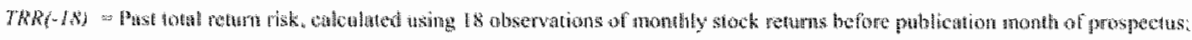

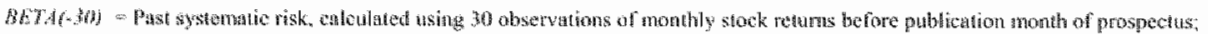

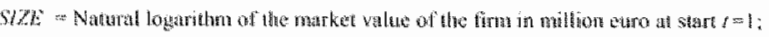

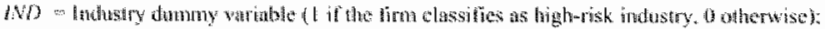

If 
How Informative Are Qualitative Risk Disclosures?

Panel $\mathrm{C}$ of Table 4 presents the results of the multivariate regression analyses of model 2 including control variables. The model is significant $(p<.01)$ and the adjusted $\mathrm{R}^{2}$ is $46 \% . R D S l$ remains significantly positively correlated with $B E T A(+30)(p<.01)$. $I N D$ is also found to be significantly positively correlated with $B E T A(+30)(p<.01)$.

Panel D of Table 4 presents the results of the multivariate regression analyses of model 4 including control variables. The model is significant $(p<.01)$ and the adjusted $\mathrm{R}^{2}$ is $60 \%$. RDSI remains significantly positively correlated with $B E T A(+30)(p<.01)$. $I N D$ is no longer correlated with $B E T A(+30) . B E T A(+30)$ is also found to be significantly positively correlated with $B E T A(-30)(p<.01)$. The correlation coefficient however is lower than the correlation coefficient of RDSI.

Overall, the results of model 1 to 4 show that RDSI is significantly positively correlated with $T R R(+T)$ and $B E T A(+30)$, suggesting that $R D S I$ can be viewed as a forecast of future equity risk. In addition, the results of model 3 and 4 indicate that RDSI is a more accurate predictor than past equity risk.

\subsubsection{Risk disclosures and market-adjusted stock returns}

Panel $\mathrm{B}$ of Table 3 presents the univariate correlations among $R D S I$ and $C M A R(+T)$ and among RDSI and BHMAR $(+T)$. The results show that $R D S I$ is systematically significantly positively correlated with $C M A R(+T)$ and $B H A M R(+T)$ up to 30 months after the issue date of the prospectus $(p<.05$ for the full sample and $p<.10$ for the sub sample of seasoned offerings). BETA(-30) is only significantly correlated with $C M A R(+30)(p<.10)$.

Figure 3 illustrates the positive association between RDSI and $C M A R(+T)$ by plotting the cumulative market-adjusted return index of three portfolios chosen on the basis of the ranking of RDSI for the first 12 months after publication of the prospectus. As can be seen, the high RDSI portfolio has increasingly higher cumulative marketadjusted returns than the low $R D S I$ portfolio. The difference is statistically significant from month 2 on.

Similarly, Figure 4 plots the buy-and-hold market-adjusted return index of three portfolios chosen on the basis of the ranking of RDSI for the first 12 months after publication of the prospectus. As can be seen, the high RDSI portfollio has increasingly higher buy-and-hold market-adjusted returns than the low RDSI. The differences are again statistically significant from month 2 on. $^{20}$ 
FICURE 3

Cumulative Market-Adjusted Return (CMAR) Index of

Three Portfolios Chosen on the Basis of the Ranking of RDSI

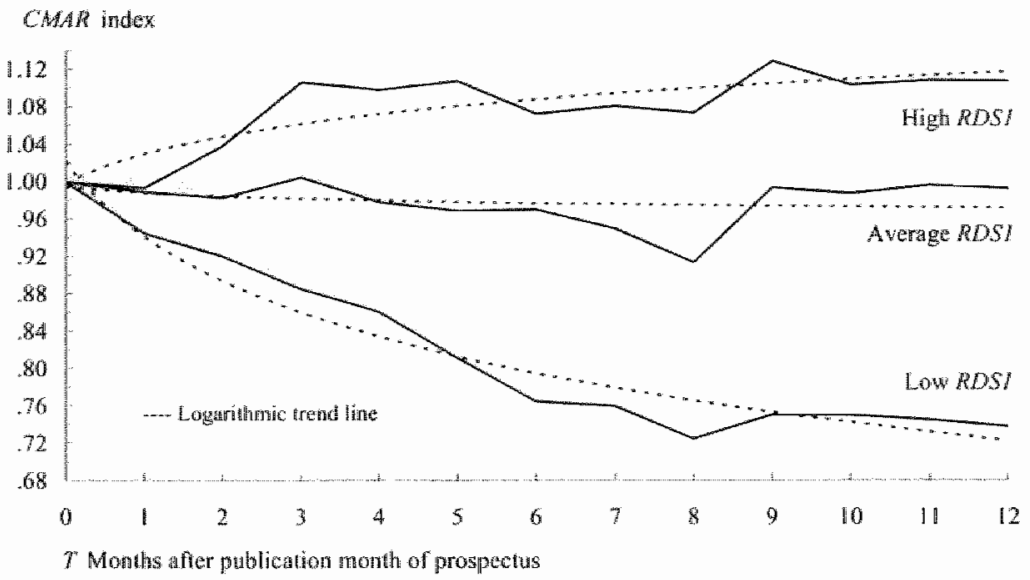

FIGURE 4

Buy-and-Hwid Market-Adjusted Return (BHMAR) Index of

Three Portfollios Chosen on the Basis of the Ranking of RDSI

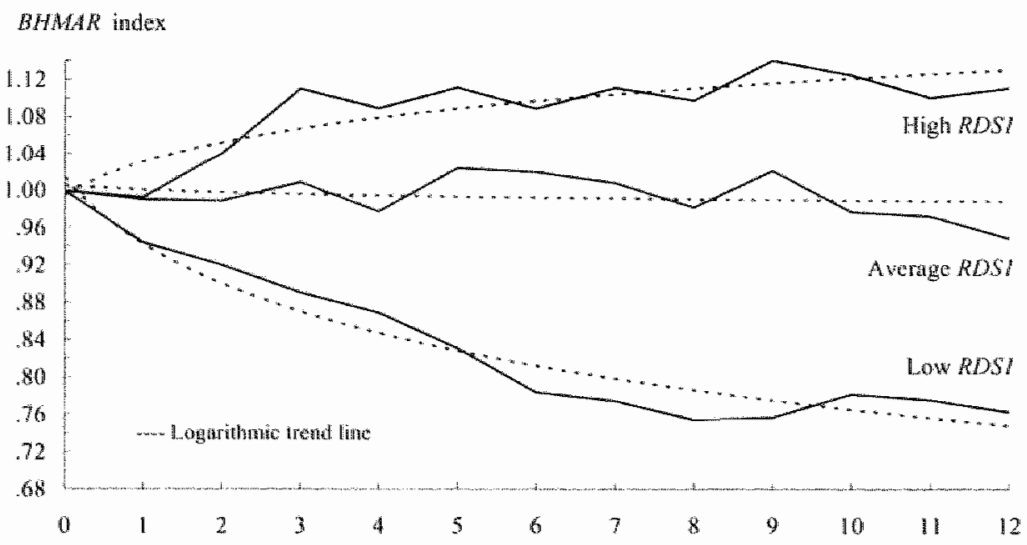

7 Months after putblication month of prospecus 
How Informative Are Qualitative Risk Disclosures?

Panel $\mathrm{A}$ of Table 5 presents the results of the multivariate regression analyses of model 5 including control variables. All models are significant $(p<05)$ and adjusted $\mathbb{R}^{2}$ range from $9 \%$ to $15 \%$. RDSI remains significantly positively correlated with $C M A R(+T)$ up to 30 months after the issue date of the prospectus $(p<.05)$. The control variables are not significantly positively correlated with $C M A R(+T)$, except $I N D$ for $C M A R(+24)(p<.10)$.

Panel B of Table 5 presents the results of the multivariate regression analyses of model 7 including the control variables. All models are significant $(p<10)$ and adjusted $\mathbb{R}^{2}$ range from $17 \%$ to $35 \%$. RDSI remains systematically significantly positively correlated with $C M A R(+T)$ up to 30 months after the issue date of the prospectus $(p<10)$. BETA $(-30)$ remains only significantly positively correlated with $C M A R(+30)(p<.10)$.

TABLEE 5

Ordinary Least Squares and Logistic Regression Results of Model 5 to 9 Including Control Variables

\begin{tabular}{|c|c|c|c|c|c|c|c|c|}
\hline \multicolumn{3}{|c|}{ Pantet A: Regression Results Model 5} & \multicolumn{6}{|c|}{ 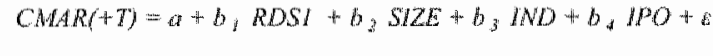 } \\
\hline \multirow{2}{*}{$\begin{array}{l}\text { Dependent } \\
\text { wariables }\end{array}$} & \multirow{2}{*}{ Sample } & \multirow{2}{*}{ N } & \multicolumn{4}{|c|}{ Estimated Standardited Coefficients } & \multirow{2}{*}{ 目-vathe } & \multirow{2}{*}{ Adjusted $R^{2}$} \\
\hline & & & $b_{i}$ & $b_{3}$ & $b$ & $b+$ & & \\
\hline$C M A R(+3)$ & All prospestuses & 90 & $33^{* * *}$ & .05 & -.03 & .05 & $329^{4 * 6}$ & $9 \%$ \\
\hline$C A A R(+6)$ & All prospestuses & 90 & $.34^{* * 4}$ & .11 & -.08 & .09 & $4.099^{\text {iktin }}$ & $12 \%$ \\
\hline$C M L A R(\mathrm{i}-9)$ & All prospestuses & 90 & $.29^{\circ \circ}$ & .13 & -.14 & .07 & $3.20^{\text {.4\% }}$ & $9 \%$ \\
\hline CMAR $(+12)$ & All prospestuses & 89 & $39^{* 0}$ & -.02 & .03 & -.09 & $3.32^{\text {nth }}$ & $9 \%$ \\
\hline$C M A R(+18)$ & All prospestuses & 86 & $28^{\circ}$ & .02 & .15 & -.03 & $296^{4 * 4}$ & $8 \%$ \\
\hline$C M A R(+24)$ & All prospestuses & 84 & $.34^{* * * *}$ & .01 & $.21^{*}$ & -.08 & $4.87^{\text {nom }}$ & $15 \%$ \\
\hline$C M A R(+30)$ & All prospestuses & 80 & $.26^{* *}$ & .21 & .18 & -.04 & $2.600^{14 * 4}$ & $8 \%$ \\
\hline
\end{tabular}

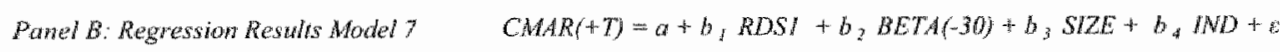

\begin{tabular}{|c|c|c|c|c|c|c|c|c|}
\hline \multirow{2}{*}{$\begin{array}{l}\text { Dependent } \\
\text { Yarables }\end{array}$} & \multirow{2}{*}{ Samplc } & \multirow{2}{*}{ N } & \multicolumn{4}{|c|}{ Estimated Standardized Coofficients } & \multirow{2}{*}{$\|=-4 a t a t e$} & \multirow{2}{*}{ Adjusied $R^{3}$} \\
\hline & & & $b_{n}$ & $b_{2}$ & $b_{3}$ & $b_{7}$ & & \\
\hline $\operatorname{CMAR}(+3)$ & Seasoned offerings & 31 & $.76^{* * *}$ & .013 & .05 & -.28 & $3.78^{16 *}$ & $30 \%$ \\
\hline$C M A R(+6)$ & Seasoned offerings & 31 & $.53^{* *}$ & .00 & .18 & -12 & $2.92^{* *}$ & $17 \%$ \\
\hline$C M A R(+9)$ & Serisoned offerings & 31 & $.51^{* *}$ & -.27 & .20 & -.02 & $3,33^{4+4}$ & $26 \%$ \\
\hline$C M A R(+2)$ & Seasonod offerings & 31 & $.50^{\circ}$ & -31 & .22 & .18 & $2.39^{\circ}$ & $18 \%$ \\
\hline$C M A R(-P B)$ & Seasoned offerings & 31 & $.55^{6 *}$ & -19 & .33 & .02 & $3.79^{.14}$ & $31 \%$ \\
\hline CMAR(+2A) & Seasoned offerings & 31 & $.67^{* *}$ & .122 & .21 & -.14 & $4.14^{.0 *}$ & $34 \%$ \\
\hline$C M A R(+30)$ & Seasoned offering & 31 & $.67^{\circ *}$ & $.43^{\circ}$ & .28 & -.19 & 4.5 .4$. & $35 \%$ \\
\hline
\end{tabular}




\section{Chapter 3}

TABLE 5 (Contiaued)

\begin{tabular}{|c|c|c|c|c|c|c|c|c|}
\hline \multicolumn{3}{|c|}{ Pand C: Ragression Resudu Moded th } & \multicolumn{6}{|c|}{$B H M A R+T=a+b, R O S I+b, S H Z E+b, M N D+b, 1 P O=8$} \\
\hline \multirow{2}{*}{$\begin{array}{l}\text { Dependent } \\
\text { variables }\end{array}$} & \multirow{2}{*}{ Satuple } & \multirow{2}{*}{$N$} & \multicolumn{4}{|c|}{ Estimated Standardized Coeflicietuts } & \multirow{2}{*}{ E-value } & \multirow{2}{*}{ Adjusied $R^{3}$} \\
\hline & & & $b$ & $b_{y}$ & $b$ & $b$ & & \\
\hline BWMAR(+3) & At prospestusers & 90 & $.31^{* 0 *}$ & .07 & -.04 & .07 & $3.110^{* *}$ & $8 \%$ \\
\hline DIMANA(4) & All prospesindes & 90 & $.31^{\circ+4}$ & .03 & .09 & -.05 & $293^{\circ}$ & $8 \%$ \\
\hline$B S M A R(-1)$ & All prosperstuses & 90 & $.32^{\cdots+*}$ & .05 & -.01 & .03 & 297 & $8 \%$ \\
\hline DHAMR(+1) & All prospestuses & 89 & $33^{\text {s:4 }}$ & -04 & .00 & -03 & $27^{*} *$ & $6 \%$ \\
\hline DHMAR(O) & All prosperstugers & 86 & .13 & .1落 & .12 & 06 & 1.65 & $3 \%$ \\
\hline BINMAR(+24) & All prospuestuses & 84 & $.27^{* 44}$ & -09 & .05 & .03 & $2088^{\circ}$ & $5 \%$ \\
\hline$B N M A R(+30)$ & Al prospesinges & 80 & $23^{\circ}$ & 10 & .10 & -13 & $2000^{\circ}$ & $5 \%$ \\
\hline
\end{tabular}

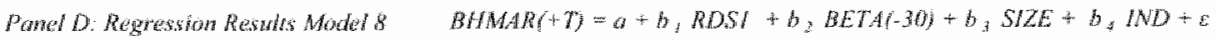

\begin{tabular}{|c|c|c|c|c|c|c|c|c|}
\hline \multirow{2}{*}{$\begin{array}{l}\text { Dependent } \\
\text { variables }\end{array}$} & \multirow{2}{*}{ Saterple: } & \multirow{2}{*}{$N$} & \multicolumn{4}{|c|}{ Eslingated Slandarlized Cocficients } & \multirow{2}{*}{ F-value } & \multirow{2}{*}{ Adjusted $R^{2}$} \\
\hline & & & $b_{1}$ & $b y$ & $b_{3}$ & $b_{4}$ & & \\
\hline$B H M A N(+3)$ & Sextsoned offerisgs & 31 & $.75^{m: 2 * 4}$ & -.03 & .06 & -30 & $3.91 *$ & $31 \%$ \\
\hline BHMAR( $=6)$ & Seusoned oflerings & 31 & $.45^{*}$ & -.08 & .22 & -.01 & $2.40^{\circ}$ & $17 \%$ \\
\hline BHANROD) & Sensoned offerings & 31 & $61^{4+14}$ & .20 & .20 & -.09 & $5.233^{-x+4}$ & $39 \%$ \\
\hline BWHANR+12J & Seatsoned offerings & 31 & $.62^{\cdots 18}$ & -.22 & .27 & -.12 & 5.14 & $39 \%$ \\
\hline$B H A H R(A)$ & Sersoned otferings & 31 & $.52^{* 4.4}$ & -.24 & .33 & -14 & $4.16^{* *}$ & $34 \%$ \\
\hline BWMAN(R-2A) & Sensoned onferings & 31 & $.56^{4.10}$ & .06 & .24 &. .13 & $2.86^{* *}$ & $22 \%$ \\
\hline$B H A N R+3 O)$ & Seatsonad orferings & $3 !$ & $.59^{* *}$ & .40 & .22 & -26 & $4.80^{\circ \cdots}$ & $38 \%$ \\
\hline
\end{tabular}

Panew E: Regression Resalds Hodel 9

$F A L(+30)=a+b_{1}, R D S R+b_{2} S I Z E+b_{3} M N O+b_{4} M P O+\varepsilon$

\begin{tabular}{|c|c|c|c|c|c|c|c|c|}
\hline \multirow{2}{*}{$\begin{array}{l}\text { Dependent } \\
\text { wariable }\end{array}$} & \multirow{2}{*}{ Sample } & \multirow{2}{*}{$\mathbf{N}$} & \multicolumn{4}{|c|}{ Estimated Coeffictents } & \multirow{2}{*}{$x^{2}$} & \multirow{2}{*}{$\begin{array}{l}\text { Nagelkerke } \\
\text { Psetdo R? }\end{array}$} \\
\hline & & & $b_{1}$ & $b_{2}$ & $b_{3}$ & $b_{a}$ & & \\
\hline $5 A M l(-30)$ & All prospectuses & 80 & $1.93^{\text {wee }}$ & -.90 & $2.38^{*}$ & -.31 & $21.37^{* 10 \times x}$ & $48 \%$ \\
\hline Fin $5(+30)$ & All prospectuses & 80 & $.82^{*}$ & -.39 & $1.88^{* * 6}$ & 13 & $23.19^{\circ * 4}$ & $36 \%$ \\
\hline FHA $75(+30)$ & All prospectuses & 80 & $1.61^{* * *}$ & $-1.02=$ & $4.05^{\text {wa }}$ & -59 & $40.10^{\text {tis:o }}$ & $60 \%$ \\
\hline FALSOC +30$)$ & All prospectuses & 80 & $.87^{\circ+}$ & -.38 & $1.24^{* *}$ & -.70 & $\| 8.10^{* * *}$ & $26 \%$ \\
\hline
\end{tabular}

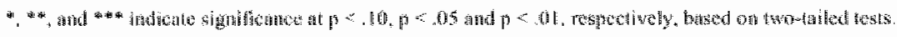

It Vulatble dutionitions:

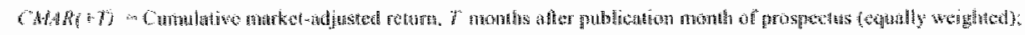

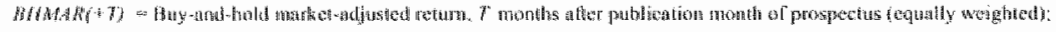

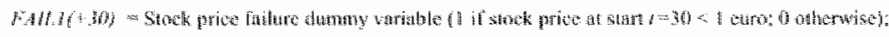

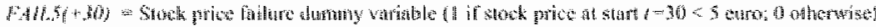

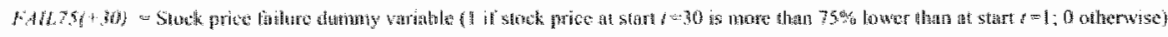

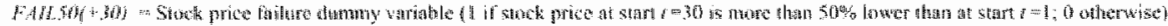

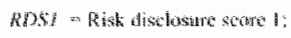

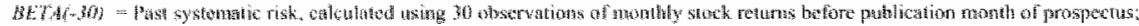

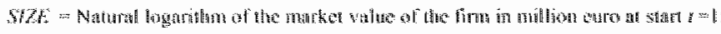

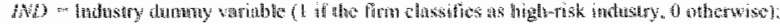

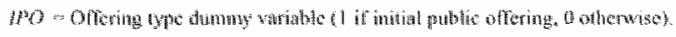


Panel C of Table 5 presents the results of the multivariate regression analyses of model 6 including control variables. Except for $B H M A R(+18)$, all models are significant $(p<.10)$ and adjusted $\mathrm{R}^{2}$ range from $5 \%$ to $8 \%$. Except $B H M A R(+18)$, $R D S I$ remains significantly positively correlated with $B H M A R(+T)(p<10)$. The control variables are not significantly positively correlated with $B H M A R(+T)$.

Panel D of Table 5 presents the results of the multivariate regression analyses of model 8 including control variables. The models are significant $(p<.10)$ and adjusted $\mathrm{R}^{2}$ range from $17 \%$ to $39 \%$. RDSI remains significantly positively correlated with $B H M A R(+T)(p<10)$. BETA $(-30)$ not significantly correlated with $B H M A R(+T)$.

Overall, the results of model 5 to 8 show that $R D S 1$ is significantly positively correlated with $C M A R(+T)$ and BHMAR $(+30)$, suggesting that $R D S I$ can be viewed as a proxy of equity risk. Moreover, the results of model 7 and 8 indicate that $R D S I$ is a more accurate proxy of equity risk than past systematic equity risk.

\subsubsection{Risk disclosures and failure of stock price in the aftermarket}

Panel B of Table 3 presents the univariate correlations among FAIL +30$), R D S I$ and control variables. The results show that RDSI and IND are significantly positively correlated with $F A L L(+30)(p<.01)$. SIZE is not significantly correlated with $F A I L(+30)$ and IPO is only significantly correlated with FAILS $(+30)$ and FALL 75 $(+30)(p<.05$ and $p<.10$ respectively).

Panel $\mathrm{E}$ of Table 5 presents the results of logistic regression analyses of model 9 including control variables. The models' $\chi^{2}$ are significant $(p<01)$ and Nagelkerke pseudo $\mathrm{R}^{2}$ range from $26 \%$ to $60 \%$. Both $R D S 1$ and $I N D$ are significantly positively correlated with $F A I L(+30)(p<.05$ and $p<.10$ respectively).

The model for FAILI $(+30)$ has a higher pseudo $\mathrm{R}^{2}$ and a higher coefficient for RDS1 than the model for FAIL $(+30)$. Similarly, the model for FAIL $75(+30)$ has a higher pseudo $\mathrm{R}^{2}$ and a higher coefficient for RDS1 than the model for FALL5O(+30). This suggests that RDSI is better at explaining more extreme stock price failures.

Overall, the results for model 9 show that RDSI is significantly positively associated with $F A I L(+30)$, which is consistent with the explanation that RDSI captures severe downside risk.

\subsubsection{Supplementary analyses}

The main analyses focused exclusively on RDSI. Alternatively, I included all three component scores in model 1 to 10 and repeated the tests. For reasons of brevity these results are not reported in tabular form. The results confirm the correlations between RDSI and TRR $(+T), B E T A(+30), C M A R(+T), B H M A R(+T)$ and FAL $(+30)$ and provide no evidence that $R D S 2$ or $R D S 3$ is systematically correlated with $T R R(+T)$, $B E T A(+30), C M A R(+T), B H M A R(+T)$ or $F A L L(+30)$. The latter finding suggests that disclosure of risk factors represented by $R D S 2$ and $R D S 3$ contain no additional information about future equity risk (as measured in this study). 
Chapter 3

\subsection{Summary and conclusion}

This chapter examined for 90 Dutch companies that issued securities on the Amsterdam Stock Exchange in the period from 1997 to 2000, how qualitative risk disclosures in the risk sections of their offering prospectuses are related to stock market risk in the aftermarket. The main analyses focused on variability of stock returns, market-adjusted stock returns and exceptionally low levels of stock prices. The purpose of assessing how well ex-ante qualitative risk disclosures reflect ex-post stock market risk is to extend existing knowledge about the relevance and reliability of qualitative risk disclosures. Qualitative risk disclosures are considered relevant if they are capable of making a difference to financial statements users' decisions, and reliable if they represent what they purport to represent. In this view, information does not necessarily have to be new to market participants to be relevant. An important role of risk sections in prospectuses may be to summarize or aggregate information about risk that is available from other sources and/or other parts of the prospectus.

The research design involved four stages: (1) developing an appropriate coding scheme for the risk factors in the risk sections of the prospectuses; (2) coding the texts of the risk sections; (3) creating composite measures of risk disclosure from the collected data; and (4) correlating the composite measures of risk disclosure with measures of stock market risk, controlling for several other factors.

The findings clearly indicate that forward-looking qualitative risk disclosures in risk sections of prospectuses are a useful source of information about future equity risk. First, the risk disclosures are positively associated with the variability of stock returns and the covariance of returns with the market (i.e. systematic risk) for at least 30 months after publication of the prospectus. Second, the risk disclosures are positively associated with average market-adjusted stock returns for at least 30 months after publication of the prospectus. As stock market prices likely quickly reflect public information - including the information in the risk sections - the observed systematic differences in stock returns are likely due to differences in risk. Third, the risk disclosures are positively associated with extreme declines in stock price over a period of 30 months after disclosure, suggesting that the risk disclosures warn investors for possible seriously negative outcomes. This is consistent with managements' and investors" conceptualization of risk.

The findings may provide useful insights for standard setters of risk disclosures, for example the Committee of European Securities Regulators (CESR). CESR recently prepared authoritative guidance on disclosure requirements established under the new Prospectus Regulation that resulted from the new Prospectus Directive of the European Parliament and of the Council (Directive 2003/71/EC). In sum the findings suggest that: (1) Risk disclosures do not necessarily have to be quantified to be relevant and reliable; (2) Forward-looking disclosures on a wide range of risks with a focus on the downside seem to be relevant and reliable; and (3) Detailed rules seem no prerequisite for relevant and reliable risk disclosures in prospectuses. 
The findings are also relevant for accounting researchers who want to employ an alternative measure of risk. Although risk is a fundamental variable in many areas of accounting research, there is little consensus regarding the meaning and measurement of risk. Most studies use ex-post risk measures derived from accounting and stock market data, seeking to capture the variability of company performance. Common measures are the variance of return on equity or return on assets, and total, systematic and unsystematic risk derived from historical stock returns. Despite the widespread use of these variability measures as risk proxies, substantial behavioral research indicates that such an approach may not reflect managements' and investors' conceptualizations of risk. Prior research suggests that managers and investors conceptualize risk in downside rather than variance terms. In addition, accounting researchers are often fundamentally concerned with managers' and investors' ex-ante decision processes. Ex-post measures may be decidedly different from ex-ante risk assessments. If ex-ante downside risk is more relevant to managerial and investor behavior than ex-post performance variability, empirical accounting research using exante measures of downside risk may provide more consistent and conclusive results than studies using ex-post variability measures of risk. By making replicable and valid inferences from the texts of managers' ex-ante risk assessments in prospectuses, this study has developed and tested a method to measure ex-ante downside risk. While the resulting measure has satisfactory face validity as suggested by behavioral research, its relative importance in predicting stock returns - especially compared to ex-post market measures of risk - indicates that the measure has promising empirical validity, Replication of this study should demonstrate whether the findings are generalizable to other populations, settings or time periods. Nevertheless, the current studly of managements' risk communications to investors yields a reliable and valid measure of risk for the firms in the sample. Consequently, the measure can be used in chapter 4 of this dissertation. 


\section{Chapter 3}

\section{Endnotes}

'Schrand and Elliot (1998) proxide a summary of the "Risk and Financial Reporting' session of the 1997 American Accounting Association (AA) and the Financial Accounting Standards Board (FASB). Although my study is partly motivated by regulators" demand for normative prescriptions on risk reporting, it is not the objective of this study to yiedd such prescriptions.

${ }^{2}$ To disclose quantitative infomation about market risks, firms must select among three disclosure formats (tabular, sensitiwity analysis, and value at risk) and three measurement bases (cash flows, earmings, and fair values). The qualitative information required about market risk includes the identification of primary market risks (i.e. interest rate, foreign exchange, commodity and other market risks such as equity price risks) and the particular markets in which the company is exposed. In addition, firms also must discuss their derivative accounting policies, risk management goals, objectives, and controls. Finally, firms must reveal how risk is managed in general and the specific types of instruments used (Hodder er al 2001).

${ }^{3}$ Jorgensen and Kirschenheiter (2003) model a multifirm setting in which the variance of each firm's future cash flow is uncertain. A manager can disclose, at cost, this variance before offering the securities for sale in a competitive stock market with risk-averse investors.

* 94 firms issued securities in the period from January 1997 to December 2000. I have complete data for 90 firms. Dala were collected in July 2003. The sample does not include more recent years because the empirical tests require at least 30 months of stock market data after the security issues. Moreover, in the period from January 2001 to July 2003 very few lims issued securities.

5 Only Simunic and Stein (1987) report that since the reporting requirements are rather general and allow considerable latitude in the nature, degree and form of disclosure, they invially (but unsuccessfully) tried to classify the risk factors as they appeared in the prospectus in categories.

-Alternatively, I identified for each text how often each risk factor was mentioned. The resulting component scores are almost identical (correlation coefficients $>.98$ with $p<.00$ ) and the results of reported tests are robust to using these component scores.

'See Didow et al. (1985) for a presentation of the general form of the PRINCIPALS transformation and an illustration of its usefuness in the context of attitude research.

"A waluteweighted index of all stocks listed on the Amsterdam Siock Exchange (the 'Centrat Bureat voor de Statistick" all share index) is used to calculate the retum on the market portfolio. Estimates of $B E T A_{i}$ are calculated from the market model: $R_{i,}=a_{i}+\beta_{i} R_{m, t}+e_{i,}$; where $R_{i, i}$ is retun on security $i$ in month $l_{\text {: }} R_{\text {au }}$ is retum on the market portfolio in month $t ; a_{i}$ and $\beta_{i}$ are parameters that wary from security to security; and $e_{i, l}$ is andom disturbance term. The market model is a variation of the capilal asset pricing model (CAPM) of Sharpe (1964) and Lintner (1965) that has long shaped the way academios and practitioners think about awerage returns and risk. The central prediction of CAPM implies that expected returns on securities are a positive linear function of their market betas and that market betas sutfice to describe the crosis-section of expected returns (Fana and French 1992).

"TRR was calculated using at least 6 and at most 30 observations of monthly stock returns. BETA should preferably be calculated using more than 30 observations of monthly stock returns, but due to the tinning of the study 30 was the maximum available for all firms in the sample. To test the robustness of the results of model 2 and 4 for the calculation of BETA, I excluded the last year of security issues from the sample and calculated $B E T A(+42 \%$. This leads to identical conclusions. 
10 There is a growing body of empirical literature that contradicts the predictions of the CAPM and by extension the usefulness of beta. Contrary to the relationship predicted by the CAPM, Fama and French (1992) find that beta is not related to average returns on stocks. Measures such as firm size, market-to-book ratio of equity, leverage and the price-eamings ratio on the other hand were found to be related to average returns. These findings have caused considerable debate among academics. Some explain them as evidence of market inefficiency, e.g. due to overreaction of stock prices (e.g. Lakonishok er al. 1994). Fama and French (1995) however argue that although the CAPM model is flawed as a description of risk/return relationships, market efficiency should not be abandoned. They state that the observed relationships are based on risk and retum considerations, i.e. measures such as furm size and the market-tombook ratio are (for unexplained economic reasons) acting as proxies for risk. Defenders of CAPM and beta argue that the empirical tests are flawed due to measurement enror (e.g. the market index is misspecifued or the ex post measures of beta are not good predictors of the $e x$ ante beta that should be used in portfolio formation). In a response, Fama and French (1996) state that even if there were flaws in their tests (which they attempt to disprove) and beta is related to returns, at best that would only save beta but not the CAPM. Fama and French argue that the fact that size and the market-to-book ratio are also related to returns contradicts the CAPM that contends that beta (however measured) is the sole risk measure.

"The calculated market-adjusted stock returns do not include the issue-day return. For investors it is frequently difficult to purchase shares at the offering price, whereas the market price represents a price that is available for a realizable portfolio strategy (Loughran and Ritter 1995). Finding a positive correlation between RDSI and long-run stock returns would suggest that RDSI is acting as a proxy for risk and therefore contradicts CAPM. However, it does not imply any long-run return anomaly (mispricing of publicly available information) and market efficiency is not abandoned. Consistent with the efficient market hypothesis, systematic differences in average returns are atributed to differences in risk (Fama and French 1995). Stock price performance of IPOs in the years after the offering has attracted much interest from academics in recent years (see Ritter and Welch 2002). As Ritter and Welch (2002) explain, in an efficient market risk-adjusted post-IPO stock price performance should not be predictable. Long run performance evidence suggests that post-IPO performance is poor, but because the asset-pricing literature has failed to provide an accepted model of risk-adjusted performance against which one can measure post-IPO performance, it still remains unclear how abnormally poor post-IPO performance is (Ritter and Welch 2002)

"Although calculating cumulative abnomal returns is a common approach to examine long-term feturns, Barber and Lyon (1997) document that cumulative abnornal returns are biased predictors of buy-and-hold abnormal returns and they advocate the use of buy-and-hold abnormal returns over cumnulative abnormal returns. In addition, they lind that there are significant biases in test statistics when long-term abnomal returns are calculated using a reference portfolio (such as a market index) like in this study. Although the reference portolio approach is a common method in winencial economics, cumulative abnomal retuns are most affected according to Barber and Lyon (1997) and the associated test statistics are generally positively biased. In contrast, they show that long-run buyand-hold abnormal returns are generally negatively biased. To avoid an incorrect interpretation of the results due to differences in calculating abnormal retums, I investigated both cumulative abnormal returns and buy-and-hold abnormal refurns. 


\section{Chapter 3}

${ }^{13}$ For IPOs and for stock offerings relating to a demerger, $C M A R(+T)$ and $B H M A R(+T)$ were necessarily calculated from the first month after the issue date of the securities instead of after the issue date of the prospectus. For these firms, the market-adjusted return for the first month does not include the issue day return, as it is frequently difficult for an investor to purchase shares at the offering price, whereas the market price represents a price that is available for a realizable portfolio strategy (Loughran and Ritter 1995).

14 Alternatively, I included four dummy variables to control for the type of offering: $O F F I$, which is I for a seasoned offering of common stock, and 0 otherwise; $O F F 2$, which is 1 for a seasoned offering. of both common stock and conwertible bonds, and 0 otherwise; OFF3, which is 1 for a seasoned offering of convertible bonds, and 0 otherwise; and OFF4, which is 1 for a stock offering relating to a merger or demerger, and 0 otherwise. This leads to identical conclusions for all analyses. The findings are also robust to controlling for the year in which the securities were offered (nneasured by dumny variables) and to excluding any specific quarter in which securities were offered from the sample. Lastly, the findings are robust to controlling for industry classification by including dummy variables that identify companies that are active in the manufacturing and trade sector.

Is The total amount of variance to be explained (the "trace') is equal to the total number of risk factors, i.e. 48. The eigenvalues represent the amount of wariance accounted for by each dimension. The percentage of variance accounted for by each dimension is equal to the eigenvalue divided by the trace.

"Additional Kolmogorov-Smimov tests show that for most variables the assumption about normality of the distribution can be rejected at conventional probability levels $(p<05)$.

17 Poor long-term performance of new issues might suggest a long-term retum anomaly, but Fama (1998) argues that the results of Brav and Gompers (1997) show that the poor long-term performance is not a special anomaly. He states that the low returns are shared with other firms similar on two dimensions - size and book to market value of equity - both known to be related to average returms. Moreover, he concludes that when refurns ate value-weighted, abnomal returns are no longer reliably different from zero.

${ }^{18}$ Despite the relatively high correlations anong the independent variables in model 1 to 9, additional tests for multicollinearity give no indication of any potential barmful effects on the results of the multivariate regression analyses.

19 Differences between the average RDSI and the high RDSI portfolio are statistically significant for month 18,24 and $30(p<05)$. Differences between the low RDS/ and the average RDSt portfolio are not statistically significant $(p>10)$.

3i) Consistent with Figure 2, additionally performed analyses of variance suggest that the variance of the cumulative as well as the buy-and-hold market-adjusted return index of the low RDS/ portfolio is in general signilicantly lower than the variance of the cumblative market-adjusted return index of the high RDS/ portfolio. 


\title{
CHAPTER 4
}

\section{The Association between Firm Risk, Managerial Ownership, Board Composition and Ownership Concentration}

\begin{abstract}
The aim of this chapter is to provide cross-sectional tests of the prediction that board composition and ownership concentration vary systematically with firm risk and managerial ownership in ways that are consistent with shareholder value maximizing behavior. The sample consists of Dutch corporations that issued securities - either an initial public offering (IPO) or a seasoned offering - at the Amsterdam Stock Exchange in the period from 1997 to 2000 . Listed Dutch firms have a two-tier board structure with a managing board consisting of inside directors and a supervisory board consisting of outside directors.

The results show that directly after an IPO, riskier firms and firms whose managing boards own less equity, employ significantly more outside directors and have a more concentrated ownership structure. Further analyses reveal that large noninstitutional shareholders account for the latter finding. These findings are consistent with the explanation that a firm's control potential, as measured by firm risk and managerial ownership, affects the adoption of control mechanisms in a way that is consistent with shareholder maximizing behavior. For firms in the sample with a seasoned offering, I find no or considerably weaker associations. A possible explanation for this finding is that board and ownership structure are chosen more optimally in response to firm risk and managerial ownership at the time of the IPO and evolve over time due to other factors.
\end{abstract}

\section{I Introduction}

Economic growth is critically dependent on an environment that encourages risk taking. The institution of stock markets, where investors can both diversify their risks and reverse decisions at will, has provided an environment that encouraged a higher overall level of risk taking over time than would have been likely under other circumstances (Bernstein 1998). Crucial in this respect is that the establishment of stock markets has facilitated the separation of ownership and control (Berle and Means 1932), which enables firms to hire professional managers and to spread risks over a large group of shareholders, who benefit from portfolio diversification. 
Since the notion that modern corporations are characterized by the separation of ownership and control, the issue of aligning the interests of the owners, managers and other stakeholders has given rise to a large economic literature and has been subject of intense public policy debate. The accounting, fnnance and strategic management literature has documented the existence of a variety of agency conflicts that result from the effect of the divergence between owners and insiders on decision making. Several governance mechanisms have been investigated that can mitigate the agency problem (Rediker and Seth 1995), including market mechanisms such as the threat of takeover (Grossman and Hart 1980) and the managerial labor market (Fama 1980), incentive effects of management's share ownership (Jensen and Meckling 1976) and other elements of compensation packages such as stock options (Haugen and Senbet 1981), monitoring of top management by outsiders on the board of directors (Fama 1980 and Fama and Jensen 1983) and monitoring of top management by large shareholders (Demsetz and Lehn 1985, Huddart 1993). A vast amount of previous empirical research has examined factors that influence the structure of these mechanisms, as well as the effectiveness of these mechanisms in limiting the agency conflict.

This chapter intends to contribute to the former stream of literature by investigating the influence of a specific factor - firm risk - on two specific forms of governance - outsiders on the board of directors and large shareholders - while controlling for the possible influence of other factors, including alternative govemance mechanisms that simultaneously operate in the firm. More specifically, the study provides cross-sectional tests of the prediction that board composition and ownership concentration correlate systematically with firm risk and managerial ownership in ways that are consistent with shareholder value maximizing behavior.

The study differs in a number of ways from prior research on board composition and ownership concentration. First, the sample consists of firms that issue securities, either a seasoned offering or an initial public offering (IPO). In this way, I investigate large, more established firms that are typically studied, and firms that raise equity from dispersed investors for the first time. Investigating the latter may provide a particularly clear test of the agency-based perspective that is adopted in this study. Because existing shareholders bear the cost of suboptimal governance, board composition and ownership structure are more likely to be chosen optimally at the time of the IPO (Baker and Compers 2003). In contrast, at the time of a seasoned offering, board and ownership structure is as much a consequence of past performance, top executive changes and corporate control threats as it is a measure of the quality of corporate governance (Denis and Sarin 1999). Second, the measure of firm risk is obtained through a content analysis of top managements" own risk assessments in the prospectuses. In this way, firm risk is measured ex-ante (before the outcomes) rather than ex-post. In addition, the measure better reflects boards' and owners' interpretation and perception of risk. Boards and owners likely react to their own interpretation and perception of firm risk, rather than to traditional variance-based measures of risk used in the accounting and finance literature. Third, the study provides empirical evidence 
The Relationship between Risk and Control

on the determinants of two-tier boards, whereas most research has focused on one-tier boards.

The following section presents a brief background on the theoretical relationship between firm risk and corporate governance and discusses prior empirical studies that investigated the effect of governance mechanisms on risk taking as well as prior empirical studies that investigated the effect of firm risk on governance mechanisms. Section 3 details the hypotheses. Section 4 describes the data and section 5 defines the variables and specifies the model. The results are presented in section 6 . The final section summarizes and concludes the chapter.

\subsection{Background and previous research}

According to agency theory, conflicts between the goals of shareholders and nanagers can arise for various reasons, including differences in their preferred levels of managerial effort and their attitudes toward risk, with managers assuming a posture that is generally more risk averse than shareholders (Eisenhardt, 1989). As Ellstrand, Thanyi and Johnson (2002) argue, reducing risk can be advantageous for management for several reasons. Less risk for example implies job security and less risky outcomes will generally lead to more certain rewards for managers. Shareholders generally favor actions that have riskier outcomes because they can both diversify against risk, and reverse their decisions at will. As corporate risk-taking behavior is often considered critical to firm performance, several studies have investigated the impact of the ageney conflict (and factors that mitigate the agency conflict) on corporate investment decisions that involve risk taking. Taking an agency perspective, Agrawal and Mandelker (1987) for example found a positive relationship between security holdings of management and changes in return variance. Wright et al. (1996) found that large institutional shareholders exert a positive influence on future risk taking, whereas the effect of other blockholders was negligible. More recently, Ellstrand et al. (2002) found a positive association between monitoring by outside directors and the level of political risk in firms' portfolios of global operations.

While Agrawal and Mandelker (1987), Wright et al. (1996) and others hypothesize that the incentive effect of security holdings by top management affects the level of risk taking, Beatty and Zajac (1994) studied the reverse relationship, i.e. the effect of firm risk on managerial incentives. Their underlying agency theory assumption however is the same: managers - unlike owners - have already invested most of their non-diversifiable and non-tradable human capital in the firm. As a result, the agent is relatively risk averse, while the principal is relatively risk neutral. Building on this argument, their hypothesis is that the ability of firms to use executive compensation contracts to address managerial problems is hampered by the riskbearing concerns that stem from the risk aversion of top managers, and that this problem is particularly severe for riskier firms. For a sample of initial public offering firms, they indeed find that top managers in riskier firms have smaller equity holdings and fewer stock options in their compensation contracts, supposedly providing them with fewer incentives. Beatty and Zajac also find that firms whose top managers have 
fewer incentives, compensate this with more extensive monitoring of top management by outside directors and large shareholders to ensure sufficient supervision of managerial behavior.

Although their study clearly shows how firm risk can indirectly induce monitoring of top management by outside directors and large shareholders, Beatty and Zajac do not investigate a possible direct effect of firm risk on these monitoring mechanisms. Empirical research on determinants of board composition (e.g. Prevost, Roa and Hossain 2002, Hermalin and Weisbach 1988, 1991, 1998, 2003) has hardly investigated a direct effect of firm risk. One of the few empirical studies that hypothesized a direct effect was conducted by Pearce and Zahra (1992). From a strategic contingency perspective they observed a positive association between the uncertainty of a firm's environment (as perceived by the executives of the firm) and the proportion of outside directors to total directors. Considering the results of Beatty and Zajac, this association however might be the result of omitting important correlated variables such as the level of managements' equity holdings.

Pearce and Zahra's arguments for a relationship between uncertainty of a firm's enviromment and board composition may nevertheless be valid and stem from resource dependence theory, as originally theorized by Pfeffer and Salancik (1978). As Hillman and Dalziel (2003) point out, resource dependence theorists view outside directors as providers of resources (e.g. legitimacy, advice and counsel, links to other organizations) and stress board capital, which consists of both human capital (e.g. experience, expertise, reputation) and relational capital (e.g. network of ties to other firms and external contingencies). The idea is that resources can help diminish uncertainty for the firm (Pfeffer 1972). Pearce and Zahra argue for example that outsiders on the board can, by providing links between the organization and the external environment, help a company pursue new markets and industries. In this way, outsiders on the board help to make environmental threats more manageable. This suggests that as uncertainty of the environment increases, the representation of outsiders will rise (Pearce and Zahra 1992). Integrating the agency and resource dependence perspective, Hillman and Dalziel (2003) conclude that boards of directors serve two important functions for organizations: monitoring management on behalf of the shareholders (Fama 1980 and Fama and Jensen 1983) and providing resources (Pfeffer and Salancik 1978).

The role of large shareholders is similar. New, unlisted firms usually raise a significant amount of their equity capital from venture capitalists, banks, insurance companies, pension funds, and other companies and individuals. This investment is often a high-risk proposition promising huge returns - if the firm doesn't go bankrupt first. Unlike shareholders in publicly held companies, these early-stage investors cannot sell their stock. As a result, they likely demand a great deal of control over the company and closely monitor the entrepreneur. In addition to providing money and monitoring management, they often bring business skills and advice to a company, i.e. they are providers of resources (e.g. assist in the management of the company, help with policy decisions and financial problems, recruit new management staff, define 
The Relationship between Risk and Control

new areas of activity, contribute knowledge to product markets) (Shapiro and Balbirer 2000). At the time of the initial public offering these shareholders cannot immediately cash out. To signal their confidence in the firm's prospects (and prevent underpricing of the shares), the selling shareholders must often retain a substantial amount of equity and enter a 'lock-up' agreement that limits selling or transferring their shares for a certain period after the offering. In this way, they have a strong incentive to actively monitor management's activities during this period. Also after the 'lock-up' period, large shareholders are possibly more willing and able to play an active monitoring role than investors with small shareholdings for whom it is more expensive and difficult to do so (Demsetz and Lehn 1985, Huddart 1993). Demsetz and Lehn (1985) argue that the choice by owners in favor of more concentrated ownership structure is consistent with value maximizing behavior and depends - among others - on the firm's control potential, which they define as the wealth gain achievable through more effective monitoring of managerial performance by the firm's owners. Demsetz and Lehn believe that a firm's control potential is directly associated with the uncertainty of the environment in which it operates. The less stable a firm's environnent, they argue, the more difficult it becomes to disentangle the effects of managerial behavior on firm performance from other largely exogenous factors. Because this increases the payoff to owners in maintaining tighter control, less stable environments should give rise to more concentrated ownership structures. Important in this respect is that Demsetz and Lehn take the view that owners believe they can influence the success of their firm and that all outcomes are neither completely random nor completely foreseeable. 'This belief constitutes an assertion of the existence of risks, opportunities, and managerial shirking that are in some degree controllable by owners for the profit of owners' (Demsetz and Lehn 1985, 1159). ${ }^{2}$ Consistent with this view, they observe that instability in a firm's environment, as measured by variance in stock returns and accounting returns, is positively associated with ownership concentration.

Summarizing, prior empirical research on outside directors and large shareholders suggests that these mechanisms are a vehicle for risk management as much as for risk taking. The monitoring role of outside directors and large shareholders refers directly to their possibility to monitor top management on behalf of shareholders. In addition, outside directors and large shareholders can provide resources to the firm that help managing firm risk.

Before discussing the hypotheses, I will briefly outline the main aspects of the Dutch corporate governance environment that are relevant for this study. First, the market for corporate control is barely helpful in aligning the interests of managers and shareholders in the Netherlands. Adoption of anti-takeover mechanisms is a rule rather than an exception and hostile takeovers are rare (Kabir et al. 1997). Second, shareholder legal protection is relatively low in the Netherlands (La Porta et al. 2000), which reduces the likelihood that small shareholders are using their voting rights. Third, like in most countries, large shareholdings are common in the Netherlands. Ownership is more concentrated than in the U.S. (Kabir et al. 1997). Shleifer and Vishny (1997) argue that ownership concentration might be a substitute for weak legal 


\section{Chapter 4}

protection. ${ }^{3}$ Fourth, next to concentrated ownership, the supervisory board fulfills an important governance role (Kabir et al. 1997, Van Ees et al. 2003). Corporations in the Netherlands generally have a two-tier board system with a managing board consisting of inside directors (top management) and a supervisory board consisting of outside directors. ${ }^{4}$ Although the supervisory board does not specifically represent the shareholders, employees or any other group of stakeholders, it must act in accordance with the best interests of the corporation (Douma 1997, Maassen and Bosch 1999). This objective seems well in line with enlightened value maximization and enlightened stakeholder theory as defined by Jensen (2001). The basic idea is that long-term market value of an organization cannot be maximized if important stakeholders are ignored or mistreated. Fifth, Moerland (1995) characterizes the corporate system in the Netherlands - and most countries of continental Europe - as relatively networkoriented. In a network-oriented system, tight direct control mechanisms are at work through the interference of strategic partners, who often combine a number of functions like supply of equity capital and board representation (Moerland 1995). The intricate networking ties in the Dutch corporate governance system also manifest in the fact that a large majority of supervisory board members hold positions at boards in other firms (Van Ees et al. 2003). As argued before, such networking facilitates access to resources that can help diminish uncertainty for firms (Pfeffer 1972).

FWCURE 1

Predictive Vallidity Model

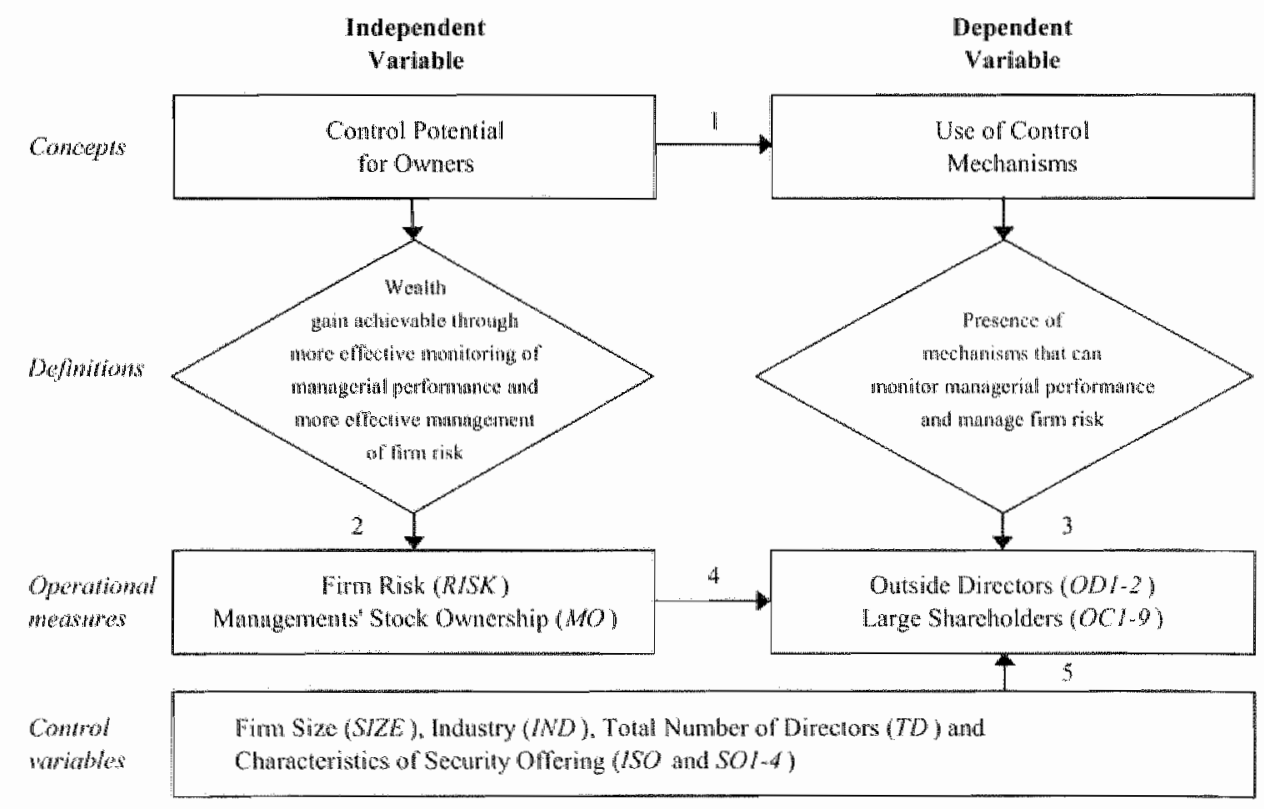

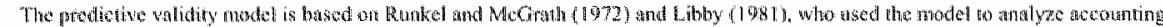
mownd questions. 
The Relationship between Risk and Control

\subsection{Hypotheses}

I organize the development of the hypotheses around a "Predictive Validity Model" that is displayed in Figure 1. The model summarizes the conceptual relationships between independent and dependent variables, as well as their operational measures and treatment of other influential factors.

Link I - The underlying proposition that I examine is that a firm's control potential plays a vital role in explaining the choice by owners to strengthen control mechanisms in a way that is consistent with shareholder value maximizing behavior. The underlying cause (control potential for owners) and effect (use of control mechanisms) are the two theoretical constructs examined. Both are defined conceptually and are not directly observable. Following Demsetz and Lehn (1985), I define control potential as the combined wealth gain for owners that is achievable trough more effective monitoring of managerial performance and more effective management of firm risk by or on behalf of owners. Use of control mechanisms is defined as the presence of mechanisms that can monitor managerial performance and provide resources to manage firm risk. ${ }^{6}$

Link 2 - At the operational level, I seek to investigate two firm-specific characteristics that shape a firm's control potential: firm risk and managements' equity ownership. The riskier a firm's environment, the greater the payoff for owners of more effective risk management and monitoring of managerial performance (Demsetz and Lehn 1985). Monitoring of managerial performance is also more appropriate when shareholders' and managements' incentives are only weakly aligned. The degree of the incentive problem has traditionally been defined, in part, by the level of managements' equity ownership (Jensen and Meckling 1976, Jensen and Murphy 1990a). Section 5 further details the operational measures firm risk (RISK) and managements' equity ownership ( $M O$ ).

Link 3 - Two control mechanisms are examined that monitor managerial performance and provide resources to the firm to manage risk: outside directors (Pfeffer 1972, Pfeffer and Salancik 1978, Fama 1980, Fama and Jensen 1983, Hillman and Dalziel 2003) and large shareholders (Demsetz and Lehn 1985, Huddart 1993). Section 5 further details the operational measures of the level of control by outside directors $(O D I-2)$ and large shareholders $(O C I-9)$.

Link 4 -Following the hypothesized relationship between the theoretical constructs and the operationalization of these constructs, I hypothesize the following associations between the operational measures of independent and dependent variables:

$\mathrm{H}_{\mathrm{a}}$ : Ceteris paribus, the higher a firm's control potential, as measured by firm risk, the higher the level of control by outside directors.

$\mathrm{H}_{\mathrm{ib}}$ : Ceteris paribus, the higher a firm's control potential, as measured by firm risk, the higher the level of control by large shareholders. 
$\mathrm{H}_{2}$ : Ceteris paribus, the lower a firm's control potential, as measured by managements' equity ownership, the lower the level of control by autside directors.

$\mathrm{H}_{2 b}$ : Ceteris paribus, the lower a firm's control potential, as measured by managements' equity ownership, the lower the level of control by large shareholders.

\subsection{Data}

The sample consists of 90 Dutch firms that issued securities on the Amsterdam Stock Exchange in the period from 1997 to $2000 .^{7}$ More specifically, the sample includes 49 $(54 \%)$ initial public offerings (IPOs) of common stock, $31(34 \%)$ seasoned offerings of common stock and/or convertible bonds, and $10(11 \%)$ stock offerings relating to a merger or demerger (see also Table 1). As pointed out before, studying firms that sell their stock to the general investing public for the first time in addition to studying larger, more established firms has several advantages.

Various data sources were combined for this study. Most data on the dependent and independent variables were obtained from the prospectuses that firms must provide when they issue securities. A prospectus details a firm's risk profile, ownership structure and board composition, along with other information relevant to prospective investors. Additional ownership data were retrieved from a public database of the Dutch exchange supervisor 'Autoriteit Financiële Markten'. Data were further obtained from firms' annual reports and the commercial databases 'DATASTREAM', 'REACH' and "Het Financieel Economisch Lexicon".

\subsection{Variable definitions and model specification}

\subsubsection{Measures of control by outside directors (OD1-2)}

In prior research on one-tier board systems, the level of monitoring by outside directors is typically measured as the proportion of outside and inside directors serving on the board (Ellstrand, Tihanyi and Johnson 2002). Outside directors are defined as non-management directors not otherwise affiliated with the firm and inside directors are defined as management directors or directors with close ties to the firm, e.g. the former CEO and family of management directors (Hermalin and Weisbach 1998). For directors with close ties to the firm, some studies also define an intermediate category called 'gray" or 'affiliated' directors.

I use two measures for the level of control by outside directors: (1) the total number of outside directors (i.e. number of supervisory board members) (ODI); and (2) the percentage of outside directors to total directors (OD2). So-called "affiliated' directors are excluded from these measures. ${ }^{8}$

If supervisory boards are determined optimally, the size of the supervisory board $(O D I)$ balances the costs and benefits of additional supervisory directors. While marginal directors bring in additional resources and monitoring, too large supervisory 
The Relationship between Risk and Control

boards are possibly hampered by complexily and free riding of directors. As a result they may become an ineffective control mechanism. For one=tier boards, Yermack (1996) shows thet performance, measured by Tobin's $\mathrm{Q}$ and operating ratios, is indeed decreasing in proportion to the size of the board. Although this study appears to reveal a clear relationship, it raises the important issue of whether an equilibrium or an outof-equilibrium phenomenon is being estimated (Hermalin and Weisbach 2003). If supervisory board size is chosen optimally, any cross-sectional variation in its use reflects differences in firms" underlying environments. If these differences are controlled for, there should be no cross-sectional relation between the extent to which these mechanisms are used and firm performance (Agrawal and Knoeber 1996). Apart for that, the median board size in Yermack's sample is 12 and firms with a board size of less than 7 have the highest levels of $Q$. While I do find supervisory boards as large as 10 , the median board size of the firms in the sample is 4 and the vast majority $(83 \%)$ has less than 7 members.

Although $O D 2$ resembles the regular measure for the level of monitoring by outside directors in prior research on one-tier board systems, it may seem at odds with the formal separation of managing and supervisory board's duties in the Dutch two-tier system. I use this measure nevertheless because of the reality of supervisory board's meetings, where most of their monitoring activities take place. According to Douma (1997) and Maassen and Bosch (1999), these meetings are generally held in the presence of all members of the managing board. This is simply necessary for the supervisory board to adequately perform their duties: raising critical questions to the chairman and other members of the managing board to evaluate their judgment and suitability. ${ }^{9}$ Supervisory boards usually meet only once a year in the absence of the members of the managing board to decide on the composition of the managing board and to set compensation. ${ }^{10}$

\subsubsection{Measures of control by large shareholders (OC1-9)}

Large shareholders are defined as equity holdings by non-insiders of more than $5 \%$." The level of control by large shareholders is measured in three ways. First, I calculate the percentage of ownership by all large shareholders after the issue of securities by adding up the percentages of equity ownership greater than $5 \%(O C /)$. Second, I calculate a Herfindahl measure of ownership concentration by summing squared percentages of equity ownership greater than $5 \%$. Next, a $\log$ transformation is applied to this Herfindahl measure of ownership concentration $(O C 2)$. The third measure is a large shareholder dummy variable that is 1 if at least one shareholder owns more tham $5 \%$ of equity and 0 otherwise $(O C 3)$. Because the level of control by large shareholders may differ per type of owner, $O C 1-O C 3$ are calculated separately for large institutional shareholders, defined as venture capital firms, banks, insurance companies and pension funds $(O C 4-\sigma)$, and large non-institutional shareholders, defined as other companies and individual investors $(O C 7-9)$. 
4.5.3 Combined measure of control by outside directors and large shareholders (COM1-2)

As was argued in previous sections, both outside directors and large shareholders are control mechanisms that can monitor managerial performance and provide resources to the firm to manage risk. Hence, $O D I-2$ and $O C l-3$ are considered operational measures of the same theoretical construct. In addition to examining each control mechanism separately, an alternative approach is to consolidate these operational measures of control by outside directors and large shareholders.

Using exploratory factor analysis, I combine $O D I$ and $O C 2$ into a single measure COMI. The two variables load positively $(.76)$ on one factor that extracts $58 \%$ of total variance and has an eigenvalue greater than 1 . Similarly, $O D 2$ and $O C 2$ are combined into COM2. These two variables also load positively (.77) on one factor that extracts $60 \%$ of total variance and has an eigenvalue greater than 1 .

\subsubsection{Measure of managements' equity ownership (MO)}

As Jensen and Murphy (1990b) explain, direct ownership of shares by the CEO is probably the most powerful link between shareholder wealth and executive wealth. Jensen and Murphy note that one can look at management stock ownership from several perspectives, e.g. the dollar value of the holdings or the value of the shares as a percentage of annual cash compensation. However, what really matters when trying to understand the incentive consequences of stock ownership is the percentage of the company's outstanding shares that top management owns (Jensen and Murphy 1990b). By holding a meaningful percentage of total equity, top management experiences a direct and powerful 'feedback' effect from changes in market value. In the Netherlands, the managing board often functions as a collective. Therefore, the measure of managements' equity ownership (MO) is calculated by dividing the number of shares held by the entire managing board by the total number of shares outstanding after the issue of securities.

\subsubsection{Measure of firm risk (RISK)}

As researchers do not agree about the measurement of risk, multiple measures exist (Slovic 1966, Weber 1988, Hodder, Koonce and McAnally 2001). The proxy for risk in this study is derived from a content analysis of top managements' qualitative assessment of investment. risk in the prospectus. Listing and issuing rules of the Amsterdam Stock Exchange govern the content of the prospectus. A separate section must provide a risk profile. The cover of the prospectus usually explicitly refers to this section as 'certain factors that should be carefully considered by prospective investors'. Considering the risk of legal liability and loss of reputation of issuer, lead manager and other experts, the companies" risk profile in the prospectus likely captures fundamental aspects of inwestment risk. ${ }^{12}$ Although more people may be involved in drafting the risk section, it is treated in this study as a manifestation of perceptions, beliefs, and judgments of top management as a group. 
Compared to traditional measures of risk from accounting and finance (e.g. variance of returns, variance of cash flows, variance of eamings or the covariance of retums with the market), investigating managements" perception of investment risk has several advantages. First, perceived investment risk can be neasured ex-amte (before the outcones), rather than an ex-post. Second, the resulting measure better reflects boards' and owners' conceptualization of firm risk and therefore has better face validity. As shown by Lipe (1998), experimental research with individuals shows weak support for variance and covariance as descriptive measures of risk (see also Payne and Braunstein 1971, Slovic and Lichtenstein 1968). As mentioned by Hodder et al. (2001) substantial research in psychology and applied fields shows greater support for risk construed as loss or downside potential (Dreman 1998, March and Shapira 1987, Yates and Stone 1992). Baird and Thomas (1990) surveyed 670 fmancial analysts concerning their definitions of risk. The first four definitions of risk, in order of frequency of mention, were size of loss, probability of loss, variance, and lack of information. Olsen (1997) surveyed 630 portfolio managers about their perception of investment risk. The principal risk attributes appear to be the potential for a below-target return, the potential for a large loss, investor's feeling of control and the level of knowiedge about an investment.

In previous research on IPO firms, the number of risk factors described in the prospectus is a common proxy for ex-amte risk (see for example Feltham, Hughes and Simunic 1991, Beatty and Zajac 1994 and Beatty and Welch 1996). A simple count of these risk factors combines them into one single measure and is comparable to a summated scale. An advantage of this approach is that it does not focus on one particular risk, i.e. isolating specific risks to the exclusion of other possibly interrelated risk factors. However, a disadvantage is that the interrelation between the risk factors is assumed and cannot be tested for. An essential requirement for a composite measure is that the items are unidimensional, meaning that they are strongly associated with each other and represent a single concept (Hattie 1985, McDonald 1981). For a multifaceted concept like risk, this is not a realistic assumption.

Instead of a mere count of the number of risk factors listed in the prospectus, the alternative approach taken in this study is to investigate the attributes of risk described by top management. Data were collected and quantified through a detailed content analysis. The content analysis involved four broad stages that were further described in chapter 3 of this dissertation. The result of the content analysis is an empirically validated measure of firm risk (RISK) ${ }^{13}$ In the period after the issue of securities, RISK is positively associated with the variability of returns (total return risk), the covariance of returns with the market (systematic risk), and average market-adjusted stock returns. 


\subsubsection{Control variables}

Several control variables are included in the model. Because prior research has shown that measures of board composition, ownership concentration, firm risk and management ownership are related to firm size, 1 control for the effect of firm size $(S I Z E)$, defined as the natural logarithm of market value of the firm in million $€$ one month after the issue. The operational variables are also likely affected by the industry in which a firm operates. For this reason, I control for industry effects by including an industry dummy variable (IND) that is 1 if the firm operates in a high-risk industry (defined as information technology, biotechnology or telecommunication), and 0 otherwise. ${ }^{14}$ The measure of firm risk may be influenced by the range of the offering. For this reason $I$ include an international security offering dummy wariable (ISO) that is 1 if the securities were issued to investors at a foreign exchange, and 0 otherwise. Next, I control for the total number of directors (i.e. managing and supervisory board members) (TD) because the total number of supervisory board members may be an artifact of total board size. Four dummy variables are included to control for the type of security offering: SOI, which is 1 for a seasoned offering of common stock, and 0 otherwise; $\mathrm{SO}$, which is 1 for a seasoned offering of both common stock and convertible bonds, and 0 otherwise; $S O 3$, which is 1 for a seasoned offering of convertible bonds, and 0 otherwise; and $\mathrm{SO} 4$, which is 1 for a stock offering relating to a merger or demerger, and 0 otherwise.

\subsubsection{Model specification}

The following regression equations are estimated to test the hypotheses:

$$
\begin{aligned}
\text { ODI-2 }= & a+b_{1} R I S K+b_{2} M O+b_{3} S I Z E+b_{4} I N D+b_{5} I S O+b_{6} T D \\
& +b_{7} S O I+b_{8} S O 2+b_{9} S O 3+b_{10} S O 4+\varepsilon \\
\text { OCI-9 }= & +b_{1} R I S K+b_{2} M O+b_{3} S I Z E+b_{4} I N D+b_{5} I S O \\
& +b_{6} S O I+b_{7} S O 2+b_{8} S O 3+b_{9} S O 4+\varepsilon \\
C O M I-2= & a+b_{1} R I S K+b_{2} M O+b_{3} S I Z E+b_{4} I N D+b_{3} I S O+b_{6} T D \\
& +b_{7} S O I+b_{8} S O 2+b_{9} S O 3+b_{6 \ell} S O 4+\varepsilon
\end{aligned}
$$

where:

$O D 1-2=$ Measures of control by outside directors;

$O C 1-9=$ Measures of control by large shareholders;

COMI-2 = Measures of control by outside directors and large shareholders;

RISK = Firm risk;

$M O=$ Percentage of managements' equity ownership after security issue; 
The Relationship between Risk and Control

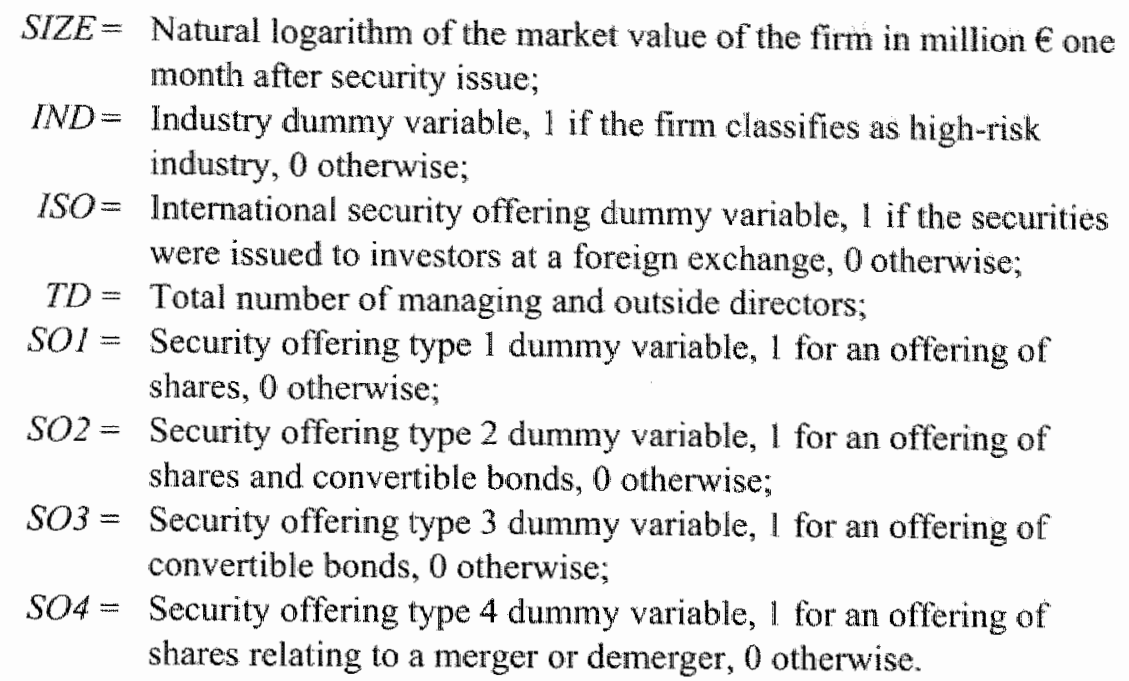

Measures of control by large shareholders $(\mathrm{OCl}-9)$ are intentionally not included in equation 1, and measures of control by outside directors $(O D /-2)$ are intentionally not included in equation 2 . The reason for this is that $O D 1-2$ and $O C 1-9$ are considered operational measures of the same conceptual construct (i.e. control mechanisms that monitor managerial performance and provide resources to manage firm risk). Alternatively, both measures are consolidated into the combined measures COMI-2. ${ }^{15}$

\subsection{Results}

\subsection{Descriptive statistics and univariate tests}

Table I presents the descriptive statistics of the variables in model I to 3. The median firm in the sample has 4 supervisory board members. The minimum number of supervisory board members is 2 and the maximum is 10 . The firms in the sample have on average more outside directors (4.52 supervisory board members) than inside directors (2.93 managing board members), resulting in an average ratio of outside directors to total directors of $61 \%$. The firm in the sample with the lowest ratio of outside directors to total directors (33\%) has 4 managing directors and only 2 supervisory board members. In contrast, the firm in the sample with the highest ratio of outside directors to total directors ( $89 \%$ ) has only 1 managing board member and 8 supervisory board members. 


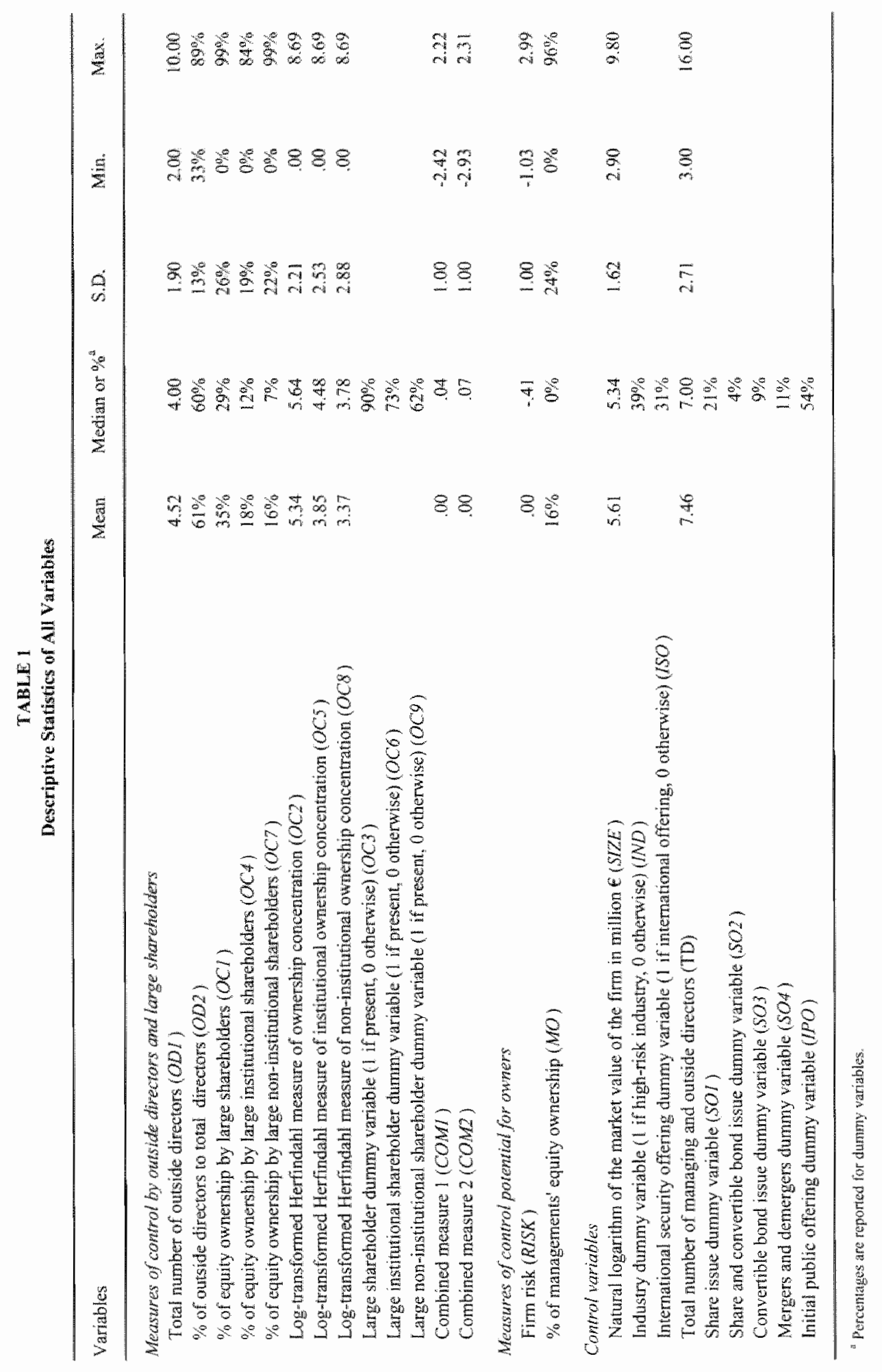


Of the firms in the sample $90 \%$ have at least one large shareholder. Total equity ownership by large shareholders is on average $35 \%$. The median firm in the sample is $29 \%$ owned by large shareholders. Of the firms in the sample, $73 \%$ have at least one large institutional shareholder and $62 \%$ have at least one large non-institutional shareholder. Total equity ownership by large institutional and non-institutional shareholders is on average $18 \%$ and $16 \%$, respectively. Additional non-parametric McNemar and Wilcoxon Signed Rank tests show that equity ownership by institutional and non-institutional shareholders is not significantly different $(p>10)$ for all three measures, including the log-transformed Herfindahl measure. The combined measures of control by outside directors and large shareholders have a mean of 0 and standard deviation of 1 as a result of the statistical procedures used to construct these variables. Managing boards of the firms in the sample own on average $16 \%$ of the shares of their company. However, the median managing board owns less than $1 \%$. Additional Kolmogorov-Smirnov and Shapiro-Wilk tests show that for all variables the assumption about the normality of the distribution can be rejected at conventional probability levels $(p<05)$.

Table 2 presents the correlations among the measures of control by outside directors and large shareholders. ${ }^{16}$ Notably, the percentage of outside directors to total directors $(O D 2)$ is significantly positively correlated with all three measures of noninstitutional ownership concentration $(O C 7, O C 8$ and $O C 9$ ), but not with the measures of institutional ownership concentration ( $O C 4, O C 5$ and $O C 6$ ). The percentage of equity ownership by large institutional shareholders $(O C 4)$ and the Herfindahl measure of institutional ownership concentration $(O C 5)$ are both significantly negatively correlated with the corresponding measures for non-institutional ownership (OC7 and OC 8 ).

Panel A of Table 3 presents the correlations among dependent and independent variables. The correlations provide a univariate test of the hypotheses. As hypothesized, the percentage of managements' equity ownership (MO) is significantly negatively correlated with measures of control by outside directors $(O D /-2)$, large shareholders $(O C 1-9)$ and combined measures (COMI-2). Firm risk (RISK) however is only weakly correlated with the total percentage of equity ownership by large noninstitutional shareholders (OC7) and combined measure 1 (COMI).

Panel B of Table 3 presents the correlations among the explanatory variables. The last column shows that the IPO firms in the sample are considerably different from the other firms in the sample. The IPO firms are more risky, smaller in size and have a significantly higher percentage of managements' equity ownership. 


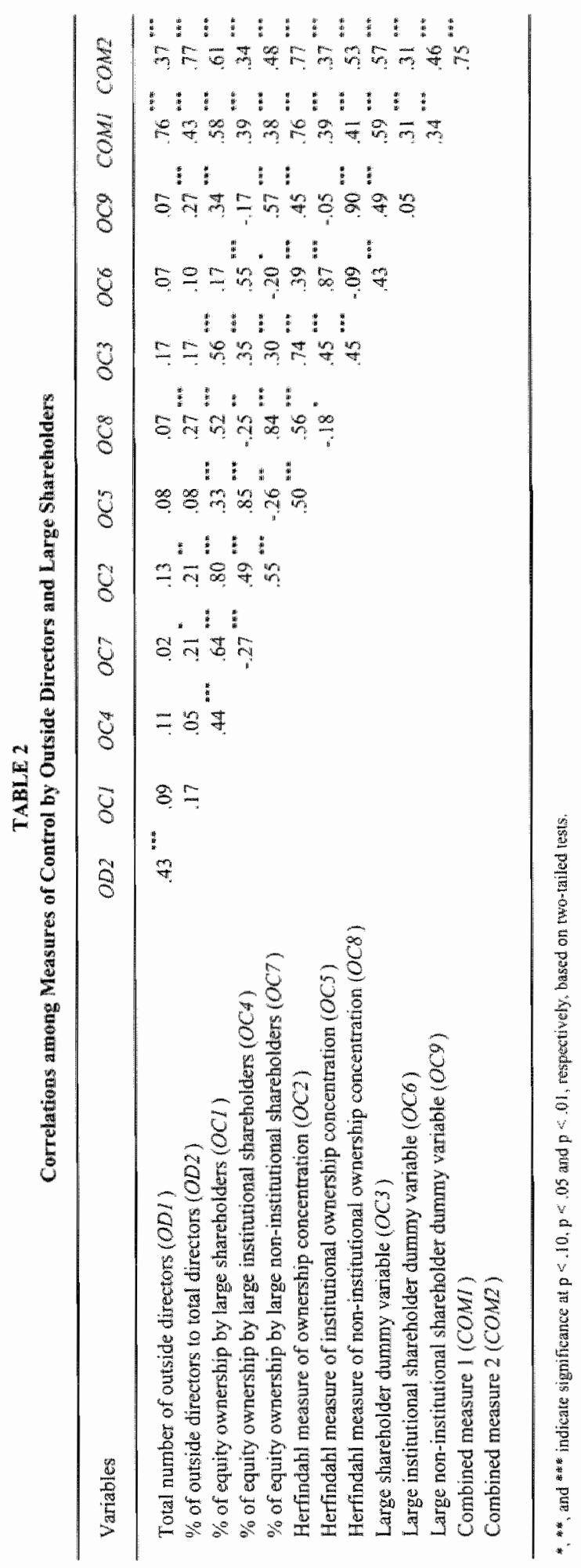




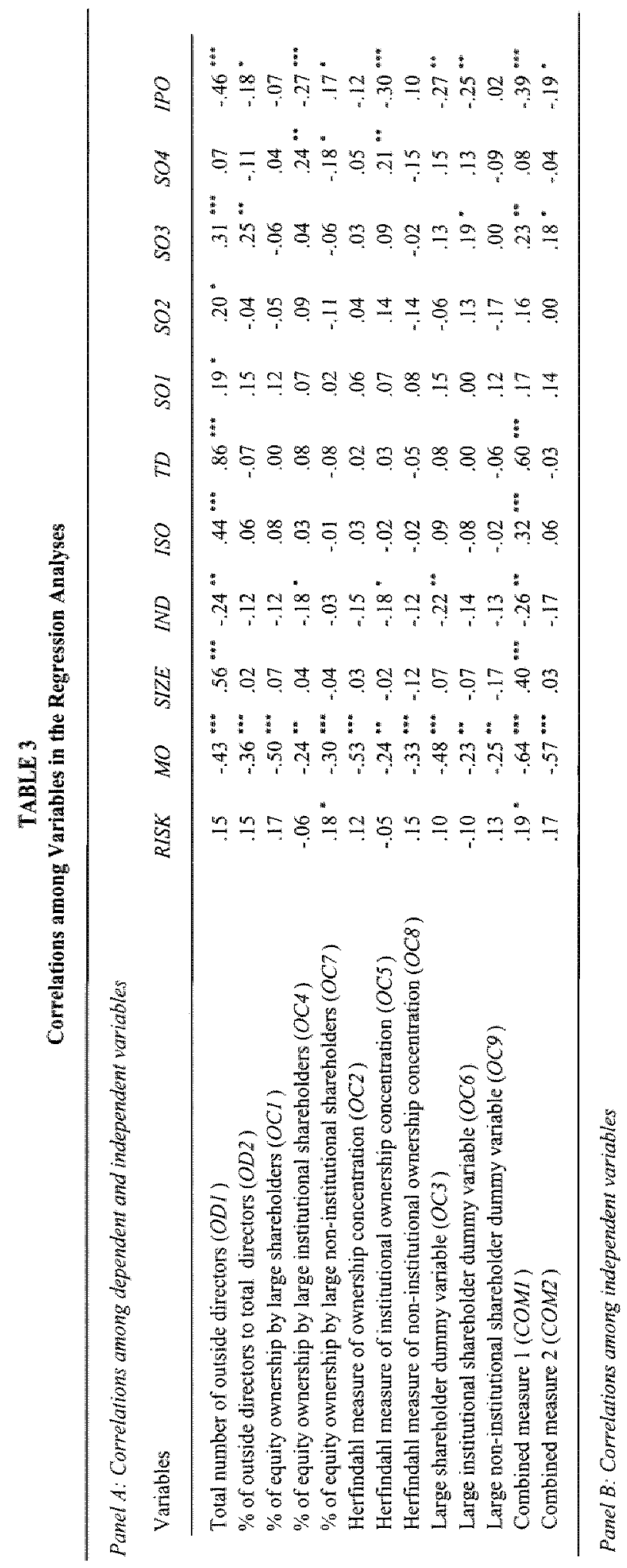

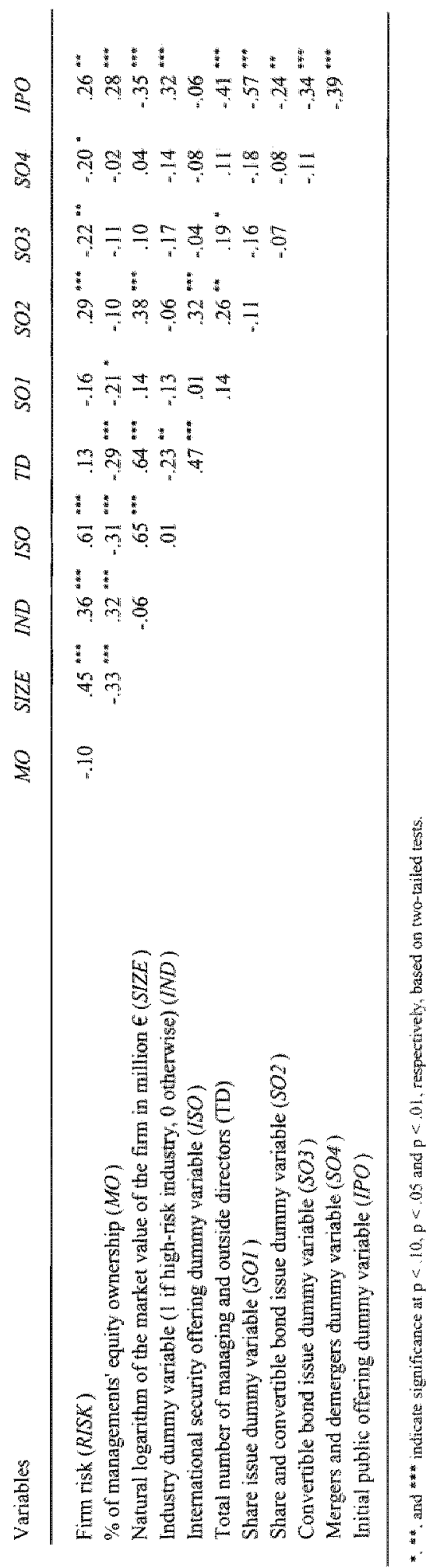




\subsubsection{Multivariate tests}

Logistic regression models were estimated when the dependent variables of interest were dichotomous (i.e, $O C 3, O C 6$ and $O C 9$ ) and an ordered probit model was estimated for $O D 1 .{ }^{17}$ For the other variables ordinary least squares (OLS) regressions were estimated. OLS assumes a linear model with errors terms that are homoscedastic, independent and normally distributed. White's heteroskedasticity test shows no evidence of heteroskedasticity and Jarque-Bera tests for normality indicate that the residuals from the regressions are normally distributed. ${ }^{18}$

Panel A of Table 4 shows the results of the ordered probit, OLS and logistic regressions for the full sample. Given the number of number of control variables, the coefficients for the offering type dummy variables (SOI-4) are not reported.

Considering the significance levels of the LR statistic (reported for the ordered probit regression), F-statistic (reported for the OLS regressions) and Chi-Square statistic (reported for the logistic regressions), the null hypothesis of no statistical association can be rejected for all regressions, except for the regression with $O C 4$ as dependent variable. The adjusted $R^{2}$ (reported for the OLS regressions) and pseudo $R^{2}$ (reported for the ordered probit and logistic regressions) measure the regressions' goodness-of-fit. For the significant regressions, the goodness-of-fit of varies from $11 \%$ to $61 \%$.

Overall, the results show that RISK is significantly positively correlated with $O D I-2$ and $O C l-9(p<.05$ or $p<.01)$. These findings are consistent with hypothesis 1a and hypothesis $1 \mathrm{~b}$. In addition, the results demonstrate that $M O$ is significantly negatively correlated with $O D I-2$ and $O C l-9 \quad(p<.05$ or $p<.01)$. These findings are consistent with hypothesis $2 a$ and hypothesis $2 b$.

Differentiating between type of large sharehoiders, the results show that the measures of control by large non-institutional shareholders $(O C 7-9)$ are significantly positively correlated with $R I S K$ and significantly negatively correlated with $M O$ $(p<05$ or $p<01)$. This finding is consistent with the explanation that non-institutional investors take large stock positions to gain an advantage by maintaining tighter control. In contrast, the measures of control by large institutional shareholders ( $O \mathrm{CA}_{-}$ 6) are only weakly significantly negatively correlated with $M O(p<.10)$ and uncorrelated with RISK. As a result, the goodness-of-fit statistic and significance of the regressions with $O C 4-6$ as dependent variables is lower. The latter finding suggests that exercising control is not an important objective of institutional shareholders and supports the frequently made claim in the public policy debate about their weak monitoring role. ${ }^{19}$

RISK is also significantly positively correlated with COMI-2 $(p<01)$. This finding provides further support for hypothesis $1 \mathrm{a}$ and hypothesis $I b$. In addition, the results show that $M O$ is significantly negatively correlated with $C O M l-2(\mathrm{p}<.01)$. This finding provides further support for hypotheses $2 \mathrm{a}$ and $2 \mathrm{~b}$. 
4.6.3 Separaie multivariate tests of $1 P O$ and non-IPO finns in the sample

As reported in section 6.1 , characteristics of the IPO firms in the sample are considerably different from the other firms in the sample. Moreover, the setting of IPO and non-IPO firms differs to a large extent. Beatty and Zajac (1994) argue that governance relationships become formalized when an organization becomes an open corporation and its stock is openly traded for the first time. Although the models tested so far include dummy variables that control for the type of offering, examining the IPO firns separately may provide a particularly clear test of the hypothesized effects. The reason for this is twofold.

First, board composition and ownership structure are more likely to be chosen optimally at the time of the IPO (Baker and Gompers 2003). Early work on the determinants of board composition by Hermalin and Weisbach (1988) suggests that boards evolve over time depending on the CEO succession process and firm performance. Hermalin and Weisbach found that when a CEO is near retirement, firms tend to add inside directors who may be possible candidates for the next CEO. Just after a CEO change inside directors appear more likely to leave the board. In addition, outside directors are more likely to join the board following poor performance. Results of Denis and Sarin (1999) confirm these findings and show that board composition and ownership structure change over time due to factors like executive turnover, prior stock price performance, and corporate control threats and that these changes are not reversed in subsequent years. Moreover, the findings of Denis and Sarin suggest that changes in board and ownership structure are to minor extent the result of changes in firm-specific determinants. As a result, for the non-IPO firms in the sample, board and ownership structure may be as much a consequence of past performance, top executive changes and corporate control threats as it is determined by firm risk.

Second, firm risk and the explained variables may be jointly determined for the non-IPO firms in the sample. Following the reasoning of Wright et al. (1996) and Ellstrand et al. (2002), board composition and ownership concentration possibly influence the level of risk taking subsequent to the IPO, because owners in an open corporation are more diversified and may favor more risk than managers. As a result, for the non-IPO firms in the sample, firm risk and the explained variables may be jointly determined. Because the single equation techniques used in this study do not take into account this simultaneity, the estimated parameters for firm risk may be biased upward. ${ }^{20}$

Panel B of Table 4 shows the results of the ordered probit, OLS and logistic regressions for the IPO firms in the sample. The significant correlations in the directions hypothesized between RISK and ODI-2,OCl-3,OC7-9 and COMI-2 remain intact. Institutional ownership concentration $(O C 4-6)$ is no longer weakly significantly correlated with $M O$, probably due to the fact that IPO firms in the sample have lower institutional ownership. Except for $O C 3$ and $O C 4-6$, the LR-statistic, Fstatistics and Chi-Square statistics improve remarkably. The adjusted or 'pseudo' $R^{2}$ for $O D 1, O D 2, O C 1, O C 2, O C 7, O C 8, O C 9$ and $C O M /$ increase by $10 \%, 11 \%, 9 \%$, $10 \%, 17 \%, 25 \%, 34 \%$ and $24 \%$, respectively. 


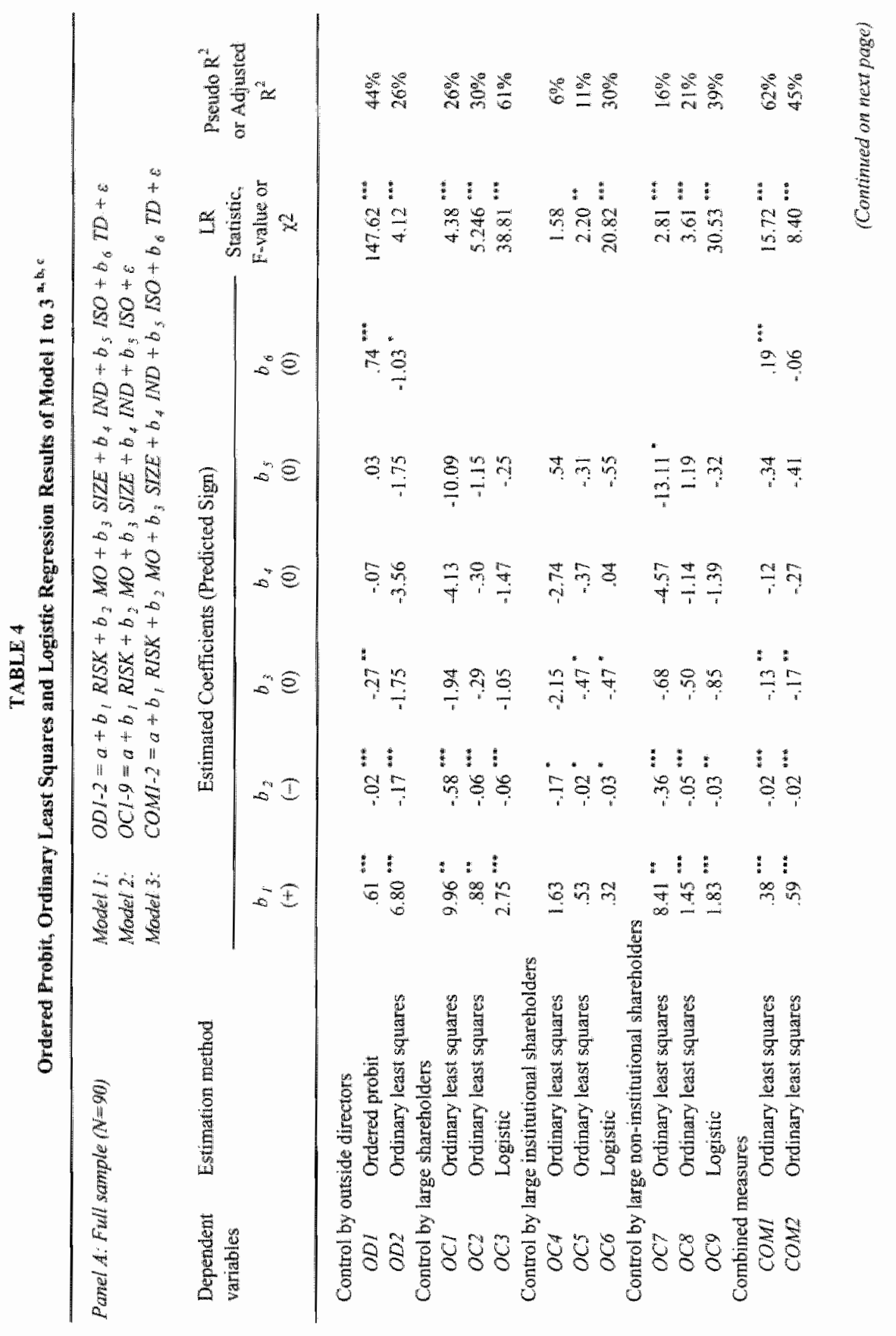




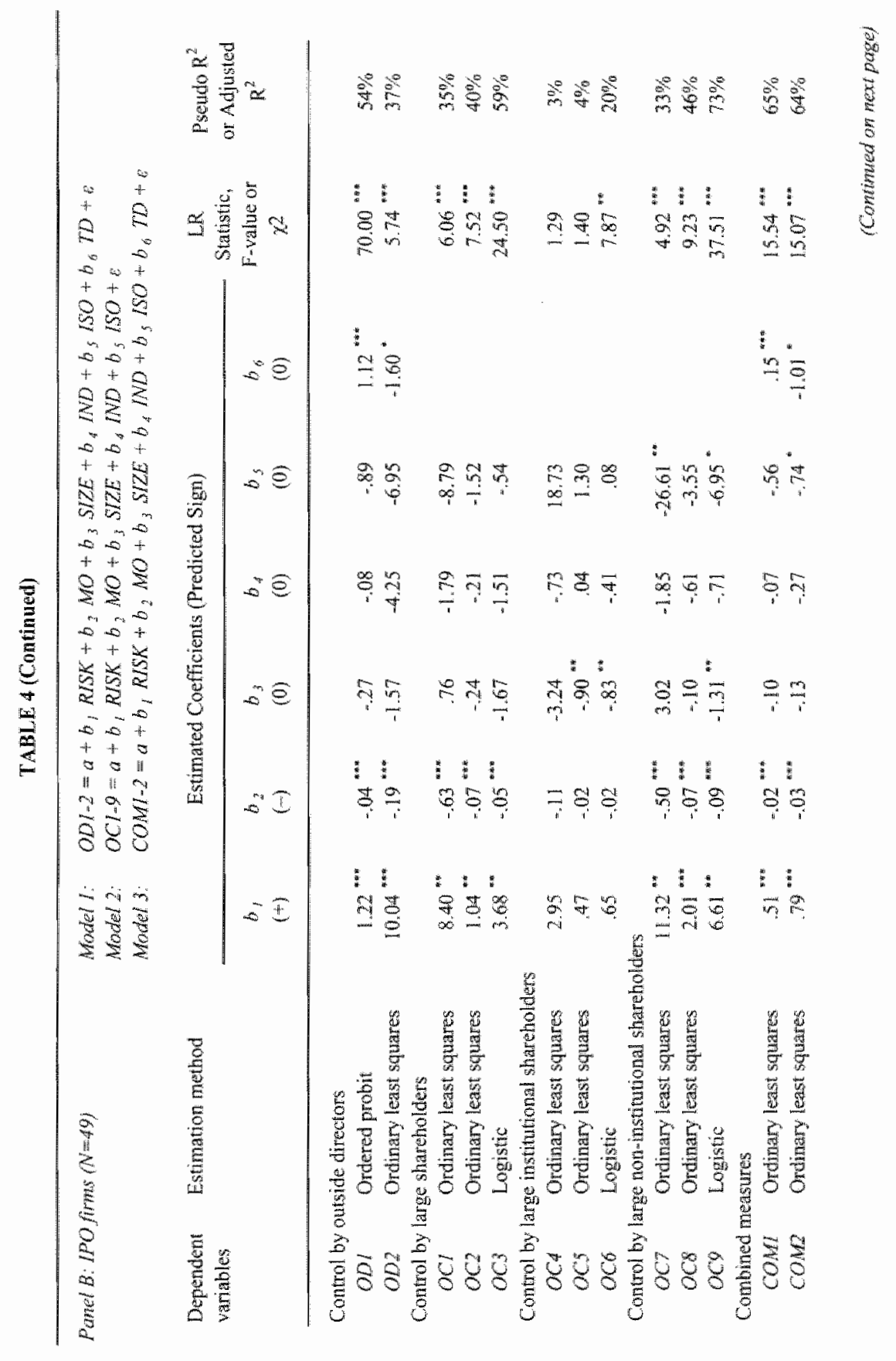




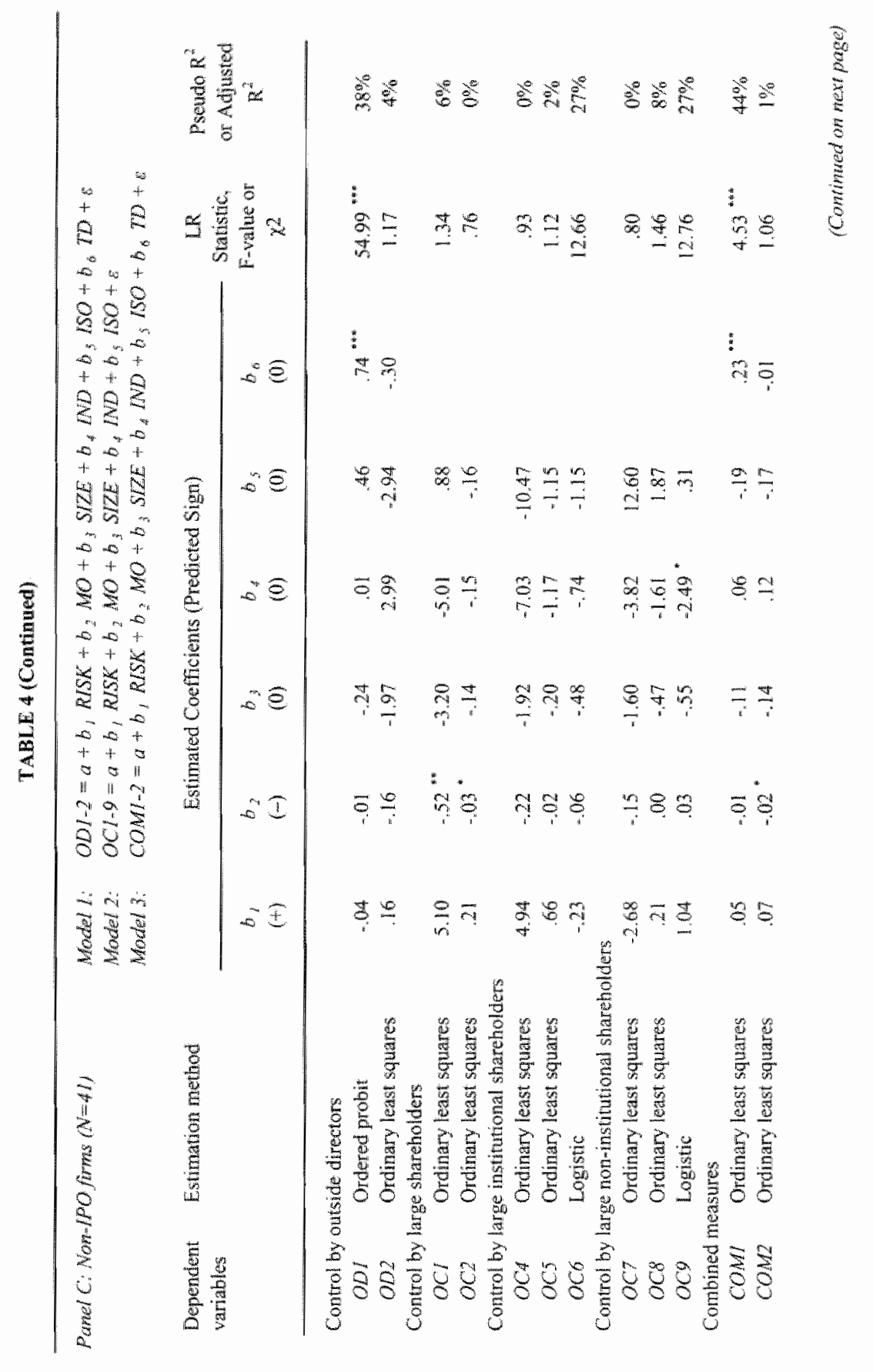




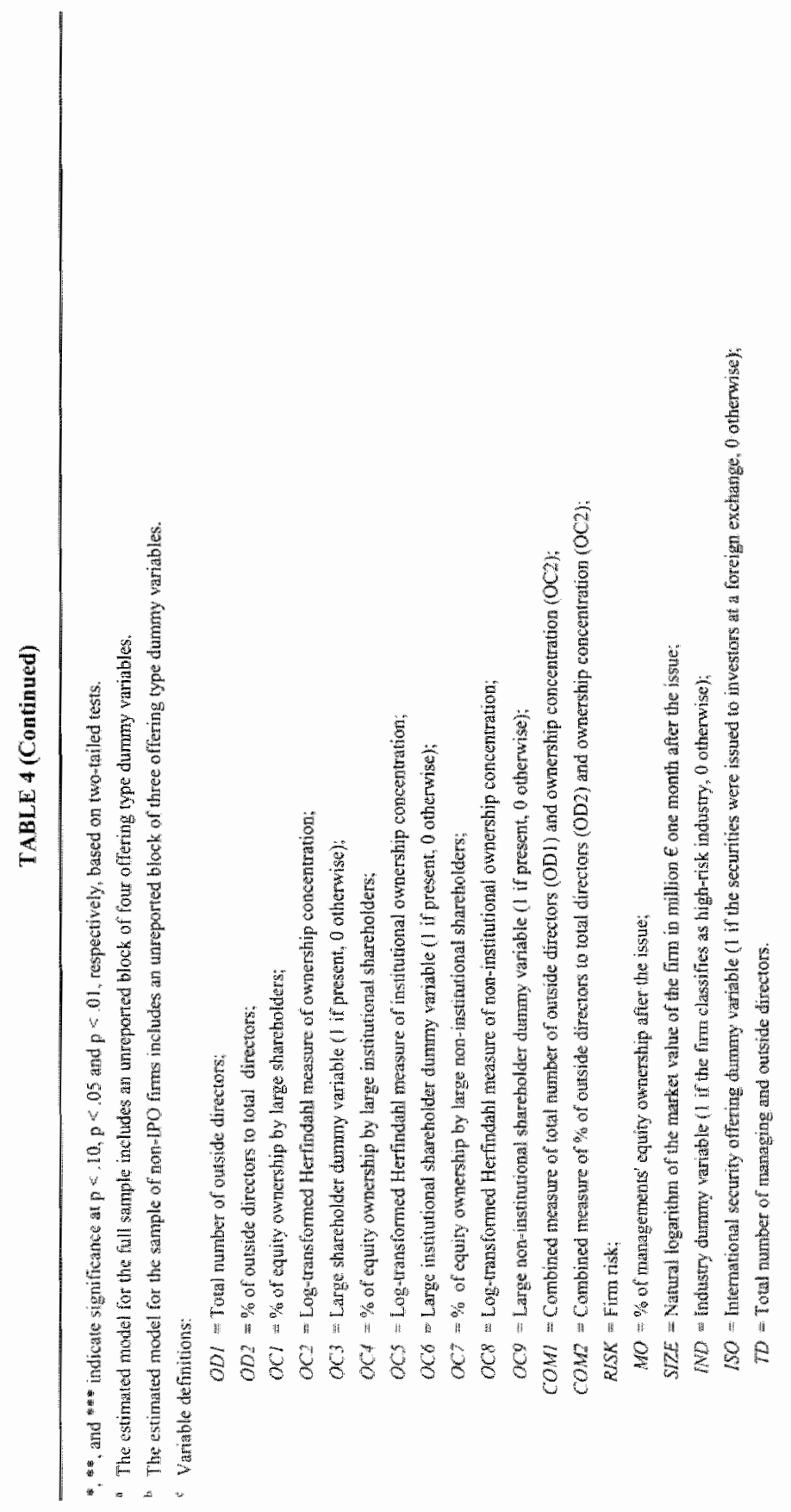


The overall improvement of the regression models' goodness-of-fit is consistent with the idea that board composition and (non-institutional) ownership concentration vary more systematically with firm risk and managerial ownership in ways that are consistent with shareholder value maximizing behavior at the time of the IPO.

Panel $C$ of Table 4 shows the results of the ordered probit, OLS and logistic regressions for the non-IPO firms in the sample. $O C 3$ is excluded here because almost all non- $I P O$ firms have at least one large shareholder. The goodness-of-fit statistics have decreased to a large extent and the null hypothesis of no statistical association can no longer be rejected for most regressions, except for the regressions with $O D 1-2$ and $C O M I$ as dependent variable. The significance of these regressions is due to the correlation with the control variable TD. RISK and $M O$ are no longer significantly correlated with the dependent variables. Although the correlations between $M O$ and $O C l-2$ and between $M O$ and COM2 remain somewhat intact $(p<.05$ or $p<10)$, the regressions are no longer significant.

The findings for non-IPO firms suggest that both board composition and ownership concentration do no longer reflect firm risk and the level of incentive alignment through managerial ownership at the time of a seasoned offering. Potential simultaneity for non-IPO firms in the sample is not a likely explanation for this finding, as this would bias the estimated parameters for firm risk upward. A more likely explanation for this finding is that board composition and ownership concentration have evolved over time due to other factors (like executive turnover, poor performance and corporate control threats) and to less extent due to changes in firm-specific determinants of board composition, like firm risk and managerial ownership.

\subsection{Summary and conclusion}

Supervisory boards consisting of outside directors and large shareholders are integral parts of the corporate governance sitructure of listed Dutch companies. Knowing factors that affect the absolute and relative number of outside directors and ownership concentration hellps in understanding their role in corporate govemance. Besides monitoring of managerial performance, outside clirectors and large shareholders can provide resources to the firm that control firm risk. In order to examine the use of these abilities, this study focused on two factors that possibly influence the presence of outside directors and ownership concentration: firm risk and managerial ownership.

For riskier firms the wealth gain for owners of more effective monitoring and more effective risk management is likely greater. Accordingly, the first hypothesis tested is that the use of mechanisms that have the ability to monitor management and manage firm risk increases with firm risk. To test this prediction, 1 investigated a sample consisting of IPO firms and larger, more established listed firms that issued securities. In this way, I could use a measure of ex-ante firm risk obtained from the prospectus. This measure is more likely to reflect boards' and owners' interpretation and perception of risk that they react to. Moreover, for the IPO firms in the sample, the 
The Relationship between Risk and Control

measure of firm risk is not jointly determined with the number of outside directors and ownership concentration. For IPO firms in the sample, the results of cross-sectional tests confirm the first hypothesis. Controlling for other factors, firm risk is positively associated with the relative and absolute number of outside directors as well as with ownership concentration. Large non-institutional shareholders account for the latter finding. Several explanations were offered for this result, but further analysis of the role of different types of large shareholders represents an interesting area of future research. Firm risk is also positively correlated with a combined measure of board composition and ownership concentration, providing further support for the first hypothesis. For non-IPO firms in the sample however, I find no support for the first hypothesis. This is consistent with the explanation that the number of outside directors and ownership concentration have evolved over time due to other factors.

If managerial ownership corresponds with the level of incentive alignment between management and investors, the wealth gain for owners of more effective monitoring is greater if the managing board owns a smaller fraction of equity. Accordingly, the second hypothesis tested is that the use of mechanisms that have the ability to monitor management decreases with managerial ownership. Again, for IPO firms in the sample, the results of cross-sectional tests confirm the hypothesis. Controlling for other factors, managerial ownership is negatively associated with the relative and absolute number of outside directors as well as with (non-institutional) ownership concentration. Managerial ownership is also negatively correlated with a combined measure of board composition and ownership concentration, providing further support for the second hypothesis. ${ }^{21}$ For non-IPO firms in the sample, I find very weak to no support for the second hypothesis, particularly with respect to board composition. This is again consistent with the explanation that the number of outside directors and ownership concentration have evolved over time due to other factors. Although negative correlations between managerial ownership and the explained variables that were found for the IPO firms have been reported by a number of studies, the findings here must be interpreted cautiously. The reason for this is that the relationship between the explanatory variable (management ownership) and the explained variables is possibly reciprocal. Because the reverse effect is expectedly negative as well, the estimates of the single equation techniques used here are to some degree biased in favor of the hypothesized effect. This makes it difficult to interpret the strong negative correlations for managerial ownership for the IPO firms in the sample.

The current study can be extended in several ways. First, an attempt could be made to solve the problem of simultaneity of the explanatory and explained variables. An econometric solution would be to use multiple equation estimation techniques that rely on exogenous instruments. Unfortunately, such instrumental variables are very difficult to identify. Another problem with this econometric approach is that the explanatory power from the regressions is frequently quite low, which also produces a variety of undesirable econometric properties (Bound, Jaeger and Bakers 1995). 
A second extension of the current study would be to focus on the IPO firms in the sample. As was argued, the measures of control by outside directors and large shareholders are formalized at the time of the $\mathrm{PO}$ and have not yet evolved over time. Future research could investigate how these control mechanisms evolve over time due to the factors reported by Denis and Sarin (1999) and changes in firm risk and management ownership. ${ }^{22}$ Studying how the control mechanisms evolve over time would also enable a closer examination of the relationship between the two mechanisms. It would for example be interesting to see if changes in one of these mechanisms lead to subsequent changes in the other. Future research focusing on the IPO firms could also attempt to advance the empirical measurement of control by outside directors at the time of the IPO, possibly differentiating between the monitoring and risk management ability of outside directors. Certain attributes of outside directors may directly reflect the hazards to which a firm and its constituencies are exposed. For example, if a firm's ability to commercialize its products depends upon its compliance with government regulations, it is perhaps more likely to appoint a (former) politician as a member of the supervisory board. Similarly, a firm that is vitally dependent on the success of its research and development activities may be more likely to hire a renowned professor in the field of engineering as a supervisory director. $^{23}$ Using managers' own detailed descriptions of firms' hazards in prospectuses, empirical analyses can be performed cross-sectionally at the time of the IPO. 
The Relationship between Risk and Control

\section{Endnotes}

'Evidence on post-iPO venture capital holdings is presented by Barty, Muscarella, Peavy and Vetsuypens (1990).

${ }^{2}$ The most obvious cost of concentrated ownership is that concentrated owners bear excessive firmspecific risk that could be born at lower cost by well-diversified shareholders. The fact that ownership in firms is often concentrated however suggests that the benefits of exercising control may outweigh the potential gains of diversification (Demsetz and Lehn 1985 , Schleiter and Vishny 1997). Moreover, large shareholders are not necessarily undiversified. Banks, insurarace companies and pension funds for example have well-diwersified portfolios of assets, both domestically and internationally.

${ }^{3}$ Consistent with the supposed monitoring role of large shareholders, the lindings of Kabir $e t$ al. (1997) suggest that defense measures that limit the power of common shareholders are relatively easily adopted by top management if there are no large shareholders to counteract management's attempts.

4 See Maassen and Bosch (1999) and Peek (2000) for a detailed outline of how formal authorities of supervisory boards (e.g. whether they have the right to appoint and dismiss managing directors, make amendments to the annual financial statements, and reject important decisions) and the way in which the members are appointed and dismissed (either by themselves - called 'controlled co-optation' - or by the general meeting of shareholders) are influenced by different legal regimes in the Netherlands (i.e. structure, mitigated structure, common and exempted regime). In short, the disputed structure regime transfers most control rights from the general meeting of shareholders to the supervisory board. In addition, shareholders have very little influence on the composition of the supervisory boards under the structure regime. Peek (2000) argues that supervisory boards of firms that are subject to the structure regime have relatively more disciplinary power. This view however is not unquestioned as firms can voluntary adopt the structure regime, and allegedly do so to protect management from investor pressure (Van Ees et al. 2003). To test the robustness of the reported results in section 6 for possible influences of different legal regimes on the relationships between dependent and independent operational measures in this study, I added several control variables for different legal regimes to the model presented in section 5. The findings proved robust and lead to identical conclusions for all analyses.

S Networking seems also particularly facilitated by the syslem of alppointment and dismissal of supervisory board members through 'controlled cooptation' (supra note 4). In the Dutch press, the pool of professional supervisory directors is typically - and not always positively - referred to as the "old boys network". The relationship between multiple directorships and monitoring ability of supervisory board members is more ambiguous (apart of course from so-called interlocking directorships, where director A monitors director $B$ at firm $X$ and vice versa at firm $Y$ ). Although better monitors are likely appointed at multiple supervisory boards - perhaps further increasing their monitoring ability by the possibility to compare performance of managing directors across firms - supervisory board members have to allocate their monitoring activities to multiple firms.

"It should be noted that my definition of control is broader than the traditional definition of 'decision control' as derived in Fama and Jensen (1983). From the four steps of a basic decision process in organizations, they combined initiation (step 1) and implementation (step 3) of decisions under the term decision management, and ratification (step 2) and monitoring of decisions (step 4) under the 
lerm decision control. Although the distinction between decision control and decision management has proved very useful for forming hypotheses about relations between risk-bearing and decision processes of organizations, the decigion process from which the convenient definition of decision control is derived laeks the notion wat a conscientious decision-maker considers the potential risks associated with decisions and undertakes steps to manage the perceved risks as best as possible.

"In this period 94 firms were identified to have issued securities. For 90 firms 1 have complete data.

"Not exchuding "affliated" directors does not change the results presented in section 6 and leads to identical conclusions, Maassen and Bosch (1999) interviewed 30 chairmen of supervisory boards in we Netherlands and report that a majority favors the appointment of former managing directors to obtain more detalled information about the company. A minority indicates that the appointment may impede the independent position of the supervisory board.

"Because occasions were decisions made by the managing board are rejected by the supervisory board are rare, evaluating the managing boand seems also the purpose of the supervisory board's formal right to ratify important decisions. By letting the chairman of the managing board explain and defend important decisions, the supervisory board can evaluate him (Douma 1997).

10 Additional operational measures of the extent of monitoring and provision of resources to manage risk by outside directors were considered. Information about the supervisory boards activities (e.g. frequency of boards meetings) and average remuneration per stpervisory director could not be retrieved for a substantial number of firms in the sample. Formation of subconmittees (e.g. audit and remuncration committees), which resembles the practices of one-tier boards, is in a two-tier board system mainly a by-product of the size of the supervisory board (ODI). Fomal authorities of supervisory boards and the way in which the members are appointed and dismissed are complicated by different legall regimes (supva note 4 ). The richness of individual board members' chatacteristics however (e.g. number of links to other organizations) can be further exploited in a subsequent study.

"This percentage corresponds to the upper bound of the lowest percentage range referred to in the Dutch Act on Disclosure of Holdings in Listed Companies. To test the sensitivity of the results, large shareholders were alternatively defined as equity holdings that exceed $10 \%$. This does not affect the results presented in section 6 and leads to identical conchusions.

${ }^{12}$ According to the listing and issuing rules, top management signs a responsibility statement that this information is accurate and that no information necessary for a rasonable investor to make an investment decision, is omitted. The lead manager (an investment bank or stockbroker admitted to the exchange) provides assistance in drafting the prospectus and must conduet a "due diligence" investigation into the accuracy and completeness of the information provided in the prospectus. This investigation is usually perfomed in cooperation with other experts like auditors and legal advisors.

${ }^{13}$ R/SK equals the first risk disclosure score RDSI in chapter 3. The other two risk disclosure scores, RDS2 and RDS3. are not used in this chapter, because the results of the analyses in chapter 3 suggest that disclosure of risk factors represented by these scores contain no additional information about furture equity risk.

14 "To ensure that that board composition and ownership concentration are not simply the result of industry practices or traditions, I also analyzed the effect of including a number of industry dumny variables based on two digit codes of the North American Industry Classification System (NAICS). 
nchuding alternative dummy variables however - both one-by-one and simultaneously - does not influence the results reported in section 6 and leads to identical conclusions.

The underlying assumption of these models is further that RISK and MO are not jointly detemined with the explained variables $O D /-2, O C /-9$ and COM1-2. Violation of this assumption causes sumultaneity problems because the parameters of the single equation estimation techniques that $\mathbb{1}$ use will be biased. Whether or not simulltaneity is a serious problem depends however on the direction of the bias. If the impact of the explanatory variable on the explained variable has the same (expected) sign as the reversed impact, the estimates are biased in favor of the hypothesized effect (Chenhall and Moers 2004). The (potential) problems caused by simultaneity are further discussed in section 6 and 7 .

16 Pearson's correlation coefficients are reported in Table 2 and 3 . Nonparametric neasures of association (Spearman's tho and Kendall's tau) show similar results for both direction and significance of the correlation coefficients.

17 The ordered probit model of Aitchison and Silvey (1957) takes into account the ordinal nature of ODI and makes no assumptions regarding the distribution of the explanatory variables.

18 I also used the Newey and West (1987) covariance matrix estimator instead of the standard OLS formula. The Newey and West (1987) cowariance matrix estimator provides correct estimates of the coefficient covariances in the presence of both heteroskedasticity and autocomrelation of unknown form. This did not affect the results presented in section 6 and leads to identical conclusions. In addition, 1 estimated an ordered probit model of Aitchison and Silvey (1957) for all non-dichotomous variables of interest after ranking the variables. Under a variety of assumptions about the latent error distribution, the results of the ordered probit analyses lead to identical conclusions as the OLS regressions.

tha Institutional shareholders such as banks, insurance companies and pension funds have large portfolios of assets, both domestically as internationally. As a result they may be less able to actively monitor management and provide the company with resources to mitigate risk. In contrast, noninstitutional shareholders (i.e. other companies and individuals) of the frrms in the sample own a substantial amount of shares in only one or two listed Dutch companies. As a result, these owners may be more able to actively monitor top management and provide the company with resources that can help to reduce risk. Furthemore, they may be much more able to provide the firm with resources because they are often active in the same sector and top management frequently refers to them as 'strategic partner' in the prospectus.

20 The bias would be upward because the impact of the explanatory variable (firm risk) on the explained variables (relative and absolute number of outside directors and ownerstip concentrition) has the same expected sign as the reversed impatet.

21 An alternative explanation for the negative correlation between managerial ownership and the relative and absolute number of outside directors for the IPO firms in the sample is that managerial ownership measures bargaining power of the managing board versus (large) shareholders (Baker and Compers 2003, Hermalin and Weisbach 2003y. If the managing board has more bargaining power, it might use its influence to decrease the level of monitoring by the supervisory board.

22. The measure of firm risk employed in this study can not be used for such analyses however, as it call only be obtained when companies issue additional securities. 


\section{Chapter 4}

${ }^{23}$ Other possible attributes of outside directors that can be investigated include the number of links to other organizations and the nature of these organizations (e.g. important suppliers or strategic partners). 


\section{Summary and Conclusion}

\subsection{Introduction}

This dissertation brought together three empirical accounting studies on particular topics related to business risk and control. More specifically, the first study focused on voluntary reporting on internal control by publicly listed firms. The second study dealt with qualitative risk disclosures in offering prospectuses that are published when firms issue new securities to investors. The third study examined the relationship between business risk and two important sources of control: the supervisory board and large shareholders.

This final chapter summarizes the purpose, design and empiricall results of the three studies. In addition, the chapter draws attention to some limitations of the studies. Finally, the chapter discusses conclusions, implications and directions for future research.

\subsection{Summary}

\subsubsection{Voluntary reporting on internal control}

The aim of the first study was to examine the contracting role of voluntary reporting on internal control by company management. For this purpose, I developed the argument that voluntary reporting on internal control is a monitoring mechanism that mitigates the efficiency loss of agency problems. Agency theory predicts that if voluntary reporting on internal control is a monitoring mechanism, company management will voluntarily report more (less) on internal control if agency problems are higher (lower). The sample consisted of Dutch companies listed on the Amsterdam Stock Exchange during the period 1997 to 1999. A disclosure index (ICRS) measured the extent of voluntary reporting on internal control.

Overall, the results corresponded with the explanation that voluntary reporting on internal control is a monitoring mechanism. The main results showed that ICRS is systematically associated with company characteristics that proxy for agency problems in the direction hypothesized, while control ling for the degree of foreign operations, industry classification, the quality of the indlependent auditor, the level of monitoring by outside directors and foreign stock exchange listing. More specifically, the disclosure score ICRS was found to be negatively associated with management's equity ownership (hypothesis 1). ICRS was also found to be negatively associated with the percentage of shares held by large investors (hypothesis 2). Except for 1997, ICRS was found to be positively associated with leverage (hypothesis 3). In addition, ICRS was consistently higher for larger companies (hypothesis 4) and companies listed at the London Stock Exchange. 
Further sensitivity tests indicated that two items in the disclosure index accounted for the main results. The results suggested that disclosures of activities to manage risk (item 6) and reporting the fact that the supervisory board discussed the internal control system in their meetings (item 1) are consciously reported for monitoring purposes. Moreover, the influence of item 1 on the results seems to have decreased and the influence of item 6 seems to have increased during the period 1997 to 1999. On the other hand, relatively infrequent disclosures about the purpose of internal controls (item 2), managements' responsibilities for the system (item 3), the effectiveness of internal controls (item 4) and the role of the internal auditor (item 5) are only weakly associated with company characteristics that proxy for agency problems, suggesting that these items are to lesser extent reported for monitoring purposes (on average). One possible explanation for the latter finding is that several managers in the sample were not familiar with the international public policy recommendations that lie behind reporting on these items. Another possible explanation is that the average manager in the sample had too many doubts about reporting on these items for monitoring purposes.

\subsubsection{Qualitative risk disclosures}

The aim of the second study was to examine the decision-making role of managers" forward-looking qualitative risk disclosures when their firms issue new securities to investors. Through a detailed content analysis of the risk sections in offering prospectuses, I investigated what kinds of risk are disclosed and whether the disclosures are associated with stock market values. The main analyses focused on variability of stock returns, market-adjusted stock returns and exceptionally low levels of stock prices. The research design involved four stages: (1) developing an appropriate coding scheme for the risk factors in the risk sections of the prospectuses; (2) coding the texts of the risk sections; (3) creating composite measures of risk disclosure from the collected data; and (4) correlating the composite measures of risk disclosure with measures of stock market risk, controlling for several other factors. The sample consisted of 90 prospectuses of Dutch companies that issued securities on the Amsterdam Stock Exchange in the period 1997 to 2000 . Public equity markets in this period seemed willing to invest in extremely risky businesses and listing and issuing rules allowed management considerable latitude in the nature, degree and form of their risk disclosures.

The content analysis revealed that management mostly assigns the label 'risk' to factors - either inside or outside the firm - that could adversely impact future firm performance. In addition, management describes risk as loss or probability of loss, variance, lack of information, and lack of control by small investors. The findings of subsequent empirical tests were uniformly supportive of the view that forward-looking qualitative risk disclosures are a useful source of information about equity risk. First, the risk disclosures were positively associated with the variability of returns (total return risk) and the covariance of returns with the market (systematic risk) in the period after disclosure. Second, the risk disclosures were positively associated with 
average market-adjusted stock returns in the period after disclosure, which is consistent with the view that the market judges firms with more extensive risk disclosures to be riskier, and penalizes them with a higher cost of capital. Third, the risk disclosures were positively associated with extreme declines in stock prices in the period after disclosure, suggesting that the risk disclosures warn investors for possible seriously negative outcomes.

\subsubsection{Relationship between business risk and control}

The aim of the third study was to provide cross-sectional tests of the prediction that board composition and ownership concentration vary systematically with firm risk and managerial ownership in ways that are consistent with shareholder value maximizing behavior. Supervisory boards consisting of outside directors and large shareholders are integral parts of the governance structure of listed Dutch companies. Knowing factors that affect the absolute and relative number of outside directors and ownership concentration helps in understanding their role in corporate governance. Besides monitoring of managerial performance, outside directors and large shareholders can provide resources to the firm that help to control business risk. The payoff for owners of more effective monitoring of managerial performance and better risk management is greater for riskier firms. Monitoring of managerial performance is also more appropriate when shareholders' and managers' incentives are weakly aligned. The degree of the incentive problem has traditionally been defined, in part, by the level of management's equity ownership. For this reason, 1 developed and tested the hypothesis that business risk and managerial ownership play a significant role in explaining choices by managers and owners to strengthen control by outside directors and large shareholders. The sample consisted of Dutch corporations that issued securities - either an initial public offering (IPO) or a seasoned offering - at the Amsterdam Stock Exchange in the period 1997 to 2000.

The results showed that directly after an IPO, riskier firms and firms whose managing boards own less equity, employ significantly more outside directors and have a more concentrated ownership structure. Further analyses revealed that large non-institutional shareholders account for the latter finding. These results are consistent with the explanation that a firm's control potential, as measured by firm risk and top management's equity ownership, affects the adoption of control mechanisms in a way that is consistent with shareholder value maximizing behavior. For firms in the sample with a seasoned offering, no or considerably weaker associations are found. A possible explanation for this finding is that board and ownership structure are chosen more optimally in response to firm risk and managerial ownership at the time of the IPO and evolve over time due to other factors.

\subsection{Limitations}

The three empirical studies in this dissertation are subject to several potential limitations. When interpreting the results, these potential limitations must be kept in mind. 


\subsubsection{Limitations pertaining to the content analysis}

A substantial part of the data that is analyzed in this dissertation was obtained by content analysis of written communications. The use of content analysis to gather data has advantages and disadvantages. A main advantage is that it allows assessment of the association between firm characteristics and message content (the first study), in addition to the association between message content and investor responses (the second study). This way, content analysis provided an empirical starting point for generating evidence about the nature and effects of communications about risk and internal control. In addition, content analysis allowed an unobtrusive appraisal of communications about risk. This was particularly valuable for the measurement of risk in the third study, because direct methods of - necessarily ex-post - inquiry of management or investors might have yielded biased responses.

An inherent weakness of content analysis is that the method is susceptible to the effects of researcher bias. To overcome this problem, careful consideration was given to procedures to avoid this potential weakness. To minimize researcher's subjectivity and obtain an objective and systematic quantification of the communications content, precise operational definitions of categories were used and detailed rules and procedures for coding were followed. This likely reduced researcher bias and allows replication by others (a check on researcher bias). In addition, a second, trained, independent coder was employed. This enabled assessment of interjudge reliability, which is largely influenced by the procedural issues mentioned and is often perceived as the standard measure of content analysis quality. The interjudge reliability statistics showed a sufficient degree of consistency between coders applying the same set of categories to the same content. This indicates that the quality of the content analysis in terms of objectivity, systemization, and quantification, is acceptable.

\subsubsection{Limitations pertaining to the research strategy}

Following McGrath's (1982) typology of research strategies, the three empirical studies in this dissertation can be classified as field studies that investigate behavior in a natural setting. The studies use a combination of primary data (collected by the researcher using content analysis) and secondary data (collected by a person, agency or organization other than the researcher). According to McGrath, the great strength of this research strategy is realism of context, because it occurs in a real-world setting. This enabled examining phenomena that are very difficult to replicate in the laboratory. Its major disadvantage however lies in its threats to internal and construct validity, because of lack of experimental control over the behavioral variables and use of imprecise operational measures. Specific threats to internal validity and construct validity of the three studies are discussed below.

Without construct validity, no inferences can be legitimately made from the operational measures to the theoretical constructs on which those operational measures are based. To mitigate threats to construct validity, most operational measures used are well-established in prior empirical research. Nevertheless, operational measures are inherently flawed relative to the constructs on which they are based. In addition, 
operational variables are usually measured with some error. Measurement error for example exists for the variable management's equity ownership in the first and third study, because shareholdings smaller than $5 \%$ of total shares are not accounted for. Measurement errors are a problem in the sense that they may lead to incorrectly faling to reject the null-hypothesis (Type II errors). Hence, in the cases were the null hypothesis for management's equity ownership was rejected, measurement error is considered less of a problem. To mitigate the threat of Type II errors for the other operational variables, I just gathered the best possible data.

Low internal validity makes it infeasible to state strong claims about causeeffect relationships between dependent and independent variables. The issue of causality is especially a concern for the regression models in the first and third study. For the second study it is less of a concern, because the purpose of the models tested is essentially to predict the explained variables with the explanatory variables of interest. Besides measurement error, threats to internal validity of the regression models in this dissertation originate from omitted variable bias, sample selection bias and simultaneous causality bias. Each issue is briefly addressed below.

Omitted variable bias arises if an omitted variable is both a determinant of the explained variable and correlated with at least one included explanatory variable. To the extent that omitted variables are only a determinant of the explained variable (and not associated with explanatory variables), no bias occurs and including them would (merely) add additional predictive power to the models. The fact that theory and prior research provided guidance in carefully selecting the variables that are included in the regression models, mitigates the threat of omitted variable bias to a certain extent. If no data was available for an important variable, I used a proxy for this variable. Inevitably however, there will be secondary, omitted variables that may be important within the regression models. In the possible case that explanatory variables are omitted that are associated with both the explained and explanatory variables, this may have led to incorrectly rejecting a null-hypothesis (a Type I error) or incorrectly failing to reject a null-hypothesis (a Type II error).

Sample selection bias may be present if a selection process influenced the availability of data and that process is related to the explained variable. To mitigate this threat, the samples were collected in a way that avoided sample selection bias.

A last threat to the internal validity of the empirical studies in this dissertation is simultaneous causality bias, which arises when one or more of the explanatory variables in the regression models are jointly determined with the explained variable. This especially complicates the interpretation of the results of the third study. I first consider this issue for the firms in the sample with a seasoned offering. Next, I will address it for the IPO firms in the sample. In case of the seasoned offerings in the sample, both the explanatory variables (firm risk and management ownership) may be jointly determined with the explained variables. The impact of the explained variables on the explanatory variables has the same (expected) sign as the hypothesized effect. For this reason, the results are likely biased in favor of the hypothesized effect. The potential bias however did not actually lead to incorrectly rejecting the null- 


\section{Chapter 5}

hypothesis, because I did not find the hypothesized associations. In case of the IPO firm in the sample, one explanatory variable (management's equity ownership) may be jointly deternined with the explained variables. Again, the impact of the explained variable on the explanatory variables has the same expected sign as the hypothesized effect, which creates a possible bias in favor of the hypothesized effect. For the IPO firms in the sample however, I cannot conclude that the potential bias did not actually lead to incorrectly rejecting the null-hypothesis for management's equity ownership, because I do find the hypothesized association. Regrettably, this limitation could not be solved by using instrumental variables regressions, because relevant exogenous instruments that are required for such regressions could not be identified.

Finally, a threat exists to the external validity of the three studies. While the samples of data used are representative of their target populations (i.e. all listed Dutch mon-financial companies in the in the period 1997 to 1999 in the first study and all non-financial Dutch companies that issued securities in the period 1997 to 2000 in the second and third study), generalizing the findings to other populations, settings or time periods is hazardous.

\subsection{Conclusions, implications and directions for future research}

\subsection{Voluntary reporting on internal control}

The agency literature has demonstrated that contracts between managers and investors can reduce the efficiency loss of agency problems, if investors can monitor that contractual agreements are adhered to. Based on the empirical results of the first study, I concluded that woluntary reporting on internal control partly arose as a monitoring mechanism for firms' contracts and is therefore one of the monitoring devices enabling the contracting process to function. This conclusion is consistent with the view that by voluntary reporting on internal control, managers try to convince investors that they strive for a sound internal control system that provides reasonable assurance about the reliability of reported financial accounting information. Assurance about the reliability of financial accounting information is considered useful for investors, because this information plays an important role in defining and monitoring contractual terms. Price protection for investors due to competition in the capital market was offered as an explanation why managers voluntarily make expenditures on reporting on internal control in response to agency problems.

The results also have practical implications. The conclusion that reporting on internal control partly arises as a monitoring mechanism for firms' contracts is relevant to the public policy debate on internal control reporting, because part of this debate has focused on the issue whether reporting on internal control should be voluntary or mandatory. By assuming that information about internal control in annual reports is a public good, proponents of mandatory reporting on internal control have argued that managers "underproduce" information about internal control in the absence of regulation. This reasoning however ignores private contracting incentives or assumes that private contracting costs are higher than the government's direct and indirect costs 
of remedying the alleged underproduction. Empirical evidence on relative costs and benefits of private production of information and governmentally regulated production of information about internal control can inform the discussion. This study has started with examining the relative costs and benefits of private production of information on intemal control. Since the results suggest that private contracting incentives indeed exist, they should not be ignored in the discussion. For example, the best practice provisions of the Tabaksblat Committee (2003) regarding reporting on internal control can be welcomed in light of the results, as the provisions emphasize the importance of transparency regarding internal controls, but allow listed companies to explain in their annual report whether, and if so why and to what extent, they do not apply the best practice provisions (known as the 'comply or explain' principle).

Without further empirical evidence of the relative cost and benefits of governmentally regulated production of information about internal control, it is unclear whether more rigorous regulation will improve economic efficiency. Investigating the relative cost and benefits of governmentally regulated production of information about internal control is therefore an interesting and important topic for future empirical research. Relatively recent certification requirements in the United States, resulting from the Sarbanes-Oxley Act of 2002, provide an excellent opportunity for such research. Especially section 404 of the Sarbanes-Oxley Act mandates extensive changes. Section 404 , in conjunction with the related Security and Exchange Commission rules and Auditing Standard No. 2 established by the Public Company Accounting Oversight Board, requires management of a public company and the company's independent auditor to issue two new reports at the end of every fiscal year. First, management must report annually on the effectiveness of the company's internal control over financial reporting. Second, in combination with the audit of the company's financial statements, the company's independent auditor must issue a report on internal control over financial reporting, which includes both an opinion on management's assessment and an opinion on the effectiveness of the company"s internal contro\ over financial reporting. On top of that, the SarbanesOxley Act requires management to certify to the completeness and accuracy of their financial statements and imposes severe penalties for false certifications. Expectedly, these measures will force managers to become more sensitive and knowledgeable about internal controls and improve the reliability of financial statements. The certification requirements however are also very costly for companies in terms of Jabor and time required for additional internal control documenting and testing that is necessary for management and external auditors to support their assertions and attestations. Beforehand it is questionable whether the internal control certification requirements will strike the right balance of cost and benefits for everyone. Perhaps the government should allow markets to enable individuals and companies to achieve their own balance. Future empirical research can attempt to shed light on this issue. 


\subsubsection{Qualitative risk disclosures}

The empirical results of the second study showed that firms with more extensive forward-looking qualitative risk disclosures had higher total return risk and higher systematic risk in the months after disclosure. In addition, the stock price was more likely to drop below regular levels (like 5 or 1 euro), if the risk disclosures were more extensive. Consequently, I concluded that the disclosures in the risk sections of prospectuses were potentially useful for investors who wanted to assess future equity risk. Furthermore, the empirical results suggested that the market penalized furms with more extensive risk disclosures with a higher cost of capital. Based on the latter finding, I concluded that the risk disclosures were actually used and made a difference in investment decisions, or - at least - accurately summarized and aggregated information about firm risk that was available from other sources. For investors, such aggregate information is allso potentially useful as it helps them to form predictions about the outcomes of future events.

According to the conceptual statements of the United States Financial Accounting Standards Board (FASB 1980), the two primary characteristics that make accounting information useful for decision making are relevance and reliability. To be relevant, information must be timely and must have predictive value or feedback value (or both). To be reliable, information must have representational faithfulness and must be verifiable and neutral. Management's forward-looking qualitative risk disclosures in the prospectuses of the firms in the sample seem to meet several of these criteria. First, the information about risk is available before the outcomes occur and predicts future outcomes. Second, management's description of their firm's exposure to different sorts of risk seems to represent what it purports to represent, i.e. has representational faithfulness. In sum, I concluded that forward-looking qualitative disclosures about a wide range of risks, with a focus on the downside, can aid investors in assessing risk.

This conclusion may provide useful insights for standard setters of risk disclosures, for example in the European Union (EU). The new Prospectus Directive of the European Parliament and of the Council of 4 November 2003 (Directive 2003/71/EC), explicitly states that: "Investment in securities, like any other form of investment, involves risk. Safeguards for the protection of interests of actual and potential investors are required in all Member States in order to enable them to make an informed assessment of such risks and thus to take investment decisions in full knowledge of the facts' (EU 2003, 65). The Prospectus Directive further clearly recognizes the importance of risk disclosures: "Information is a key factor in investor" protection; a summary conveying the essential characteristics of, and risks associated with, the issuer, any guarantor and the securities should be included in the prospectus. To ensure easy access to this information, the summary should be written in nontechnical language' (EU 2003, 66). As a result, the regulations implementing the new Prospectus Directive require 'prominent disclosure of risk factors that are specific to the issuer or its industry in a section headed "Risk Factors"' (EU 2004, 24). The regulations however do not specifically prescribe the types of risk that should be 
discussed in the prospectus and allow managers a large degree of flexibility in expressing their judgment. In the public policy debate about these new regulations, this almost immediately raised the question whether the risk disclosure requirement can be effective. Although flexibility enables management to make disclosures more informative through firm-specific (rather than predetermined) choices, some argue that it also creates the opportunity for manipulation and allows firms to report almost anything (or nothing) without violating the requirements. Based on the empirical results of the second study however, I expect that the new regulations will be effective in the Netherlands and - perhaps - also in other Member States. The reason for this is that the new rules for risk disclosures are in essence similar to existing requirements in the Netherlands. Under the old rules, firms in the sample provided investors with qualitative information about a wide range of - inherently firm or industry specific operating risk. These disclosures were demonstrated to be useful for investors. To see whether this prediction proves correct, future empirical research should assess the effectiveness of the risk disclosures made under the new Prospective Directive in the Member States.

The results of are also relevant for accounting researchers who want to employ an alternative measure of risk. Although risk is a fundamental variable in many areas of accounting research, there is little consensus regarding the meaning and measurement of risk. Most accounting studies use ex-post risk measures derived from accounting and stock market data, seeking to capture the variability of company performance. Common measures are the variance of return on equity or return on assets, and total, systematic and unsystematic risk derived from historical stock returns. Despite the widespread use of these variability measures as risk proxies, substantial behavioral research indicates that such an approach may not reflect managements" and investors' conceptualizations of risk. Prior research suggests that managers and investors conceptualize risk in downside rather than variance terms. In addition, accounting researchers are often fundamentally concerned with managers' and investors' ex-ante decision processes. Ex-post measures may be decidedly different from ex-ante risk assessments. If ex-ante downside risk is more relevant to managerial and investor behavior than ex-post performance variability, empirical accounting research using ex-ante measures of downside risk may provide more consistent and conclusive results than studies using ex-post variability measures of risk. By making replicable and valid inferences from the texts of managers" ex-anie risk assessments in prospectuses, the second study has developed and tested a method to measure ex-ante downside risk. While the resulting measure has satisfactory face validity as suggested by behavioral research, its relative importance in predicting stock returns - especially compared to ex-post market measures of risk - indicates that the measure has promising empirical validity. Replication of this study should demonstrate whether the findings are generalizable to other populations, settings or time periods. 
The findings of the second study are also relevant for managers who want advice about risk disclosure in annual reports. Whereas the current study has established that companies make extensive risk disclosures in prospectuses, managers seem to provide rather less complete information in annual reports. Some proposals for improving risk disclosures have claimed that they should aspire, at a minimum, to maintaining prospectus standards of risk disclosure in their annuat report (e.g. ICAEW 1999). Like most corporate decisions however, the decision to disclose more or different kinds of information in annual reports should be based on a cost-benefit analysis that shows that the benefits outweigh the costs. Conventional wisdom says that among the cost of disclosure are the costs of creating and distributing the information, cost imposed by competitors who exploit the information to the detriment of the disclosing firm, and litigation costs that arise when a firm is sued in connection with a disclosure (Botosan 1997). Theory generally suggests that through reducing information asymmetry between managers and investors, the ultimate benefit of enhanced disclosure (in general) is a lower cost of capital and thus a higher stock price. According to the ICAEW (1999), this is also the ultimate benefit of better risk disclosure. The findings of the second studly however indicate that enhanced risk disclosure may well lead to a higher cost of capital for some firms. For example, if management truthfully discloses that certain factors that the market is uninformed about are severely threatening promised future firm performance, the share price will likely drop, despite the fact that information asymmetry is reduced. This raises interesting questions about the real costs and benefits of risk disclosures in annual reports. One benefit of risk disclosure seems to be avoiding litigation costs, as management is more likely to be sued for not disclosing certain risk factors if performance falls short of expectations, than for being forthright about risks and uncertainties involved. A second and perhaps more important benefit of risk disclosure has been put forward by Fuller and Jensen (2002): risk disclosure can prevent overvaluation of corporate equity. Fuller and Jensen emphasize that overvalued equity, by encouraging overpriced acquisitions and other value-destroying forms of overinvestment, can be as damaging to the long-term health of a company as undervalued equity. Preventing overvaluation requires among others that managers must be clear about risks and uncertainties. While this can cause the share price to fall, the associated pain for management is only slight compared to colluding to unrealistic market expectations, as the latter will eventually lead to massive destruction of corporate value and shortened management careers (Fuller and Jensen 2002). In this light, the ultimate benefit of enhanced risk disclosure for managers and investors would be a more accurate cost of capital rather than a lower cost of capital.

Although the current findings suggest that maintaining prospectus standards of risk disclosure in annual reports - either voluntarily or mandatory - will indeed help investors in making better investment and valuation decisions, future empirical research should further investigate risk disclosures in annual reports. This may shed new light on the role, costs and benefits of risk disclosure in annual reports. Future research should also extend this study by assessing the information value of risk 
Summary and Conclusion

disclosure for various other stakeholders, who likely have differential risk concerns. Finally, there is still little empirical evidence on how (Individual) investors and other stakeholders perceive and react to risk disclosures. As noted by Koonce, McAnally and Mercer (2004), regulators in other domains (e.g., nuclear power, AIDS, and smoking) have found that it is often easier to tailor risk disclosures to users" understanding of risk than it is to re-train individuals to think differently about risk. However, in order to take this approach, managers and regulators must first understand the factors that investors consider when judging risk. For this reason, $\mathbb{l}$ believe that future empirical research on the topic of how risk-relevant information is communicated to and evaluated by investors and other stakeholders of a firm is very useful.

\subsubsection{Relationship between business risk and control}

Prior research suggests that outside directors and large shareholders are important control mechanisms for publicly listed firms, because they can monitor managerial performance and provide resources to the firm to manage risk. Prior research also suggests that firm risk and managements" equity ownership shape a firms" potential for control. The riskier a firm's environment, the greater the payoff for owners of more effective risk management and monitoring of managerial performance. Monitoring of managerial performance is also more appropriate when shareholders' and managements' incentives are only weakly aligned. The degree of the incentive problem has traditionally been defined, in part, by the level of managements' equity ownership. The results of the third study showed that directly after an IPO, riskier firms and firms whose managing boards own less equity, employ significantly more outside directors and have more concentrated (non-institutional) ownership. Based on these results, $I$ concluded that a firm"s control potential, as measured by firm risk and management's equity ownership, plays a vital role in explaining choices by owners to exercise control at the time of the IPO.

The previous section indicated that the study is subject to several potential limitations, which suggests additional research. Future research could first try to remedy the polential simultaneous causality bias. An econometric solution would be to use instrumental variables regressions that rely on relevant exogenous instruments. Unfortunately, such instrumental variables are difficult to identify. Another potential problem with this econometric approach is that the explanatory power from the regressions is frequently quite low, which also produces a variety of undesirable econometric properties (Bound, Jaeger and Bakers 1995). A second extension of the current study would be to focus solely on the IPO firms in the sample, because the measures of control by outside directors and large shareholders are formalized at the time of the IPO and have not yet evolved over time. Future research could also investigate how these control mechanisms evolve over time due to the factors reported by Denis and Sarin (1999) and changes in firm risk and management ownership. Studying how the control mechanisms evolve over time would also enable a closer examination of the relationship between the two mechanisms. 
Future research focusing specifically on IPO firms could also attempt to advance the empirical measurement of control by outside directors at the time of the $I P O$, preferably differentiating between the monitoring and risk management abilities of outside directors. Certain attributes of outside directors may directly reflect the hazards to which a firm and its constituencies are exposed. For example, if a firm's ability to commercialize its products depends upon its compliance with government regulations, the superwisory board is perhaps more likely to appoint a former politician as a member. Similarly, if a firm is vitally dependent on the success of its research and development activities, the supervisory board may be more likely to hire a renowned professor in the field of engineering. To identify the firms' specific hazards, researchers can further exploit the information contained in risk sections of prospectuses. 


\section{References}

Abdel-khalik, A. R. (1993). 'Why do private companies demand auditing? A case for organizational loss of control', Joumal of Accounting. Auditing and Finance, $8(1): 31-52$.

Agrawal, A. and C. R. Knoeber (1996). 'Firm performance and mechanisms to control agency problems between managers and shareholders', Jounal of Financial and Quantitative Analysis, 31(3): 377-397.

Agrawal, A. and G. Mandelker (1987). "Managerial incentives and corporate investment and financing decisions", Journal of Finance, 42(4): 823-837.

Aitchison, J. and S. D. Silvey (1957). 'The generalization of probit analysis to the case of multiple responses", Biometrika, 44: 131-140.

American Institute of Certified Public Accountants (AICPA) Special Committee on Financial Reporting (1994). Improving Business Reporting - A Customer Focus: Meeting the Information Needs of Investors and Creditors. New York, New York, US: AICPA.

American Institute of Certified Public Accountants (AICPA) Special Committee on Enhanced Business Reporting (2004). Enhanced Business Reporting. New York, New York, US: AICPA.

Anderson, D., J. R. Francis and D. J. Stokes (1993). 'Auditing, directorships and the demand for monitoring', Joumal of Accounting and Public Policy, 12(4): 353375 .

Baird, I. S. and H. Thomas (1990). "What is risk anyway?'. In R. A. Bettis and H. Thomas (eds.), Risk, Strategy, and Management. Greenwich, Connecticut, US: JAI Press: $21-52$.

Baker, M. and P. A. Gompers (2003). 'The determinants of board structure at the initial public offering', Joumal of Law and Economics, 46(2); 569-598.

Ball, R. and G. Foster (1982). 'Corporate financial reporting: A methodological review of empirical research', Journal of Accounting Research, 20 (supplement): 161 284.

Barber, B. M. and J. D. Lyon (1997). 'Detecting long-run abnormal stock returns: "The empirical power and specification of test statistics', Joumal of Financial Economics, 43(3): $341-372$.

Barry, C. B., C. J. Muscarella, J. W. Peavy and M. R. Vetsuypens (1990). "The role of venture capital in the creation of public companies', Journal of Financial Economics, 27(2): 447-471

Barth, M. E., W. H. Beaver and W. R. Landsman (2001). "The relevance of the valuerelevance literature for financial accounting standard setting: Another view", Journal of Accounting and Economics, 31(1-3): 77-103.

Bazley, M., P. Brown, H. Y. Izan (1985). 'An analysis of lease disclosures by Australian companies', Abacus, 21(1): 44-62. 
Beatty, R. P. and E. J. Zajac (1994). 'Managerial incentives, monitoring, and risk bearing: A study of executive compensation, ownership, and board structure in initial public offerings", Administrative Science Quarterly, 39(2): 313-335.

Beatty, R. P. and I. Welch (1996). "Issuer expenses and legal liability in initial public offerings'. Journal of Law and Economics, 39(2): 545-601.

Beaver, W. H. (1998). Financial Reporting: An Accounting Revolution. Upper Saddle River, New Jersey, US: Prentice-Hall.

Berle, A. A. and G. C. Means (1932). The Modern Corporation and Private Property. New York, New York, US: Macmillan.

Bernstein, P. L. (1998). 'Stock market risk in a post Keynesian world', Joumal of Post Keynesian Economics, 21(1): 15-24.

Botosan, C. A. (1997). 'Disclosure level and the cost of equity capital', Accounting Review, 72(3): 232-349.

Bound, J. and D. A. Jaeger (1995). "Problems with instrumental variables estimation when the correlation between the instruments and the endogenous explanatory variables is weak', Journal of the American Statistical Association, 90(430) $443-450$.

Bradbury, M. E. (1990). 'The incentives for woluntary audit committee formation', Journal of Accounting and Public Policy, 9(1): 19-36.

Brav $_{*}$ A. and P. A. Gompers (1997). 'Myth or reality? The long-run underperformance of initial public offerings: Evidence from venture and nonventure capitalbacked companies", Journal of Finance, 52(5): 1791-1821.

Cadbury Committee (Committee on the Financial Aspects of Corporate Governance) (1992a). Report of the Committee on the Financial Aspects of Corporate Governance. London, UK: Burgess Science Press.

Cadbury Committee (Committee on the Financial Aspects of Corporate Governance) (1992b). Cade of Best Practice. UK.

Chenhall, R. H. and F. Moers (2004). "The issue of endogeneity within theory-driven, quantitative management accounting research', Working paper, Monash University.

Chow, C. W. (1982). "The demand for external auditing: size, debt and ownership influences', Accounting Review, 57(2): 272-291.

Chow, C. W. and A. Wong-Boren (1987). "Voluntary financial disclosure by Mexican corporations', Accounting Review, 62(3): 533--541.

Cohen Commission (Commission on Auditor's Responsibilities) (1978). Report. Conchusions, and Recommendations. New York, New York, US: AICPA.

Collier, P. (1993). 'Factors affecting the formation of audit committees in major UK listed companies', Accounting and Business Research, 23(91A): $421-430$.

Collier, P. and A. Gregory (1999). 'Audit committee activity and agency costs', Jounal of Accounting and Public Policy, 18(4-5):31.1-332.

COSO (Committee of Sponsoring Organisations of the Treadway Commission) (1992). Internal Control - Integrated Framework. New York, New York, US: AICPA. 
COSO (Committee of Sponsoring Organisations of the Treadway Conmission) (2004). Enterprise Risk Management - Imegrated Framework. New York, New York, US: AICPA.

Craswell, A. T. and S. L. Taylor (1992). 'Discretionary disclosure of reserves by oil and gas companies: An economic analysis'. Joumal of Business. Finance and Accounting, 19(2): 295-308.

Defond, M. L. (1992). 'The association between changes in client firm agency costs and auditor switching', Auditing: A Joumal of Practice and Theory, 11(1): 1631.

Demsetz, H. and K. Lehn (1985). "The structure of corporate ownership: Causes and Consequences', Joumal of Political Economy, 93(6): 1155-1177.

Denis, D. J. and A. Sarin (1999). 'Ownership and board structures in publicly traded corporations', Journal of Financial Economics, 52(2): 187-223.

Didow, N. M., K. L. Keller, H. C. Barksdale, G. R. Franke (1985). 'Improving measure quality by alternating least squares optimal scaling', Journal of Marketing Research, 22(1): 30-40.

Douma, S. (1997). "The two-tier system of corporate governance", Long Range Planning, 30(4): 612-614.

Dreman, D. (1998). Contrarian Imvestment Strategies. New York, New York, US: Simon and Schuster.

Eisenhardt, K. M. (1989). 'Agency theory: An assessment and review', Academy of Management Review, 14(1): 57-74.

EIU (Economist Intelligence Unit) (1995). Managing Business Risks - An Imtegrated Approach. New York, New York, US: EIU.

Ellstrand, A. E., L. Tihanyi,, and J. L. Johnson (2002). 'Board structure and international political risk', Academy of Management Journal, 45(2): 769-777.

Ettredge, M., D. Simon, D. Smith and M. Stone (1994). 'Why do companies purchase timely quarterly reviews?', Jound of Accounting and Economics, 18(2): 131155.

EU (European Union) (2003). 'Directive 2003/71/EC of the European Parliament and of the Council", Official Journal of the European Union, L 345, 31/12: 64-89.

EU (European Union) (2004). 'Commission regulation No. 809/2004', Official Joumal of the European Union, L 149, 30/4: 1-187.

Fama, E. F. (1980). 'Agency problems and the theory of the firm', Journal of Political Economy, 88: 288-307.

Fama, E. F. (1998). 'Market efficiency, long-term returns, and behavioral finance', Journal of Financial Economics, 49(3): 283-306.

Fama, E. F. and K. F. French (1992). "The cross-section of expected stock returns", Joumal of Finance, 47(2): 427-466.

Fama, E. F. and K. F. French (1995). "Size and book-to-market factors in earnings and retums", Joumal of Finance, 50(1): 131-155.

Fama, E. F. and K. F. French (1996). "The CAPM is wanted, dead or alive', Journal of Finance, 51(5): 1947-1958. 
Fama, E. F. and M. C. Jensen (1983). 'Separation of ownership and control', Joumal of Law and Economics, 26(2): 301-325.

Farrelly, G. E., K. R. Ferris and W .R. Reichenstein (1985). 'Perceived risk, market risk, and accounting determined risk measures', Accounting Rewiew, 60(2): 278-288.

FASB (Financial Accounting Standards Board). (1980). Statement of Financial Accounting Concepts No. 2: Qualitative Characteristics of Accounting informalion. Stamford, Connecticut, US: FASB.

Feltham, G., J. Hughes and D. A. Simunic (199 II). 'Empirical assessment of the impact of auditor quality on the valuation of new issues", Joumal of Accounting and Economics, 14(4): 375-399.

Fields, T. D., T. Z. Lys and L. Vincent (2001.). 'Empirical research on accounting choice", Journal of Accounting and Economics, 31(1-3): 255-207.

Francis, J. R. and E. A. Wilson (1988). "Auditor changes: a joint test of theories relating to agency costs and auditor differentiation', Accounting Review, 63(4): $663-682$.

Fuller, J. and M. C. Jensen (2002). 'Just say no to Wall Street', Journal of Applied Corporate Finance, 14(4): 41-46.

Geiger, M. A. and P. L. Taylor (2003). 'CEO and CFO certifications of financial information", Accounting Horizons, 17(4): 357-368.

Grayson, K. and R. Rust (2001). 'Interrater reliability', Journal of Consumer Psychology, $10(1-2): 71-73$.

Greene, W. H. (2000). Ecomometric Analysis ( $4^{\text {th }}$ edition). Upper Saddle River, New Jersey, US: Prentice-Hall.

Grossman, S. and O. D. Hart (1980). 'Corporate financial structure and managerial incentives'. In J. McCall (ed.), The Economics of Information and Uncertainty, Chicago, Illinois: University of Chicago Press: 102-137.

Guo, R., B. Lev, and N. Zhou (2004). 'Competitive costs of disclosure by biotech IPOs', Jounal of Accounting Research, 42(2):319-355.

Hampel Committee (Committee on Corporate Governance) (1998a). Final Report of the Committee on Corporate Governance. London, UK: Gee Publishing.

Hampel Committee (Committee on Corporate Govemance) (1998b). Combined Code. UK.

Haring, J.R. (1979). 'Accounting rules and "the accounting establishment", Joumal of Business, 52(4): 507-519.

Harris, M. S. (1998). 'The association between competition and manager's business segment reporting decisions', Joumal of Accounting Research, 36(1): 111-128.

Hartzell, J. C. and L. T. Starks (2003). 'Institutional investors and executive compensation', Journal of Finance, 58(6): 2351-2374.

Hattie, J. (1985). 'Methodology review: Assessing unidimensionality of tests and items'. Applied Psychological Measurement, 9: 139-164.

Haugen, R. A. and L. W. Senbet (1981), 'Resolving the agency problems of external capital through options', Journal of Finance, 36(3): 629-647. 
Hay, D. and W. R. Knechel (2001). 'Evidence on the associations among elements of control and external assurance', Working paper, University of Florida.

Healy, P. M. and K. G. Palepu (2001). 'Information asymmetry, corporate disclosure, and the capital markets: A review of the empirical disclosure literature', Joumal of Accounting and Economics, 31(1-3): 405-439.

Hensler, D. A., R. C. Rutherford and T. M. Springer (1997). 'The survival of initial public offerings in the aftermarket', Joumal of Financial Research, 20(1): 93110 .

Hermalin, B. E. and M. S. Weisbach (1988). 'The determinants of board composition', RAND Joumal of Economics, 19(4): 589-606.

Hermalin, B. E. and M. S. Weisbach (1991). 'The effects of board composition and direct incentives on firm performance', Financial Management, 20(4): 101112 .

Hermalin, B. E. and M. S. Weisbach (1998). 'Endogenously chosen boards of directors and their monitoring', American Economic Review, 88(1): 96-118.

Hermalin, B. E. and M. S. Weisbach (2003). "Boards of directors as an endogenously determined institution: A survey of the economic literature', Economic Policy Review, 9(1): 7-26.

Hermanson, D. R. and H. M. Hermanson (1994). "The internal control paradox: What every manager should know', Review of Business, 16(2): 29-32.

Hermanson, H. M. (2000). 'An analysis of the demand for reporting on internal control', Accounting Horizons, 14(3): 325-341.

Hillman, A. J. and T. Dalziel (2003). 'Boards of directors and firm performance: Integrating agency and resource dependence perspectives', Academy of Management Review, 28(3): 383-396.

Hodder, L., L. Koonce and M. L. McAnally (2001). 'SEC market risk disclosures: Implications for judgment and decision making', Accounting Horizons, 15(1): $49-70$.

Holthausen, R. W. and R. L. Watts (2001). "The relevance of the value-relevance literature for financial accounting standard setting', Journal of Accouning and Economics, 31(1-3): 3-75.

Hribar, P. (2004). 'Discussion of competitive costs of disclosure by biotech IPOs', Jownal of Accounting Research, 42(2): 357-364.

Huddart, S. (1993). "The effect of a large shareholder on corporate value", Management Science, 39(11): 1407-1421.

ICAEW (Institute of Chartered Accountants in England and Wales) (1999). No Surprises: The Case for Betrer Risk Reporting, London, UK: ICAEW.

Jensen, M. C. (2001). 'Value maximisation, stakeholder theory, and the corporate objective function', European Financial Management, 7(3): 297--317.

Jensen, M. C. and K. J. Murphy. (1990a). 'Performance pay and top-management incentives', Journal of Political Economy, 98(2): 225-264.

Jensen, M. C. and K. J. Murphy. (1990b). "CEO incentives: It's not how much you pay, but how', Harvard Business Review, 68(3): 138-153. 
Jensen, M. C. and W. H. Meckling (1976). "Theory of the firm: Managerial behavior, agency costs and ownership structure', Journal of Financial Economics, 3(4): 305-360.

Jorgensen, B. N. and M. T. Kirschenheiter (2003). "Discretionary Risk Disclosures", Accownting Review, 78(2): 449-469.

Jorion, P. (2002). 'How informative are value-at-risk disclosures?', Accounting Review, 77(4): $911-931$.

Kabir, R., D. Cantrijn and A. Jeunink (1997). 'Takeover defenses, ownership structure and stock returns in the Netherlands: An empirical analysis', Strategic Management Joumal, 18(2): 97-109.

Kassarjian, H. H. (1977). 'Content analysis in consumer research', Journal of Consumer Research, 4(1): 8-18.

Keasey, K. and M. Wright (1993). 'Issues in corporate accountability and governance: An editorial', Accounting and Business Research, 23(91A): 291-303.

Keasey, K. and M. Wright (1997). 'Corporate governance, accountability and enterprise', In Keasey, K. and M. Wright (eds.), Corporate Governance: Responsibilities, Risks and Remumeration. Chichester, UK: Wiley: 1-21.

Kinney. W. R. (2000a). Information Quality Assurance and Internal Control for Management Decision Making. Boston, Massachusetts, US: McGraw-Hill Higher Education.

Kinney, W. R. (2000b). 'Research opportunities in internal control quality and quality assurance', Auditing: A Journal of Practice and Theory, 19(1): 83-90.

Knechel, W. R. (2001). Auditing: Assturance and Risk. Cincinnati, Ohio, US: SouthWestern College Publishing.

Kolbe, R. H. and M. S. Burnett (1991), "Content-analysis research: An examination of applications with directives for improving research reliability and objectivity', Journal of Consumer Research, 18(2): 243-250.

Koonce, L.. M. L. McAnally and M. Mercer (2004). "How do investors judge the risk of financial items?", Accounting Review, $80(1): 221-241$.

Kothari, S. P. (2001). 'Capital markets research in accounting', Journal of Accouming and Economics, 31(1-3): 105-231.

La Porta, R., F. Lopez-de-Silanes, A. Shleifer and R. Vishny (2000). 'Agency problems and dividend policies around the world', Joumal of Finance, $55(1)$ : $11-33$.

Lakonishok, J. and A. Shleifer and R. W. Vishny (1994). 'Contrarian investment, extrapolation, and risk', Journal of Finance, 49(5): 1541-1578.

Leftwich, R. W., R. L. Watts and J. L. Zimmerman (1981). 'Voluntary corporate disclosure: The case of interim reporting'. Joumal of Accounting Research, 19(supplement): $50-77$.

Libby, R. (1981). Accounting and Human Information Processing: Theory and Applications. Englewood Cliffs, New Jersey, US: Prentice-Hall.

Linsmeier, T. J. and N. D. Pearson (1997). 'Quantitative disclosures of market risk in the SEC release', Accounting Horizons, 11(1): 107-135. 
Linsmeier, T. J., D. B. Thomton, M. Venkatachalam and M. Welker (2002). 'The effect of mandated market risk disclosures on trading volume sensitivity to interest rate, exchange rate, and commodity price movements", Accounting Review, 77(2): 343-377.

Lintner, J. (1965). 'The valuation of risk assets and the selection of risky investments in stock portfolios and capital budgets", Review of Economics and Statistics, 47(1): 13-37.

Lipe, M. (1998). 'Individual investors' risk judgments and investment decisions: The impact of accounting and market data', Accounting, Organizations and Society, 23(7): $625-640$.

Lokshin, B., M. Carree and R. Belderbos (2004). 'Testing for complementarity and substitutability in case of multiple practices', Working paper, Universiteit Maastricht.

Loughran, T. and J. R. Ritter (1995). "The new issues puzzle", Jounal of Finance, $50(1): 23-52$.

Loughran, T. and J. R. Ritter (1997). "The operating performance of firms conducting seasoned equity offerings', 52(5): 1823-1850.

Maassen G. and F. A. J. van den Bosch (1999). 'On the supposed independence of two-tier boards: Formal structure and reality in the Netherlands', Corporate Governance: An Imternational Review, 7(1): 31-37.

Maijoor, S. J. (2000). 'The internal control explosion', International Joumal of Auditing, 4 (March): 101-109.

March, J. G. and Z. Shapira (1987). 'Managerial perspectives on risk and risk taking", Management Science, 33(11): 1404-1418.

McDonald, R. P. (1981). 'The dimensionality of tests and items', British Journat of Mathematical and Social Psychology, 34: 100-117.

McGrath, J. E. (1982). "Dilemmatics: The study of research choices and dilemmas". In J. E. McGrath, J. Martin and R. A. Kulka (eds.), Judgment Calls is Research. Newbury Park, California, US: Sage Publications: 69-102.

McMullen, D. A., K. Raghunandan and D. V. Rama (1996). 'Internal control reports and financial reporting problems', Accounting Hortzons, 10(4): $67-75$.

Meier, H. H., P. Alam and M. A. Pearson (1993). 'Auditor lobbying for accounting standards: The case of banks and savings and loan associations", Accounting and Business Research, 23(92): 477-487.

Menon, K and J. D. Williams (1994). 'The use of audit committees for monitoring', Jounal of Accounting and Public Policy, 13(2): 121-139.

Milgrom, P. and J. Roberts (1992). Economics, Organization and Management. Englewood Cliffs, New Jersey, US: Prentice-Hall.

Milgrom, P. and J. Roberts (1995). 'Complementarities and fit: Strategy, structure, and organizational change in manufacturing, Journal of Accounting and Economics, 19(2/3): 179-208.

Miller, K. (1992). 'A framework for integrated risk management in international business', Journal of International Business Studies, 23(2): $311-331$. 
Mills, R. (1997). 'Internal control practices within large UK companies'. In Keasey, K. and Wright, M. (eds.), Corporate Governance: Responsibilities, Risks and Remuneration. Chichester, UK: Wiley: 121-143.

Moerland, P. W. (1995). "Alternative disciplinary mechanisms in different corporate systems", Journal of Economic Behovior and Organization, 26(1): 17-34.

Newey, W. and K. West (1987). 'A. Simple Positive Semi-Definite, Heteroskedasticity and Autocorrelation Consistent Covariance Matrix', Ecomometrica, 55: 703708.

Nunnally, J. L. (1978). Psychometric Theory. New York, New York, US: McGrawHill.

Olsen, R. A. (1997). 'Investment risk: The experts' perspective', Financial Analysts Journal, 53(2): 62-66.

Payne, J. and M. Braunstein (1971). "Preferences among gambles with equal underlying distributions', Journal of Experimental Psychology, 87(January): $13-18$.

Pearce, J. A. and S. A. Zahra (1992). 'Board composition from a strategic contingency perspective', Journal of Management Studies, 29(4): 411-438.

Peek, E. (2000). "Corporate structure and the informativeness of provision management: Evidence from the Netherlands', Working paper, Universiteit Maastricht.

Perreault, W. D. and L. E. Leigh (1989). "Reliability of nominal data based on qualitative judgements', Journal of Marketing Research, 26(2): 243-250.

Peters Committee (Committee on Corporate Governance) (1997). Recommendations on Corporate Governance in the Netherlands.

Pfeffer, J. (1972). 'Size and composition of corporate boards of directors: The organization and its environment', Administrative Science Quarterly, 17:218229.

Pfeffer, J. and G. R. Salancik (1978). The external control of organizations: A resource dependence perspective. New Y'ork, New York, US: Harper and Row.

Pincus, K., M. Rusbarsky and J. Wong (1989). "Voluntary formation of corporate audit committees among NASDAQ firms', Jounal of Accoumting and Public Policy, 8(4): 239-265.

Prevost, A. K., R. P. Roa, and M. Hossain (2002). 'Board composition in New Zealand: An agency perspective', Journat of Business Finance and Accounting, $29(5-6): 731-760$.

Public Oversight Board (1993). In the Public Interest. Stamford, Connecticut, US: POB.

Raghunandan, K. and D. V. Rama (1994). 'Management reports after COSO', Internal Audiror, 51(4): 54-59.

Rajgopal, S. (1999). "Early evidence on the informativeness of the SEC's market risk disclosures: The case of commodity price risk exposure of oil and gas producers', Accounting Review, 74(3): 251-280. 
Rediker, K. J. and A. Seth (1995). 'Boards of directors and substitution effects of alternative governance mechanisms', Strategic Management Journal, 16(2): $85-99$.

Ritter, J. R. (1991). 'The long-run performance of initial public offerings', Journal of Fixance, 46(1): 3-27.

Ritter, J. R. and I. Welch (2002). 'A review of IPO activity, pricing, and allocations', Joumal of Finance, 57(4): 1795-1828.

Robinson, J. P., P. R. Shaver and L. S. Wrightsman (1991). Measures of Personality and Social Psychological Attitudes. San Diego, California, US: Academic Press.

Ruefli, T. W., J. M. Collins and J. R. Lacugna (1999). 'Risk measures in strategic management research: Auld lang syne?', Strategic Management Journal, 20(2): $167-194$.

Runkel, P. and J. McGrath (1972). Research on Human Behowior - A Systematic Guide to Method, New York, New York, US: Holt, Rinehart and Winston.

Rutteman Committee (Working Group of the Committee on the Financial Aspects of Corporate Governance) (1994). Internal Control and Financial Reporing: Guidance for Directors of Listed Companies. UK.

Ryan, S. G. (1997). 'A survey of research relating accounting numbers to systematic equity risk, with implications for risk disclosure policy and future research', Accounting Horizons, 11(2): 82-95.

Schnatterly, K. (2003). 'Increasing firm value through detection and prevention of white-collar crime", Strategic Management Journal. 24(7): 587-614.

Schrand, C. M. and J. A. Elliot (1998). 'Risk and financial reporting: A summary of the discussion at the 1997 AAA/FASB conference', Accounting Horizons, 12(3): $271-282$.

Securities and Exchange Commission (SEC). (1997). Disclosure of Accounting Policies for Derivative Financial Instruments and Derivative Commodity Instruments and Disclosure of Quantitative and Qualitative Information about Market Risk Inherent in Derivative Financial Instruments. Other Financial Instruments, and Derivative Commodity Instruments. Washington, District of Columbia, US: Securities and Exchange Commission.

Shapiro, A. C. and S. D. Babirer (2000). Modern Corporate Finance, Upper Saddle River, New Jersey "US: Prentice-Hall.

Sharpe, W. F. (1964). 'Capital asset prices: A theory of market equilibrium under conditions of risk', Joumal of Finance, 19(3): 425-442.

Shleifer, A. and R. Vishny (1997). 'A survey of corporate govemance', Joumal of Finance, 52(2): 737-783.

Short, H., K. Keasey, M. Wright and A. Hull (1999). 'Corporate governance: From accountability to enterprise", Accounting and Business Research, 29(4): 337 352. 
Simunic D. A. and Stein M. T. (1987). Product differentiation in auditing. Auditor choice in the market for unseasoned new issues. Vancouver, Canada: Canadian Certified General Accountant's Research Foundation.

Slovic, P. (1966). 'Trust, emotion, sex, politics, and science: Surveying the riskassessment battlefield'. In M. Bazerman, D. Messick, A. Tenbrunsel and K. Wade-Benzoni (eds.), Psychological Perspectives to Environment and Ethics in Management. San Francisco, California, US: Jossey-Bass: 217-313.

Slovic, $\mathrm{P}$. and S. Lichtenstein (1968). "Importance of variance preferences in gambling decisions", Joumal of Experimental Psychology, 78: 646-654.

Solomon, M. B. and J. R. Cooper (1990). 'Reporting on internal control: The SEC's proposed rules', Journal of Accountancy, 169(6): 56-63.

Spiess, D. K and J. Affleck-Graves (1995). "Underperformance in long-run stock returns following seasoned equity offerings', Journal of Financial Economics, $38(3): 511-243$.

Spiess, D. K. and J. Affleck-Graves (1999). "The long-run performance of stock returns following debt offerings', Joumal of Financial Economics, 54(1): 4573.

Tabaksblat Committee (Corporate Governance Committee) (2003). The Dutch Corporate Governance Code.

Thornton, D. B. and M. Welker (2004). "The effect of oil and gas producers" FRR No. 48 disclosures on investors" risk assessments', Journal of Accounting, Auditing. and Finance, 19(1): 85-114.

Treadway Commission (National Commission on Fraudulent Financial Reporting) (1987). Report of the National Commission on Fraudulem Financial Reporting. New York, New York, US: NCFFR.

Turnbull Committee (Working Party of the Committee on Corporate Governance) (1999). Internal Control: Guidance for Directors on the Combined Code. London, UK: ICAEW.

Van Ees, H., T. J. B. M. Postma and E. Sterken (2003). 'Board characteristics and corporate performance in the Netherlands', Eastern Economic Journal, $29(1)$ : $41-58$.

Watts, R. L. and J. L. Zimmerman (1979). 'The demand for and supply of accounting theories: The market for excuses", Accounting Review, 54(2): 273-305.

Watts, R. L. and J. L. Zimmerman (1986). Positive Accounting Theory. Englewood Cliffs, New Jersey, US: Prentice-Hall.

Watts, R. L. and J. L. Zimmerman (1990). 'Positive accounting theory: A ten year perspective", Accounting Review, 65(1): 131-156.

Weber, E. (1988). 'A descriptive measure of risk', Acta Psychologica, 69 (November): $185-203$.

Williamson, O. E. (1967). "Hierarchical control and optimum firm size", Journal of Political Economy, 75(2): 123-138.

Willis, D. M. and S. S. Lightle (2000). 'Management reports on internal controls", Jounal of Accountoncy, 190(4): 57-64. 
Wright, P., S. P. Ferris, A. Sarin and V. Awasthi (1996). "Impact of corporate insider, blockholder, and institutional equity ownership on firm risk taking", Academy of Management Journal, 39(2): 441-463.

Yates, F. and E. Stone (1992). 'The risk construct'. In F. Yates (ed.), Risk-Taking Behavior. New York, New York, US: Wiley: 1-25.

Yermack, D. (1996). 'Higher market valuation of companies with a small board of directors", Journal of Financial Economics, 40(2): 185-211. 



\section{Nederlandse Samenvatting (Summary in Dutch)}

Ondernemingen worden voortdurend geconfronteerd met risico"s. Het adequat beheersen van deze risico's is een belangrijke verantwoordelijkheid van bestuurders. Een deugdelijk ondernemingsbestuur zal daarom zorg dragen voor een op de onderneming afgestemd intern risicobeheersings- en controlesysteem. Vooral van beursgenoteerde ondernemingen eisen regelgevers en investeerders in toenemende mate dat het bestuur - verplicht dan wel vrijwillig - openheid geeft over de ondernemingsrisico's en het systeem om deze risico's te beheersen.

Dit proefschrift presenteert drie empirische studies naar vraagstukken die zijn gerelateerd aan deze onderwerpen. Hoofdstuk 1 van het proefschrift bevat de inleiding en geeft kort het doel en de motivatie van de drie studies weer. Daarnaast beschrijft dit hoofdstuk hoe de verschillende studies met elkaar samenhangen. Het hoofdstuk introduceert tevens de steekproef en de wijze waarop de data is verzameld. In de hoofdstukken 2, 3 en 4 komen vervolgens de afzonderlijke studies aan bod. Hoofdstuk 5 vat het doel, de opzet en de resultaten van de studies samen en besteedt aandacht aan de beperkingen van het onderzoek. Het hoofdstuk wordt afgesloten door een bespreking van de conclusies, praktische aanbevelingen en ambevelingen voor toekomstig onderzoek. Wat volgt is een verkorte weergave van de drie studies.

\section{Siudie I}

De eerste empirische studie onderzoekt de beweegredenen van bestuurders van beursgenoteerde ondernemingen om in het jaarverslag vrijwillig te rapporteren over het interne beheersingssysteem. Een goed intern beheersingssysteem zorgt onder andere voor betrouwbare financiële verslaggeving. Betrouwbare financiele verslaggeving stelt investeerders onder meer in staat om na te gaan of bestuurders hun contractuele verplichtingen nakomen. Door in het jaarverslag aandacht te besteden aan bepaalde aspecten van het interne beheersingssysteem, kunnen bestuurders aan investeerders duidelijk proberen te maken dat zij streven naar betrouwbare financiële verslaggeving. Naar aanleiding van recente boekhoudschalen stellen regelgevers juist op dit vlak steeds verdergaande verplichtingen aan bestuurders. Als gevolg van de Sarbanes-Oxley Act van 2002 gelden de meest radicale eisen op dit moment voor ondernemingen met een beursnotering in de Verenigde Staten. Principaal-agent theorie woorspelt echter dat (verstandige) bestuurders ook vrijwillig zullen rapporteren, mits zij op die manier de kosten die woortvloeien uit het bestaan van informatie-asymmetrie en tegengestelde belangen tussen bestuurders en investeerders op een efficiente manier kunnen verminderen. 
De eerste studie test deze voorspelling door te onderzoeken of de mate van vrijwillige rapportage over inteme beheersing systematisch samenhangt met ondernemingskenmerken die de mate van informatie-asymmetrie en tegengestelde belangen weerspiegelen. De steekproef die in deze studie is gebruikt bestaat uit alle Nederlandse vennootschappen, uitgezonderd beleggingsfondsen en financiële instellingen, met een notering aan de Amsterdamse beurs in de periode van 1997 tot en met 1999. De belangrijkste reden dat voor deze steekproef is gekozen, is het feit dat rapportage over interne beheersing in deze periode in Nederland volledig vrijwillig was. Voor elke onderneming in de steekproef is de mate van vrijwillige rapportage over interne beheersing gemeten door een score, die is opgebouwd uit zes verschillende onderdelen waarop het bestuur kan rapporteren.

De resultaten laten zien dat de mate van vrijwillige rapportage over interne beheersing daadwerkelijk samenhangt met ondernemingskenmerken die de mate van informatie-asymmetrie en tegengestelde belangen weergeven. Om precies te zijn, is de mate van vrijwillige rapportage over interne beheersing negatief gecorreleerd met het percentage aandelenbezit door het bestuur en grote aandeelhouders. Verder is vrijwillige rapportage positief gecorreleerd met de grootte van de ondememing en de mate van financiering met vreemd vermogen. Bij de analyses is gecontroleerd voor diverse andere ondernemingskenmerken die mogelijk van invloed zijn, zoals de relatieve omvang van de activiteiten in het buitenland, industrieclassificatie, de kwaliteit van de externe accountantscontrole, de mate van toezicht door externe commissarissen, en een beursnotering in de Verenigde Staten of het Verenigd Koninkrijk.

Hoewel additionele statistische tests aangeven dat de feitelijke rapportages op de verschillende onderdelen van de score voldoende samenhang vertonen om in éen score te kunnen worden opgenomen, werd over vier van de zes onderdelen slechts zeer beperkt gerapporteerd. Zo gaf gemiddeld maar $5 \%$ van de bestuurders vrijwillig een oordeel over de effectiviteit van het interne beheersingssysteem. Afzonderlijke analyses laten zien dat bovengenoemde correlaties maar voor een gering deel zijn toe te schrijven aan de niet frequent woorkomende rapportages. Een mogelijke verklaring voor deze bevindingen is dat bestuurders onvoldoende op de hoogte waren van het feit dat rapportage van deze onderdelen internationaal sterk werd aanbevolen. Een andere verklaring is dat bestuurders rapportage van deze onderdelen niet effectief of efficiënt genoeg vonden. Het enige onderdeel dat door de meerderheid van de ondernemingen werd gerapporteerd (gemiddeld $61 \%$ ) en afzonderlijk het sterkste correleert met genoemde ondernemingskenmerken, betreft vrijwillige rapportage van specifieke interne beheersingsactiviteiten. Voornamelijk op basis van deze rapportages concludeert de eerste studie dat bestuurders door aandacht te besteden aan bepaalde aspecten van het interne beheersingssysteem, aan investeerders vrijwillig duidelijk proberen te maken dat zij streven naar betrouwbare financiële verslaggeving. Op deze manier trachten ze de kosten die voortvloeien uit het bestaan van informatieasymmetrie en tegengestelde belangen tussen bestuurders en investeerders op een efficiënte manier te verminderen. 


\section{Sindie 2}

De tweede empirische studie gaat specifiek in op het verplicht versehaffen van informatie over risico's in uitgifteprospectussen die ondernemingen publiceren indien nieuw kapitaal wordt aangetrokken op de beurs. De steekproef die in deze studie is gebruikt bestaat uit Nederlandse vennootschappen die in de periode van 1997 tot 2000 nieuwe effecten hebben uitgegeven op de Amsterdamse beurs. In het prospectus beschrijven bestuurders de aan de onderneming gerelateerde risico's doorgaans in een apart hoofdstuk dat is getiteld 'risicoprofiel', 'risicofactoren' of 'investeringsoverwegingen'. Concrete vragen die de tweede studie behandelt zijn welke soorten risico's het bestuur rapporteert, hoe de gerapporteerde risico"s met elkaar samenhangen, en - voornamelijk - of de gerapporteerde risico-informatie bruikbaar is voor investeerders om de aan de onderneming verbonden risico's in te schatten.

Kenmerkend voor de verstrekte informatie in het risicoprofiel is dat het bestuur de risico's niet kwantificeert en dat de informatie toekomstgericht is. Hoewel toekomstgerichte risico-informatie potenticel relevanter is dan risico-informatie gebaseerd op gerealiseerde uitkomsten, twijfelen sommige onderzoekers aan de betrouwbaarheid van deze informatie en daardoor aan de bruikbaarheid ervan. Ook de betrouwbaarheid van niet gekwantificeerde informatie wordt vaak in twijfel getrokken, omdat het achteraf moeilijker zou zijn om deze informatie te verifiëren. Hoewel het fondsenreglement van de Amsterdamse beurs het maken van een risico-inschatting door het bestuur verplicht stelt - en het bestuur certificeert dat alle informatie in het prospectus accuraat is en dat geen materiële informatie ontbreekt - schrijft het reglement niet voor welke risico's precies moeten worden besproken. Volgens sommigen zijn deze regels niet afdoende, omdat ze het bestuur in staat zouden stellen bijna alles (of niets) te rapporteren zonder de regels te schenden. De studie haalt twee redenen aan om desondanks te verwachten dat de risico-informatie juist en volledig zal zijn. De eerste reden is dat zowel de onderneming als de begeleidende instellingen hun wettelijke aansprakelijkheid kunnen beperken door een waarheidsgetrouw beeld te geven van de aan de onderneming verbonden risico's. Bovendien voeren de begeleidende instellingen, vaak in samenwerking met de externe accountant en de juridische adviseur, een zogenaamd due diligence onderzoek uit met betrekking tor het prospectus. De tweede reden is dat bestuurders zelf het beste in staat zijn om aan to geven welke risico's relevant zijn en flexibele regelgeving hen hiertoe juist in staat stelt.

Om de eerder genoemde onderzoeksvragen te beantwoorden is een gedetailleerde inhoudsanalyse van de risicoprofielen uitgevoerd. Deze inhoudsanalyse omvatte vier stappen: (1) het ontwikkelen van een passend classificatieschema voor de risicofactoren die vermeld worden in de risicoprofielen; (2) het classificeren van de teksten van de risicoprofielen; (3) het statistisch creëren van samengestelde maatstaven van risicorapportage op basis van de verzamelde data; en (4) het correleren van de samengestelde ex-ante maatstaven van risicorapportage met ex-post maatstaven van risico gebaseerd op aandelenmarktgegevens. 
De resultaten van de eerste twee stappen van de inhoudsanalyse laten duidelijk zien dat bestuurders risico voornamelijk associëren met factoren - binmen of buiten de organisatie - die toekomstige resultaten negatief kunnen beïnvloeden. Daarnaast beschrijven bestuurders risico als verlies of de kans op verlies, als gebrek aan informatie, als gebrek aan invloed, en - soms - als variantie. Deze bevindingen sluiten atan bij eerder onderzoek naar de voorstelling van het begrip risico door bestuurders en professionele investeerders.

De resultaten van stap drie van de inhoudsanalyse laten zien hoe de gerapporteerde risicofactoren met elkaar samenhangen. De verzamelde data kon statistisch worden gereduceerd tol drie samengestelde maatstaven van risicorapportage Eén van deze maatstaven werklaart de meeste variantie en representeert veruit de meeste risicofactoren. De empirische analyses in de wolgende stap concentreren zich daarom op deze maatstaf.

De resultaten van de empirische analyses in stap vier van de inhoudsanalyse zijn drieledig. Ten eerste zijn de risicorapportages in het prospectus positief gecorreleerd met het toekomstige aandelenrisico. Hierbij is gecontroleerd voor de grootte van de onderneming, industrieclassificatie en het soort effectenuitgifte. Indien de onderneming al beursgenoteerd was vór de uitgifte van de nieuwe effecten, is bovendien gecontroleerd voor het historische aandelenrisico. Ten tweede zijn de risicorapportages in het prospectus positief gecorreleerd met toekomstige rendementen. Ook hier is gecontroleerd voor bovengenoemde variabelen, inclusief het historische aandelenrisico. Financieringstheorie voorspelt dat indien aandelen rationeel zijn geprijsd, systematische verschillen in rendementen enkel worden veroorzaakt door verschillen in risico. Van ondernemingen die als risicovoller worden beschouwd, eist de markt een hoger rendement. De resultaten suggereren daarom dat de risicorapportages het risico van een onderneming goed weergeven. Ten derde blijken de risicorapportages zeer extreme dalingen in aandelenprijzen te voorspellen. Ook hier is gecontroleerd voor eerder genoemde factoren. Deze bevinding duidt er op dat bestuurders investeerders in het prospectus waarschuwen voor de kans op bijzonder negatieve uitkomsten.

De conclusie die op basis van deze empirische resultaten wordt getrokken, is dat toekomstgerichte kwalitatieve risicorapportages in prospectussen voor investeerders bruikbare informatie bevatten om risico-inschattingen te maken. Voor regelgevers is deze conclusie mogelijk interessant, omdat dit suggereert dat de huidige flexibele regels omtrent het opnemen van risico-informatie in prospectussen adequaat zijn. Voor onderzoekers die op zoek zijn naar een ex-ante matstaf van risico zoals dat wordt gepercipieerd door bestuurders en investeerders, zijn de bevindingen ook nuttig. Door te onderzoeken of kwalitatieve risicorapportages in prospectussen bruikbare risico-informatie bevat voor investeerders, is een alternatieve maatstaf ontwikkeld en getest. Replicatie van deze studie zal echter moeten uitwijzen in hoeverre de bevindingen generaliseerbaar zijn. Voor de ondernemingen in de steekproef verschaft de huidige studie echter een betrouwbare en gevalideerde risicomaatstaf. Om deze reden kan de risicomaatstaf worden gebruikt in de derde studie van het proefschrift. 
Studie 3

In de derde empirische studie verschuift de aandacht naar de relatie tussen ondernemingsrisico en beheersing. Om precies te zijn, test de studie de veronderstelling dat de behoefte aan en aanwezigheid van exteme vormen van beheersing groter wordt als het risico dat is verbonden aan de ondernemingsactiviteiten toeneemt. De studie concentreert zich hierbij op twee specifieke vormen van beheersing: beheersing door de raad van commissarissen en beheersing door grote aandeelhouders. Evenals in de tweede studie bestaat de gehanteerde steekproef wit Nederlandse vennootschappen die in de periode van $\mathbb{1 9 9 7}$ tot 2000 nieuwe effecten hebben uitgegeven op de Amsterdamse beurs.

De meeste Nederlandse vennootschappen kennen naast het bestuur een aparte onafhankelijke raad van commissarissen, die tot taak heeft toezicht to houden op het beleid van het bestuur. Het toezicht van de raad van conmissarissen omvat onder andere de realisatie van doelstellingen, de strategie, de risico's verbonden aan de ondernemingsactiviteiten en de opzet en werking van het interne risicobeheersings-en controlesysteem. Behalve het uitoefenen van toezicht op het bestuur, kumnen commissarissen het bestuur van middelen voorzien die helpen om ondernemingsrisico's beter te beheersen. Zo kunnen commissarissen een onderneming voorzien van extra legitimiteit, deskundig advies en belangrijke contacten met andere ondernemingen en de overheid. Zowel vanwege het uitoefenen van toezicht op het bestuur als vanwege het verschaffen van middelen om risico's te beheersen, is de raad van commissarissen een belangrijk beheersingsmechanisme. Ook grote aandeelhouders kunnen fungeren als beheersingsmechanisme, omdat zij meer beweegredenen en mogelijkheden hebben om toezicht te houden op het bestuur dan kleine aandeelhouders. Daarnaast voorzien zij de onderneming niet alleen van kapitaal, maar vaak ook van advies en middelen om risico's te beheersen.

De analyses maken onderscheid tussen ondernemingen met een beursintroductie en ondernemingen met een bestaande beursnotering. In overeenstemming met de verwachte samenhang tussen ondernemingsrisico en beheersing, laten de resultaten van de analyses van ondernemingen met een beursgang zien dat risicovollere ondernemingen over een grotere raad van commissarissen beschikken, zowel in absolute zin als relatief ten opzichte van de raad van bestuur. De resultaten laten verder zien dat bij risicovollere ondernemingen met een beursgang vaker sprake is van geconcentreerd aandelenbezit. Nadere analyses wijzen uit dat dit laatste is toe te schrijven aan niet-institutionele beleggers. Bij deze analyses is gecontroleerd voor de grootte van de onderneming, industrieclassificatie en het totale aantal commissarissen en bestuurders. De maatstaf van risico in de analyses is gebaseerd op de in de tweede empirische studie uitgevoerde inhoudsanalyse van risicoprofielen in prospectussen. Omdat er op deze manier gebruik wordt gemaakt van ex-ante risico zoals dat wordt gepercipieerd door bestuurders en investeerders, voert de studie aan dat dit cen betere risicomaatstaf oplevert dan de in eerder onderzoek vaak gehanteerde ex-post matstaven van risico, die meestal gebaseerd zijn op de (co)variantie van bepaalde prestatie-indicatoren, zoals aandelenrendementen, kasstromen of winsten. 
Naast de verwachte samenhang tussen ondememingsrisico en beheersing, laten de resultaten van de analyses van ondernemingen met een beursgang zien dat de bestudeerde vormen van beheersing systematisch samenhangen met de mate van tegengestelde belangen tussen bestuurders en aandeelhouders. Ondenemingen met een beursgang hebben indien het percentage aandelenbezit door bestuurders groter is en de belangentegenstellingen daardoor kleiner zijn - gemiddeld een kleinere raad van commissarissen, wederom zowel in absolute zin als relatief ten opzichte van de raad van bestuur. Ook is bij ondernemingen met een beursgang het aandelenbezit door nietinstitutionele beleggers gemiddeld minder geconcentreerd als het percentage aandelenbezit door bestuurders groter is.

Voor ondernemingen met een bestaande beursnotering tonen de resultaten van de analyses echter gêén verwachte samenhang aan tussen ondernemingsrisico en beheersing. Ook leveren de resultaten van de analyses van ondernemingen met een bestaande beursnotering nagenoeg geen empirisch bewijs op voor het eerder genoemde verband tussen beheersing en het percentage aandelenbezit door bestuurders. De resultaten van eerder empirisch onderzoek bieden hiervoor een mogelijke verklaring: na de beursgang verandert de omvang van de raad van commissarissen en de concentratie van het aandelenbezit na verloop van tijd structureel door wisselingen van het bestuur, prestaties van de onderneming en dreigingen wan overnames. De conclusie die op basis van de empirische resultaten van cle derde studie kan worden getrokken is daarom dat het risico dat is verbonden aan de ondernemingsactiviteiten en de mate van tegengestelde belangen tussen het bestuurders en aandeelhouders ten tijde van de beursgang de mate van beheersing door raad van commissarissen en grote aandeelhouders bepaalt. 


\section{Curriculum Vitae}

Rogier Deumes was born on October $3^{\text {rd }}, 1975$ in Brunssum, the Netherlands. He attended grammar school at Romboutscollege in Brunssum, where he obtained his diploma in June 1993. From September 1993 till August 1998, he studied business economics at the Faculty of Economics and Business Administration at Universiteit Maastricht. During his studies, he worked as a student assistant for the department of Quantitative Economics and the department of Accounting and Information Management. Following graduation, he worked as a lecturer for the department of Accounting and Information Management. Since October 2000 he works as an assistant professor at the same department.

Rogier Deumes werd op 3 oktober 1975 geboren in Brunssum. Hij doorliep het atheneum aan het Romboutscollege in Brunssum, waar hij in juni 1993 zijn diploma behaalde. Van september 1993 tot augustus 1998 studeerde hij bedrijfseconomie aan de Faculteit der Economische Wetenschappen en Bedrijfskunde van de Universiteit Maastricht. Gedurende zijn studie werkte hij als student-assistent voor de vakgroep Kwantitatieve Economie en de vakgroep Accounting en Informatie Management. Na zijn afstuderen werkte hij als docent voor de vakgroep Accounting en Informatie Management. Sinds oktober 2000 werkt hij als universitair docent bij dezelfde vakgroep. 